\title{
Um Estudo de um Protocolo de Comunicação para Dispositivos Móveis usando Distributed Join- Calculus
}

\author{
Lucy Mari Tabuti
}

\author{
DISSERTAÇÃO APRESENTADA \\ $\mathrm{AO}$ \\ DEPARTAMENTO DE CIÊNCIA DA COMPUTAÇÃO \\ DO \\ INSTITUTO DE MATEMÁTICA E ESTATÍSTICA \\ DA \\ UNIVERSIDADE DE SÃO PAULO \\ PARA \\ OBTENÇÃO DO TÍTULO DE MESTRE \\ EM \\ CIÊNCIA DA COMPUTAÇÃO
}

Área de Concentração: Engenharia de Software - Métodos Formais

Orientadora: Profa. Dra. Ana Cristina Vieira de Melo

- São Paulo, SP - Outubro, 2002 - 


\section{Um Estudo de um Protocolo de Comunicação para Dispositivos Móveis usando Distributed Join-Calculus}

Este exemplar corresponde à redação final da dissertação devidamente corrigida e defendida por Lucy Mari Tabuti e aprovada pela comissão julgadora.

São Paulo, 25 de Outubro de 2002.

Banca Examinadora

- Profa. Dra. Ana Cristina Vieira de Melo (orientador) (IME-USP)

- Prof. Dr. Alan Mitchel Durham (IME-USP)

- Prof. Dr. Roberto da Silva Bigonha (UFMG) 
Aos meus pais, Cecília e Mário, que além de me darem a vida e terem sido meus melhores professores, são os alicerces e incentivos para a minha formação educacional, profissional e principalmente pessoal

Ao meu querido Rogério, colaborador gramatical, apoio, inspiração, compreensão e incentivo em minha vida

Às minhas irmãs, Meire, Lyka e Sayuri, cunhados, Celso, Hide e Maki, sobrinhos, Felipe e Larissa, que, acima de tudo amigos, sempre acreditaram e torceram por mim 


\section{Abstract}

This mastership dissertation specifies mobility aspects of a communication protocol to mobile computing using Distributed Join-Calculus. The specification has been used to verify mobility properties of the protocol. Besides, we have studied how the applicability of Distributed Join-Calculus can help to see and to understand better the behavior of mobile agents.

Join-Calculus is a formal model of concurrence that is consistent with mobility and distribution that can be seen in two ways: as a process calculus and as a programming language with functional features. The formal model used is Distributed Join-Calculus, an extension of Join-Calculus with explicit location and primitives for mobility.

The protocol chosen to be specified is RDP (Result Delivery Protocol). We have analyzed and verified if some properties inherent to the protocol were satisfied, implementing the model to RDP, in Distributed Join-Calculus, related to the mobility features. Besides, we have analyzed the use of Distributed Join-Calculus related to the protocol specification and the difficulties to specify a protocol with mobility.

This work is divided in three fases: the specification of a simple and restrict model of RDP protocol mobility features, to understand better its working and properties analyzed; this protocol specification in a global way; and the final analysis with some properties verification.

Key words: join-calculus, distributed join-calculus, formal specification, mobility, communication protocols. 


\section{Resumo}

Esta dissertação de mestrado especifica os aspectos de mobilidade de um protocolo de comunicação para computação móvel usando o Distributed Join-Calculus. A especificação foi utilizada para a verificação das características do protocolo com relação à mobilidade. Além disso, estudamos como o uso do Distributed Join-Calculus pode ajudar numa melhor visão e compreensão do comportamento de agentes móveis.

O Join-Calculus é um modelo formal de concorrência, com conceitos de mobilidade e distribuição, que pode ser visto de duas formas: como um cálculo de processos e como uma linguagem de programação baseada em técnicas de desenvolvimento formal. O formalismo utilizado foi o Distributed Join-Calculus, uma extensão do Join-Calculus com primitivas para mobilidade e localidades explícitas.

O protocolo escolhido para a especificação foi o RDP (Result Delivery Protocol). Implementando o modelo para o RDP, no Distributed Join-Calculus, em relação às características de mobilidade, analisamos e verificamos se algumas das propriedades esperadas pelo protocolo RDP são atendidas. Além disso, analisamos o uso do Distributed Join-Calculus com relação à especificação do protocolo e às dificuldades de se especificar um protocolo com mobilidade.

Para isso, o nosso trabalho foi dividido em três fases: a especificação de um modelo simples e restrito das características de mobilidade do protocolo RDP, para um melhor entendimento do seu funcionamento e das propriedades que analisamos; a especificação deste protocolo de forma global; e a análise final com a verificação de algumas propriedades.

Palavras-chave: join-calculus, distributed join-calculus, especificação formal, mobilidade, protocolos de comunicação. 


\section{Índice}

RESUMO

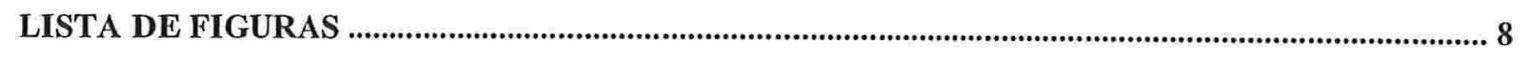

CAPÍTULO 1 - INTRODUÇÃO ................................................................................................. 9

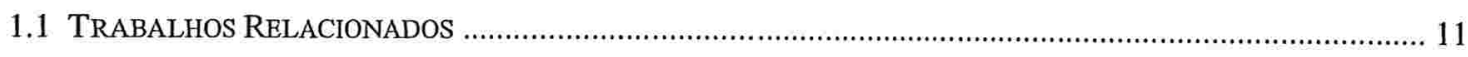

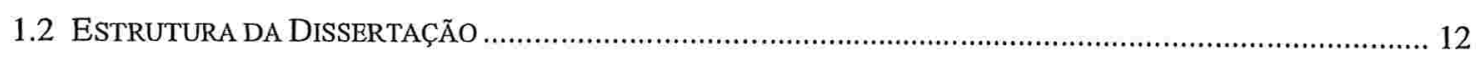

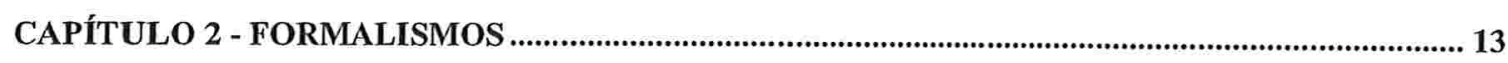

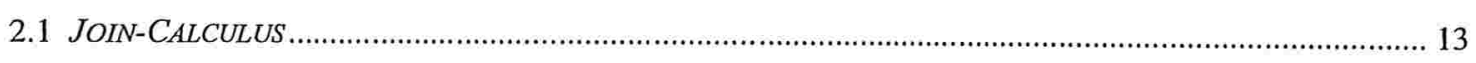

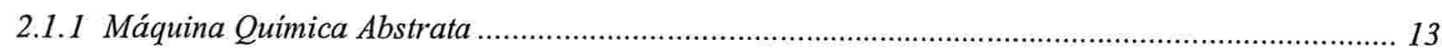

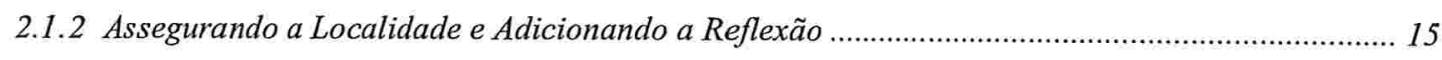

2.1.3 Join-Calculus e a Máquina Química Abstrata Reflexiva ............................................................ 16

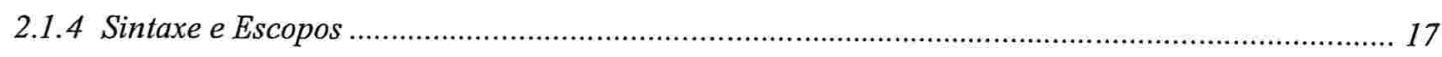

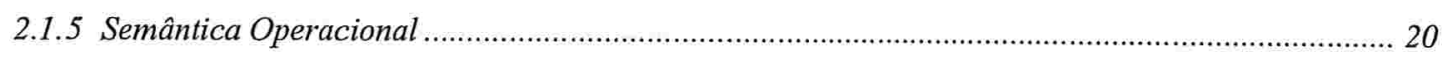

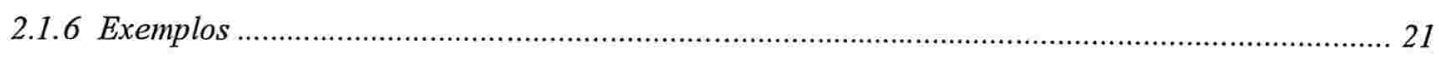

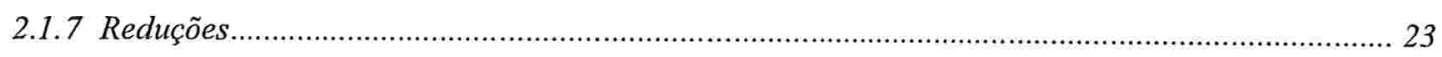

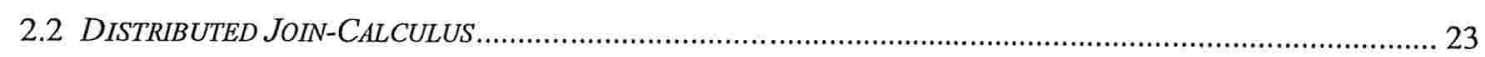

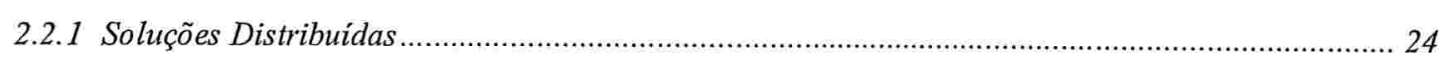

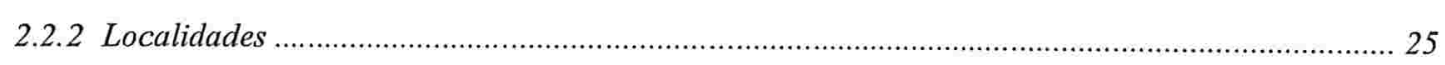

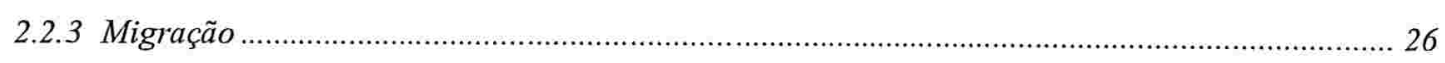

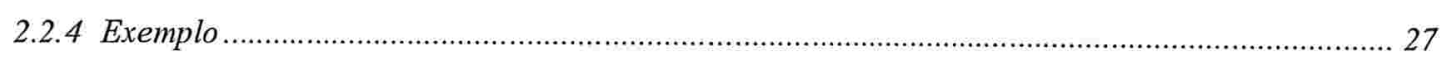

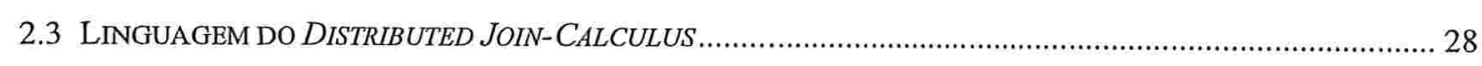

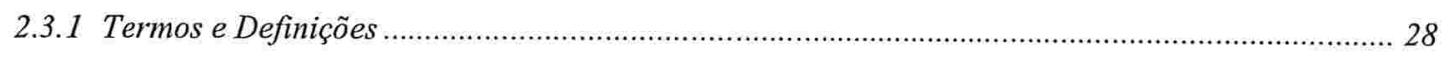

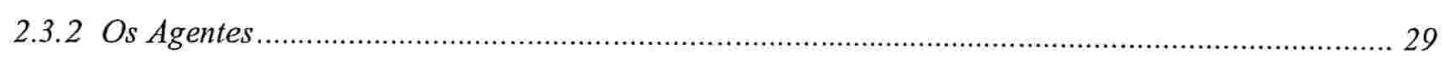

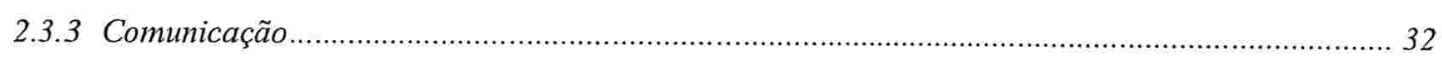

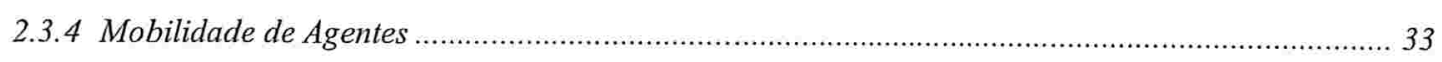

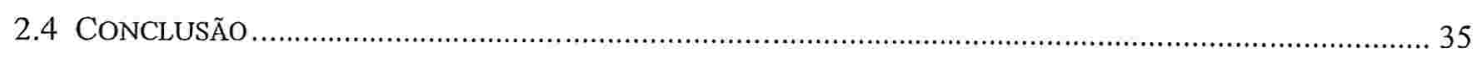

CAPÍTULO 3 - ESPECIFICAÇÃO DO RDP (RESULT DELIVERY PROTOCOL) ................................. 36

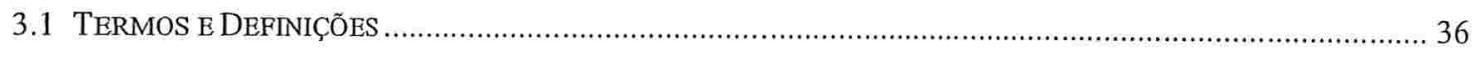

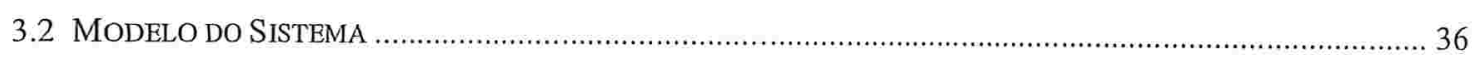

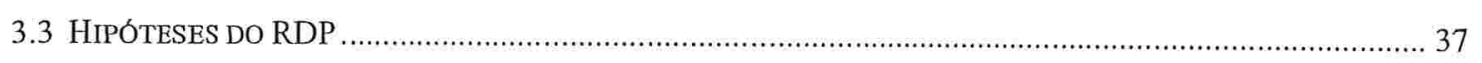

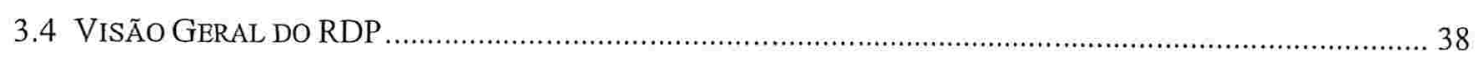


3.4.1 Exemplo de funcionamento do protocolo RDP.

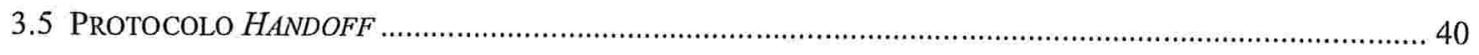

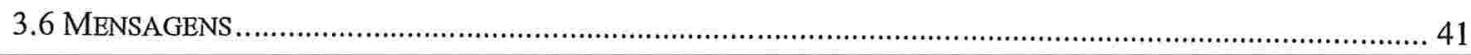

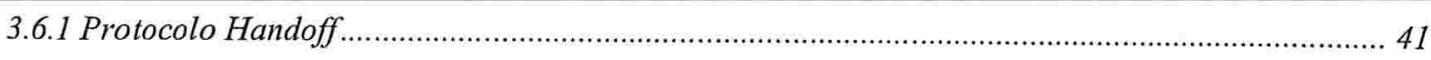

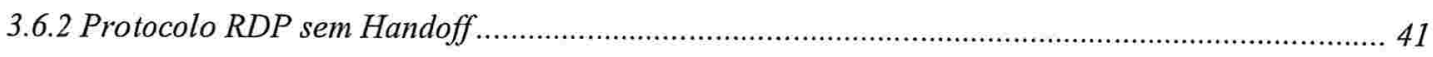

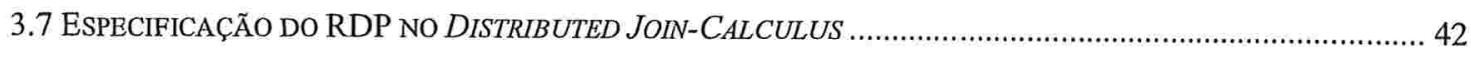

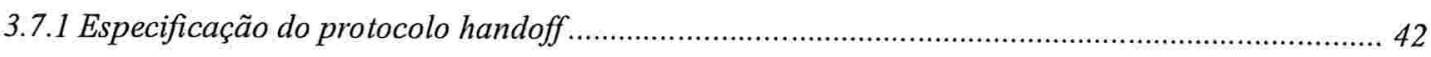

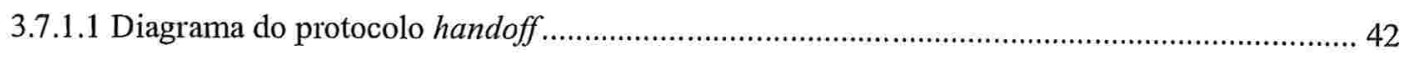

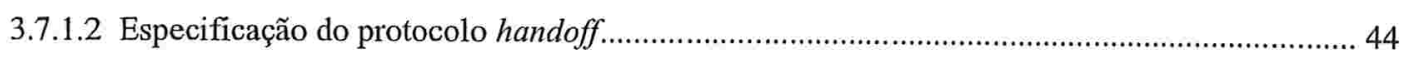

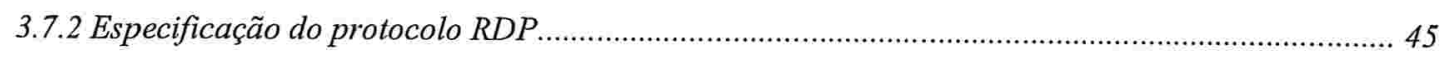

3.7.2.1 Diagrama do protocolo RDP sem handoff ............................................................................. 46

2.7.2.2 Especificação de partes necessárias do protocolo $R D P$.......................................................... 48

3.8 ANÁLISE DO USO DO DISTRIBUTED JOIN-CALCULUS PARA AGENTES MÓVEIS............................................ 53

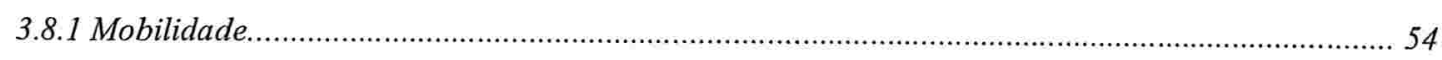

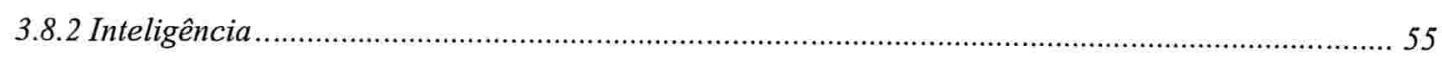

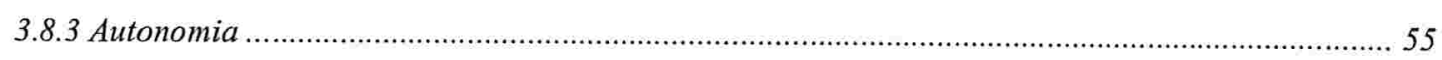

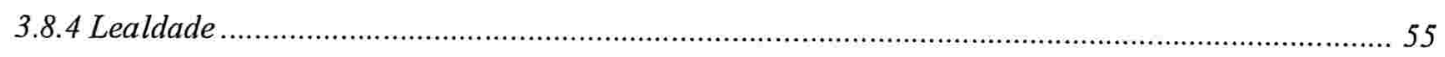

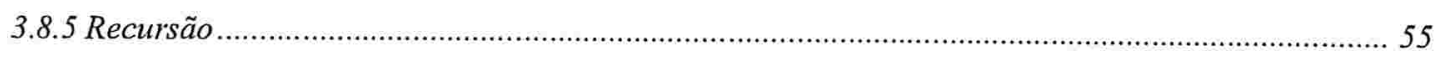

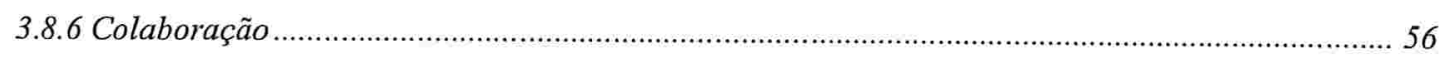

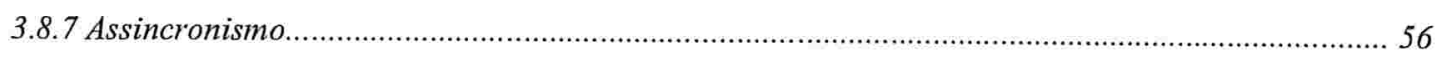

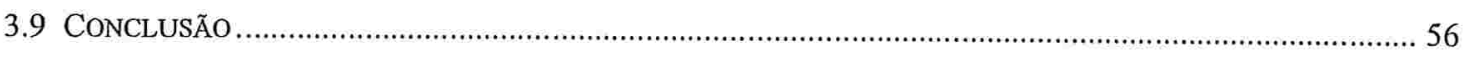

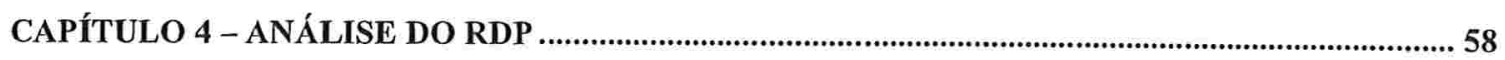

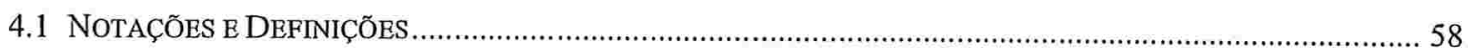

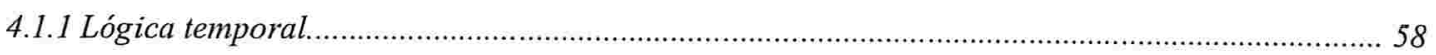

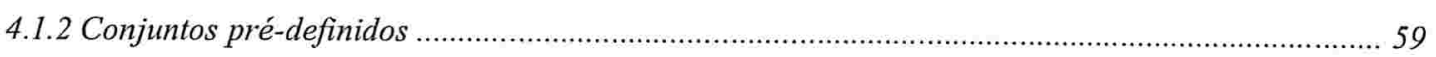

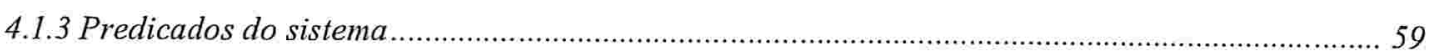

4.2 HiPóteSES E PROPRIEDAdeS Do RDP E do Protocolo HANDOFF …................................................. 60

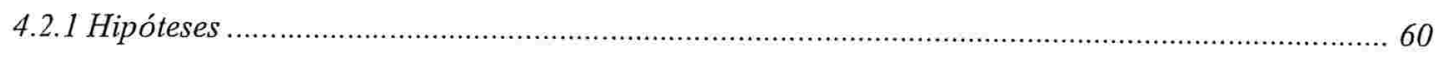

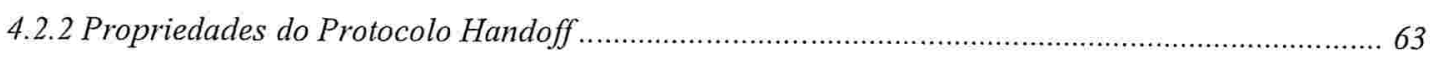

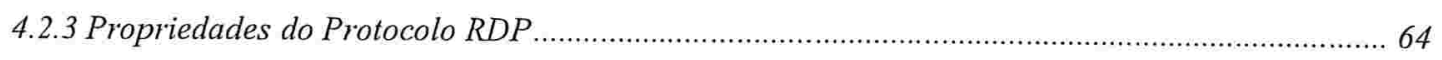

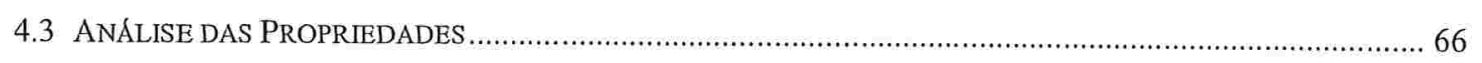

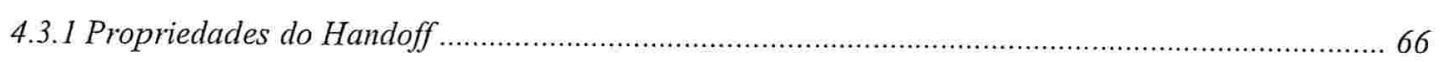

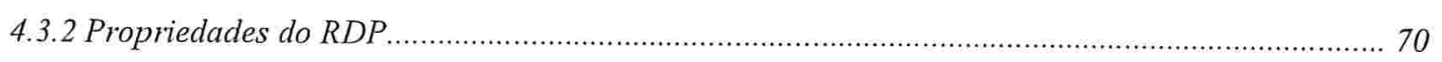

4.4 ANÁLISE DO USO DO DISTRIBUTED JOIN-CALCULUS PARA A PROVA DAS PROPRIEDADES ......................... 74

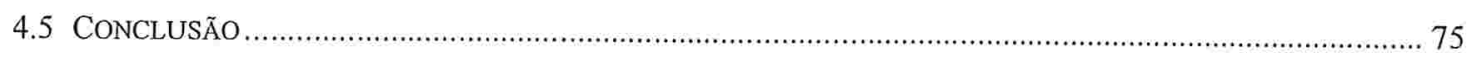




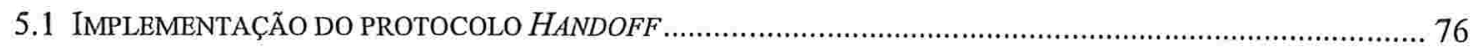

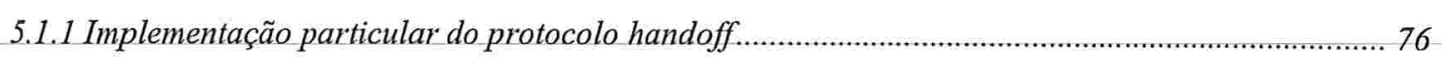

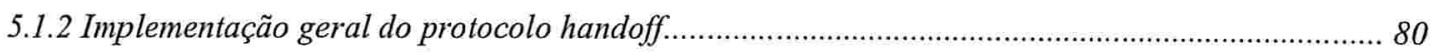

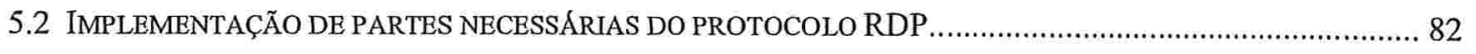

5.3 ANÁLISE DO USO DA LINGUAGEM DISTRIBUTED JOIN-CALCULUS PARA AGENTES MÓVBIS........................... 88

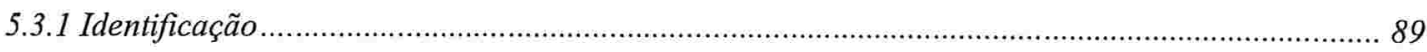

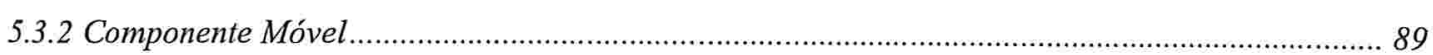

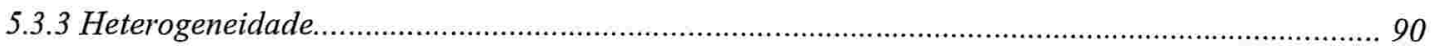

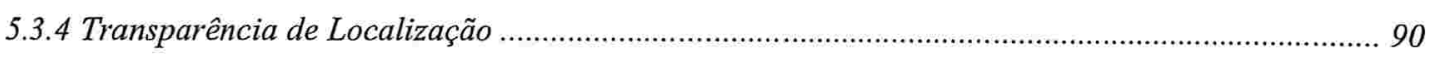

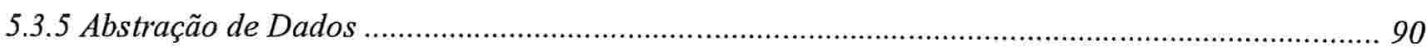

5.4 ANALISE DA TRADUÇÃO DA ESPECIFICAÇÃO DO DISTRIBUTED JOIN-CALCULUS PARA A LINGUAGEM

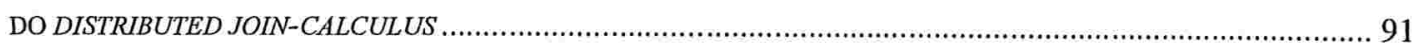

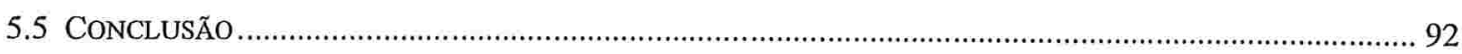

CAPÍTULO 6 - CONCLUS̃̃o E TRABALHOS FUTUROS .................................................................. 93

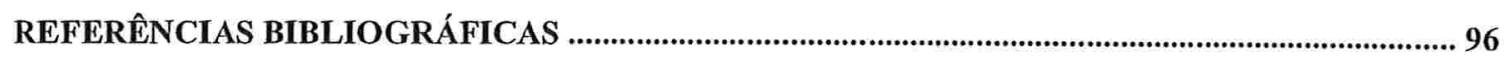

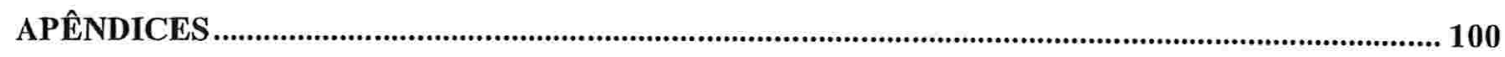

Apêndice A - SintaXe, Escopo e SemânTica Operacional do Distributed JoIN-CaLCULUS............... 100

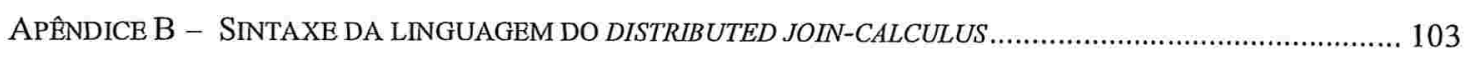

APÊNDICE C - ESPECIFICAÇÃO DO PROTOCOLO HANDOFF VERSUS LÓGICA TEMPORAL ……........................... 104

APÊNDICE D - ESPECIFICAÇÃO DE PARTES RELEVANTES DO PROTOCOLO RDP VERSUS LÓGICA

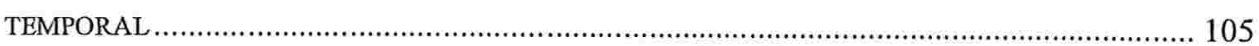

APÊNDICE E - SiMULAÇÃO DA IMPLEMENTAÇÃo DO PROTOCOLO HANDOFF NA LINGUAGEM DO

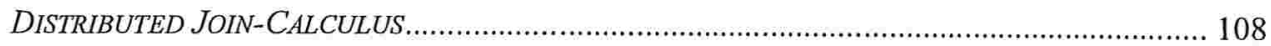

APÊNDICE F - SIMULAÇÃO DA IMPLEMENTAÇ̃̃O DE PARTES RELEVANTES DO PROTOCOLO RDP NA LINGUAGEM DO DISTRIBUTED JOIN-CALCULUS ……………………………......................... 111 


\section{Lista de Figuras}

FIGURA 1 - SINTAXE DO JOIN-CALCULUS

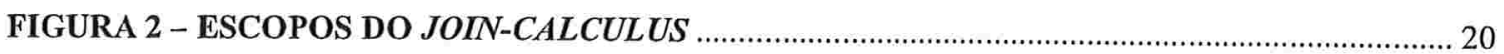

FIGURA 3 - A MÁQUINA QUÍMICA REFLEXIVA (RCHAM) ….................................................... 21

FIGURA 4 - SINTAXE DE DEFINIÇÕES DO DISTRIBUTED JOIN-CALCULUS ............................ 26

FIGURA 5 - SINTAXE DE PROCESSOS DO DISTRIBUTED JOIN-CALCULUS .............................. 27

FIGURA 6 - EXEMPLO DE MOBILIDADE DE LOCALIDADE ...................................................... 33

FIGURA 7 - EXEMPLO DE FUNCIONAMENTO DO PROTOCOLO RDP .................................... 40

FIGURA 8 - SINTAXE DO DISTRIBUTED JOIN-CALCULUS ........................................................ 100

FIGURA 9 - ESCOPOS DO DISTRIBUTED JOIN-CALCULUS ...................................................... 101

FIGURA 10 - A MÁQUINA QUÍMICA REFLEXIVA E DISTRIBUÍDA (DRCHAM)...................... 102

FIGURA 11 - SINTAXE DA LINGUAGEM DO DISTRIBUTED JOIN-CALCULUS ....................... 103 


\section{Capítullo 1 - Introdução}

Este trabalho tem como objetivo a especificação das características de mobilidade de um protocolo de comunicação usando técnicas de desenvolvimento formal. O interesse no desenvolvimento deste trabalho vem do fato de a computação móvel representar um novo paradigma computacional que tem se expandido rapidamente nos últimos anos, com expectativas de crescimento ainda maiores devido ao seu baixo custo, à necessidade da comunicação e à boa aceitação de novas tecnologias pelos usuários [ML98].

Com o crescimento do tamanho e complexidade dos sistemas de software, surgiu a necessidade de construir especificações mais precisas para descrever o comportamento destes sistemas e garantir a corretude de suas implementações. A linguagem natural que, até os dias de hoje, tem sido o meio mais utilizado para especificar sistemas, normalmente gera documentos ambíguos, incompletos e/ou inconsistentes, e não permite que tenhamos a certeza de que a especificação descreve as propriedades necessárias, e nem que a implementação está correta [DMRR00].

Atualmente, alguns serviços de acesso à informação estão sendo oferecidos aos clientes móveis, muitos dos quais são implementados por grupos de servidores distribuídos. Além disso, muitas aplicações de rede têm fortes requisitos de confiabilidade. Isto significa que a comunicação cliente-servidor nos serviços para computação móvel também deve ser confiável além das características próprias da computação móvel. Por exemplo, prover para os usuários um ambiente computacional com um conjunto de serviços comparáveis aos existentes num sistema distribuído de computadores estáticos que permita a mobilidade [ESO98].

O protocolo RDP (Result Delivery Protocol) é um protocolo cliente-servidor que implementa a entrega confiável de mensagens para unidades móveis [ESO98]. Esta confiabilidade significa que para todo pedido feito por um agente móvel num serviço de rede, eventualmente, ele receberá o resultado deste pedido, independentemente dos seus períodos de inatividade e do número de migrações. Este protocolo é apropriado para serviços de rede baseado no estilo de comunicação pedido-resultado e onde há grande probabilidade de uma unidade móvel migrar para outro domínio enquanto está esperando pelo resultado de um pedido.

Além deste, outro motivo que incentivou nossos estudos sobre esse protocolo é que ele foi desenvolvido para uso no sistema SIDAM (Sistema de Informação Distribuídos para Agentes Móveis), o qual tem como objetivo implementar serviços de informação descentralizados para consulta por agentes móveis [SIDAM] e do qual este trabalho faz parte. 
Para garantir a confiabilidade de determinadas características de mobilidade do protocolo e um melhor gerenciamento do modelo a ser desenvolvido, utilizamos métodos formais, que usam definições matemáticas rigorosas e que, atualmente, são considerados úteis para os protocolos de comunicação [DMRR00]. O formalismo utilizado será o distributed joincalculus (language, porque implementamos a especificação na sua linguagem) [FGLMR96], uma extensão do join-calculus (language) [FG96] com localidades (explícitas) e primitivas para mobilidade. O distributed join-calculus permite expressar agentes móveis, representados por localidades, que podem migrar entre domínios.

Há uma diferença entre cálculo para processos concorrentes e linguagens de programação distribuída e sistemas móveis. Cálculos como CCS ou pi-calculus [Mil89, MPW92] introduzem um pequeno número de construtores e têm uma completa metateoria estudada. Entretanto, eles são, em sua maioria, baseados em interações não locais e atômicas que são difíceis de implementar completamente num contexto distribuído. As linguagens de programação tal como Actors [AMST93] ou Obliq [Car95] têm primitivas separadas para transmissão e sincronização, por exemplo, a chamada de procedimento remoto. No entanto, eles também têm um conjunto muito grande de construtores, normalmente, incluindo primitivas imperativas, impedindo suas investigações formais.

O join-calculus é um cálculo de concorrência criado na tentativa de eliminar a distância que existe entre a teoria da concorrência e a programação distribuída [Agh86, BBP87]. Desta forma, ele é usado como base de uma linguagem de programação prática e estudado formalmente como um cálculo de processos.

O join-calculus pode ser visto como uma variante do pi-calculus assíncrono [Bou92] de Milner, pois o join-calculus é um cálculo do qual toda computação se baseia na comunicação assíncrona com troca de mensagens. Ele conserva a elegante técnica de gerenciamento de escopo de nomes desenvolvido no pi-calculus [Mil90, MPW92], e herda algumas noções de equivalência para analisar o comportamento dos programas usando técnicas eficientes de prova.

O pi-calculus tem demonstrado que, em combinação com a elegante técnica de gerenciamento de escopo de nomes, as operações de canais são computacionalmente completos. O PICT [PRT93, PT195, PT295] e o MWB [VM94] são linguagens que implementam o pi-calculus. O PICT tem mostrado também que o pi-calculus, especialmente em seu fragmento assíncrono, pode ser usado como base de uma linguagem concorrente de alta ordem.

Num contexto distribuído, no entanto, os canais introduzem interações atômicas entre emissores e receptores distantes (comunicação "in the ether" [Mil89]) que pode ser difícil de implementar. Por outro lado, os canais não são absolutamente necessários na programação distribuída de alto nível. Por exemplo, eles não são primitivas em linguagens baseados em objetos [AMST93, Car95]. Infelizmente, essas linguagens não têm alicerces 
tão simples e precisos como o pi-calculus. O join-calculus é o modelo que foi desenvolvido para eliminar tais dificuldades.

A necessidade de definições matemáticas rigorosas para os padrões de protocolos de comunicação é bastante reconhecida. Tais definições são necessárias para melhorar a especificação dos protocolos e serviços, e para verificar se os protocolos cumprem os serviços desejados, pois o uso do método de especificação formal fornece uma descrição precisa de um sistema em uma notação com sintaxe e semântica bem definidas [DMRR00]. Muitos desenvolvedores de protocolos ainda confiam nas definições informais mesmo sabendo que estas definições não garantem a confiabilidade dos serviços oferecidos. Mas com a complexidade inerente às inovações nessa nova abordagem, haverá necessidade maior de usar métodos formais que possam especificar tais protocolos e garantir que cumpram seus serviços.

Há trabalhos estudados [BA90, Ba190, EFJ91] que abrangem uma linguagem de especificação formal e que têm por base a semântica de CCS [Mil89]. Mas o uso de uma álgebra de processos tradicional, tal como a do CCS, é limitada à modelagem para grupos móveis. Por isso, o uso do distributed join-calculus e suas pesquisas [OP96, FG96, CF99] nessa área para agentes móveis.

\subsection{Trabalhos Relacionados}

Sobre protocolos e mobilidade, tem-se desenvolvido trabalhos como [BB94, Ioa93, HB93, MW93, MR97, PRM97, RMP97, AP98]. Em [AP98], é apresentada numa linguagem padrão de descrição de processos, uma versão simplificada de propostas para suporte à mobilidade na versão 6 do protocolo da Internet (IP). A preocupação neste trabalho é em relação à segurança de que as mensagens de e para agentes móveis sejam sempre entregues sem perda de conectividade (entrega confiável). Por isso, foram desenvolvidos três modelos: o primeiro é sem agentes móveis, o segundo dá suporte à mobilidade e o terceiro com algumas propriedades a mais sobre agentes móveis.

Uma das propriedades-chave, objetivo de muitos protocolos para componentes móveis, que é a questão mais importante tratada em [AP98] é também uma das propriedades que estamos preocupados em analisar: se as mensagens para e de agentes móveis são entregues antes e depois da migração de um agente.

Assim como em [AP98], da descrição informal de um protocolo existente, verificamos os aspectos que parecem relevantes para as propriedades que desejamos checar (mobilidade) e especificamos o modelo do protocolo aplicando técnicas matemáticas para verificar algumas propriedades e comportamentos. Nosso trabalho será dividido em dois modelos, sendo um primeiro restrito, com as características de mobilidade, que é o protocolo handoff e um segundo, o protocolo RDP, que usa o protocolo handoff. 


\subsection{Estrutura da Dissertação}

A forma como este trabalho foi estruturado não coincide com a seqüência realmente desenvolvida. A parte das implementações dos protocolos foi realizada juntamente com a especificação, nos auxiliando no desenvolvimento e entendimento da especificação dos protocolos no distributed join-calculus. Mas, para a análise dos protocolos e prova das propriedades, objetivo principal deste trabalho, a implementação dos protocolos não se faz necessária, por isso é apresentada no final do trabalho.

Capítulo 2: fazemos uma breve explicação sobre a máquina química abstrata. Uma visão geral do join-calculus e a máquina química abstrata reflexiva é abordada, bem como sua sintaxe, semântica, escopo e processos de redução. Uma visão geral do distributed joincalculus e a máquina química reflexiva e distribuída, principalmente, no que se refere à localidade e migração, é abordada, bem como sua sintaxe, semântica e escopo. Uma visão geral da linguagem do distributed join-calculus, principalmente, no tratamento de agentes móveis, comunicação e mobilidade é abordada, bem como sua sintaxe.

Capítulo 3: comentamos o protocolo result delivery protocol e o protocolo handoff. Um modelo do sistema e a visão geral do funcionamento do protocolo RDP e handoff são apresentadas. As mensagens e as comunicações envolvidas no sistema também são abordadas. Além disso, apresentamos a especificação do protocolo handoff e a especificação de partes necessárias do protocolo RDP no distributed join-calculus. Estas especificações são utilizadas na verificação das propriedades inerentes aos protocolos. Uma análise sobre a avaliação do distributed join-calculus é também apresentada em relação ao seu uso para agentes móveis.

Capítulo 4: apresentamos a implementação dos protocolos RDP e handoff. Inicialmente, implementamos a mobilidade do protocolo, numa especificação simples e restrita, na linguagem do distributed join-calculus, para o entendimento da linguagem. $\mathrm{E}$ posteriormente apresentamos a implementação completa do protocolo handoff e a implementação de partes relevantes do protocolo RDP, na linguagem do distributed joincalculus, de acordo com suas especificações. Uma análise sobre a avaliação da linguagem do distributed join-calculus é apresentada além da tradução da especificação para a linguagem do distributed join-calculus.

Capítulo 5: apresentamos a análise, resultado deste trabalho. Para a prova das propriedades do protocolo RDP e handoff, os conceitos e definições da lógica temporal foram introduzidos. As hipóteses e as propriedades do protocolo RDP e handoff foram escritas usando a lógica temporal e para a verificação das propriedades usamos as especificações dos protocolos no distributed join-calculus. Além disso, uma análise do uso da especificação do protocolo no distributed join-calculus para a prova das propriedades é apresentada.

Capítulo 6: apresentamos nossas conclusões e trabalhos futuros. 


\section{Capítulo 2 - Formalismos}

O uso de um formalismo nas especificações produz uma melhor visão e entendimento das características que se deseja observar, reduzindo-se a ocorrência de erros de projeto, além de garantir que um programa esteja correto em relação à especificação ou apresente certas propriedades. Isso é assegurado pelo uso de definições matemáticas rigorosas.

O formalismo utilizado neste trabalho é o distributed join-calculus [FGLMR96], uma extensão do join-calculus [FG96]. O distributed join-calculus, além das características do join-calculus, introduz o conceito de localidades, representando agentes móveis através de localidades.

Mesmo sendo um cálculo recente (criado na década de 90), o pi-calculus é bastante estudado, além de ser um cálculo de referência para outros formalismos [AP94, Mi190, Smo94, Wa195]. Apesar disso, utilizaremos o distributed join-calculus, pois nele algumas questões são mais bem tratadas como, por exemplo:

- localidade, que trata domínios inteiros em vez de agentes isolados;

- propósitos de implementação, que possibilitam a implementação das especificações numa linguagem de programação própria do join-calculus; e

- distribuição explícita.

Neste capítulo apresentamos, de forma resumida, o join-calculus, o distributed joincalculus, que é uma extensão do join-calculus e a linguagem do distributed join-calculus, que é a linguagem de implementação do cálculo.

\subsection{Join-Calculus}

Nesta seção apresentamos, resumidamente, o join-calculus: sua semântica, sintaxe, escopo e definições para as regras de redução. Mostramos apenas as características que são necessárias para o entendimento deste trabalho, de forma que nenhum aspecto será tratado em profundidade. Para um entendimento mais completo, consultar [FG96].

\subsubsection{Máquina Química Abstrata}

Como o join-calculus usa uma analogia com a química, veremos brevemente sua terminologia segundo [BB92]. Em [BB92, Bou94], Berry e Boudol introduzem a máquina química abstrata (CHAM - Chemical Abstract Machine) para descrever semânticas operacionais de sistemas concorrentes. A CHAM oferece uma forma clara e simplificada de definir semânticas baseadas em redução como equivalências estruturais moduladas por 
redução. A CHAM enfoca a noção padrão de redução, ou seja, classificada pelos passos de transição.

As semânticas químicas usam famílias de regras químicas que operam sobre um conjunto de conjuntos de moléculas, também chamadas soluções químicas. A noção de reação química é definida por meio de:

- regras de reação: regras reescritas localmente que descrevem um modelo particular. Estas regras podem ser regras estruturais ou regras de redução:

0 as regras estruturais, simbolizadas por $\Rightarrow$, são reversíveis $(\rightarrow$ simboliza o aquecimento $\mathrm{e}-$ simboliza o resfriamento). Elas representam as combinações sintáticas das moléculas na solução. O aquecimento quebra as moléculas em outras menores, e o resfriamento constrói moléculas maiores como união de seus componentes.

- as regras de redução, simbolizadas por $\rightarrow$, consomem algumas moléculas específicas na solução química, substituindo-as por outras; elas correspondem aos passos computacionais básicos.

- leis gerais: leis que explicam como as regras locais de reação se aplicam dentro de uma solução química maior. Por exemplo, para as leis químicas, toda regra de reação se aplica para qualquer conjunto de conjuntos de moléculas maior, mas as moléculas estranhas não são alteradas pela reação.

A abordagem química é ilustrada por meio do seguinte fragmento apresentado em duas regras:

- STR-JOIN

- RED

$$
\begin{aligned}
& \mathrm{P} \mid P^{\prime} \rightleftharpoons P, P^{\prime} \\
& \bar{a}<v_{1}, \ldots, v_{n}>\mid a<y_{1}, \ldots, y_{n}>. P \quad \rightarrow \quad P\left\{v_{1} / y_{1}, \ldots, v_{n} / y_{n}\right\}
\end{aligned}
$$

A regra estrutural STR-JOIN refere-se à composição paralela e define duas relações opostas: $\rightarrow$ e - . Nesta regra, qualquer molécula da forma $P \mid P^{\prime}$ pode ser aquecida (dividida) em duas outras moléculas menores $P$ e $P^{\prime}$ e, por outro lado, qualquer par de moléculas $P$ e $P^{\prime}$ pode ser resfriada (unida) em uma única molécula $\mathrm{P} \mid P^{\prime}$.

A regra de reação RED consome uma molécula simples que contém dois processos acoplados em composição paralela e que pode interagir por algum canal $a$. Esta regra produz uma molécula simples que contém o processo de recebimento depois da comunicação.

A seguir, os passos químicos são exemplificados:

$$
\begin{aligned}
& \{\bar{a}<1>|P| a(u) \cdot Q\} \quad \rightarrow \quad\{\bar{a}<1>, P, a(u) \cdot Q\} \\
& \{P, \bar{a}<1>\mid a(u) \cdot Q\}
\end{aligned}
$$


onde: na linha (1), o aquecimento é usado duas vezes para dissolver o processo inicial $\bar{a}<1>|P| a(u) \cdot Q$ nos componentes $\bar{a}<1>, P$ e $a(u) \cdot Q$; na linha (2), o resfriamento é usado em $\bar{a}<1>$ e $a(u) . Q$ para formar $\bar{a}<1>\mid a(u) . Q$; na linha (3), ocorre a comunicação na molécula $\bar{a}<1>\mid a(u) . Q$, consumindo-a e substituindo-a pela nova molécula $Q\{1 / u\}$, onde todas as ocorrências de $u$ em $Q$ são substituídas por 1 e; na linha (4), o resfriamento é usado em $P$ e $Q\{1 / u\}$ para formar $P \mid Q\{1 / u\}$.

A CHAM também enfatiza o gerenciamento de escopos usando uma estrutura química adicional. Uma membrana é a fronteira de uma subsolução ativa e é considerada como uma molécula simples dentro da solução química. Assim, uma solução química torna-se uma hierarquia de soluções aninhadas. As membranas materializam os escopos das variáveis; elas são "porosas", dado que a interação controlada pode ocorrer através da membrana.

Para conservar a localidade em regras de redução, as moléculas têm uma capacidade de comunicação externa usando um mecanismo de câmara de vácuo que isola algumas capacidades de comunicação e as deixam livres na membrana de forma reversível, como um pré-requisito para a comunicação em soluções fechadas.

\subsubsection{Assegurando a Localidade e Adicionando a Reflexão}

As interações da CHAM são locais desde que as moléculas se desloquem de uma solução química e até que elas se encontrem em pares e reajam. Assumindo que as regras químicas têm domínios desconexos, a CHAM também tem interpretação operacional: todas as moléculas passam para um local de reação associado às suas regras, onde elas são distribuídas, comparadas e prontas para reagir.

Sob esta interpretação, entretanto, a CHAM não é muito concorrente: a comunicação é centralizada em um conjunto fixo de regras de reação e o gerenciamento de cada regra é complexo. Assim, como o número de diferentes formas de moléculas esperadas pode crescer arbitrariamente, seria melhor ter um número considerável de regras de reação mais simples.

Em resumo, o modelo da máquina química abstrata reflexiva (RCHAM - Reflexive Chemical Abstract Machine) é obtido da CHAM genérica assegurando a localidade e adicionando a reflexão:

- localidade: significa que toda mensagem pode ser consumida por, no máximo, um grupo de regras químicas, definidas estaticamente, e que forneçam somente serviços de sincronização mínima entre mensagens pendentes. 
- reflexão: é adicionada permitindo que as reações ampliem uma solução química, com novos nomes, por meio de suas regras de reações exclusivas. Isto leva esse modelo a ser computacionalmente completo.

\subsubsection{Join-Calculus e a Máquina Química Abstrata Reflexiva}

Agora veremos uma idéia geral dos mecanismos da RCHAM. A definição formal será vista na próxima seção.

Esse modelo funciona numa solução de alta ordem, $\mathcal{D} \vdash P$, abrangendo dois conjuntos de conjuntos. As moléculas $P$ representam os processos em execução paralela e as reações $\mathcal{D}$ definem as regras de reações ativas.

Os nomes de canais podem ser usados tanto como endereços para enviar mensagens quanto como conteúdo de mensagem. Neste sentido, o join-calculus pertence à família dos cálculos de processos com mobilidade de nome.

Consideramos $x<y>$ para expressar que o nome $y$ está sendo enviado pelo nome $x$. Recorrendo à notação química, um átomo é uma mensagem pendente $x<y>\mathrm{e}$ uma composição de moléculas consiste em várias submoléculas acopladas pelo operador "ఏ" de paralelismo. As moléculas podem ser aquecidas em outras menores de forma reversível.

Como um primeiro exemplo, considera-se um programa de impressão que manipula os pedidos de impressão solicitados pelas estações de trabalho. Assume-se que a interface do programa de impressão consiste em duas portas: leitura e trabalho. As impressoras livres como, por exemplo, a laser, enviam seus nomes pela porta chamada leitura, enquanto os usuários enviam os arquivos como, por exemplo, 1 e 2, para serem impressos pela porta chamada trabalho.

$$
\begin{aligned}
& \vdash \quad \text { leitura }<\text { laser }>, \text { trabalho }<1>, \text { trabalho }<2> \\
\rightleftharpoons & -\quad \text { leitura }<\text { laser }>\mid \text { trabalho }<1>\text {, trabalho }<2>
\end{aligned}
$$

Há três átomos (leitura $<$ laser $>$, trabalho $<1>$ e trabalho $<2>$ ) na solução química acima em (1) e um átomo (trabalho $<2>$ ) e uma composição de moléculas (leitura<laser $>$ | trabalho $<I>$ ) em (2), onde a molécula liga a impressora laser e o arquivo 1. A equivalência estrutural $\rightleftharpoons$ relaciona as duas soluções ainda sem reação.

Considere $\boldsymbol{D}$ ou $\boldsymbol{J} \Delta \boldsymbol{P}$, uma reação consome moléculas compostas que compara um padrão de união $J$ e produz novas moléculas na solução química que são copiadas do processo $P$, onde os parâmetros formais de $J$ tenham sido instanciados para os valores transmitidos. Continuando o exemplo,

$$
D \stackrel{\text { def }}{=} \quad \text { leitura }<\text { impressora }>\mid \text { trabalho }<\text { arquivo }>\Delta \text { impressora }<\text { arquivo }>
$$


adiciona-se uma reação que compara impressoras com trabalhos e então envia o arquivo para a impressora.

Agora, adiciona-se esta reação química para a solução anterior, podendo então ser usado para consumir a composição da molécula e gerar um novo átomo.

$$
\begin{array}{lll} 
& \mathrm{D} \quad \vdash \quad \text { leitura }<\text { laser }>\text { trabalho }<1>\text {, trabalho }<2> \\
\mathrm{D} \quad \vdash \quad \text { laser }<1>\text {, trabalho }<2>
\end{array}
$$

Perceba que o não determinismo é induzido por $\rightleftharpoons$, que pode selecionar trabalho $<1>$ ou trabalho $<2>$, mas na verdade é executado pela redução.

O modelo é reflexivo, isto significa que as reações podem ser criadas dinamicamente. Isto é feito por um último tipo de molécula: a definição de molécula, def $\mathbf{D}$ in $\mathbf{P}$, que pode ser aquecida em duas partes: uma nova reação D e uma molécula P. Neste caso, as novas portas definidas podem ser usadas em D e P. A solução considerada pode vir de uma molécula simples com as seguintes regras estruturais:

$$
\begin{array}{llll} 
& & \vdash & \text { def D in leitura }<\text { laser }>\mid \text { trabalho }<1>\mid \text { trabalho }<2> \\
\rightarrow & \mathrm{D} & \vdash \quad \text { leitura }<\text { laser }>\mid \text { trabalho }<1>\mid \text { trabalho }<2> \\
\rightarrow & \mathrm{D} & \vdash \quad \text { leitura }<\text { laser }>, \text { trabalho }<1>\text {, trabalho }<2>
\end{array}
$$

\subsubsection{Sintaxe e Escopos}

Nesta seção, apresentamos a sintaxe do join-calculus e os escopos para as suas variáveis.

\section{Nomes}

O join-calculus é um cálculo de passagem de nome. Seja $\mathrm{N}$ um conjunto contável de nomes de portas, as variáveis de nomes são escritas em letras minúsculas para representar os elementos de $\mathrm{N}$ e as $\mathrm{n}$-uplas de nomes são representados por $\mathrm{x}_{1}, \mathrm{x}_{2}, \ldots, \mathrm{x}_{\mathrm{n}} \in \mathrm{N}$.

Os nomes, que são os únicos valores no join-calculus, obedecem a um escopo léxico e podem ser enviados nas mensagens. Seguindo o mesmo tratamento do cálculo de processos, usamos as palavras nome, variável, porta e canal alternativamente.

Os nomes podem ser usados para formar mensagens que carregam alguns outros nomes, por exemplo, $x\langle u, v\rangle$. A aridade de uma mensagem é o número de valores que estão sendo carregados, neste caso, dois. Enquanto isto não for necessário no join-calculus, assume-se que, para qualquer nome dado, o número de argumentos é o mesmo em toda a mensagem e em todo padrão de união. Por exemplo, seja $x<>\mid P$ e suponha que $P$ abranja qualquer processo do join-calculus, então, implicitamente, exige-se que todas as mensagens sobre $x$ 
emitidas em $P$ também sejam $x<>$, excluindo processos que possam enviar mensagens $x<u>$ ou $x<u, v>$. Isto equivale a anexar uma aridade para todos os nomes e considerar somente os processos que tenham mensagens com aridades compatíveis. Assume-se que há um número infinito de nomes para cada aridade e a notação $\mathrm{N}_{0}$ é usada para o subconjunto de nomes nulos, isto é, nomes em $\mathrm{N}$ com aridade nula.

\section{Processos e definicões}

A gramática para o join-calculus é definida por indução na Figura 1. Ela contém duas categorias de termos: os processos e as definições.

$P \quad::=$

$$
x<v_{1}, \ldots, v_{n}>
$$$$
\text { | } \operatorname{def} D \text { in } P
$$$$
\boldsymbol{P} \mid \boldsymbol{P}^{\prime}
$$$$
\mathbf{0}
$$

D $::=$

$$
\mid \begin{aligned}
& J \triangleright P \\
& D^{\wedge} D^{\prime} \\
& \mathbf{T}
\end{aligned}
$$

$J \quad::=$

$$
\begin{aligned}
& x<y_{1}, \ldots, y_{n}> \\
& \quad J \mid J
\end{aligned}
$$

processos

mensagem

definição local

composição paralela

processo nulo

definições

regra de reação

conjunção de definição

definição nula

padrões de união

mensagem padrão

união de padrões

\section{Figura 1 - Sintaxe do Join-Calculus}

Um processo $\boldsymbol{P}$ pode ser:

- a emissão assíncrona de uma mensagem poliádica $x<v_{1}, \ldots, v_{n}>$;

- a definição local de novos nomes por $\operatorname{def} \boldsymbol{D}$ in $\boldsymbol{P}$;

- a composição paralela de processos $\boldsymbol{P} \mid \boldsymbol{P}^{\prime}$; ou

- o processo nulo $\mathbf{0}$.

Uma definição $D$ pode ser:

- uma regra local $J \triangleright P$ que compara um dado padrão de união $J$ e o associa a um processo condicional $\boldsymbol{P}$;

- a composição de definições ligadas pelo operador ^; ou

- a definição nula T.

Um padrão de união $J$ pode ser: 
- uma composição paralela de mensagens formais $\left\langle y_{1}, \ldots, y_{n}\right\rangle$; ou

- um padrão de união da forma $n$, quando ele liga $n$ mensagens.

Define-se a precedência dos operadores de forma que os processos e definições da sintaxe abstrata do join-calculus sejam mostrados como termos concretos, com parênteses quando há uma ambigüidade. Para simplificar a notação, assume-se que os construtores binários | e $\wedge$ sejam associativos à esquerda e que a composição paralela limita mais que a definição local. Por exemplo,

$$
\begin{array}{ll}
\text { def } & x<\triangleright 0 \text { in } y<x>|z<>| \text { def } z<>>0 \text { in } x<>\mid z<> \\
\text { def } & x<>\triangleright 0 \text { in }(y<x>|z<>|(\text { def } z<>\triangleright 0 \text { in }(x<>\mid z<>)))
\end{array}
$$

\section{$\underline{\text { Escopos e Substituicões }}$}

Intuitivamente, as regras locais definem como as mensagens são consumidas com o fornecimento de padrões de união que engatilham processos condicionais. Elas podem ser consideradas como uma extensão de funções nomeadas com sincronização. Por exemplo, as variáveis de nomes $f$ e $x$ no processo def $f\langle x\rangle \triangleright P_{1}$ in $P_{2}$ obedecem às regras de escopo léxico similar às variáveis $f$ e $x$ no processo let $f x=e_{1}$ in $e_{2}$ encontrado em linguagens de programação. Geralmente, os nomes que aparecem num processo $\boldsymbol{P}$ podem ser capturados pela definição de fechamento. O único limitador é o padrão de união $J=x<v_{1}, v_{2}, \ldots, v_{n}>$ | ... . Mas, o escopo de seus nomes depende de sua posição nas mensagens.

- Os parâmetros formais $v_{1}, v_{2}, \ldots, v_{n}$, que são recebidos em $J$, são limitados no processo condicional correspondente. Eles devem ser distintos dois a dois.

- Os nomes $x$, que são definidos parcialmente em $J$, são limitados recursivamente em todo o processo de definição def $\boldsymbol{D}$ in $\boldsymbol{P}$, ou seja, no processo principal $\boldsymbol{P}$ e, recursivamente, em todo o processo condicional dentro da definição $D$. Eles podem aparecer no máximo uma vez em todo o padrão.

As variáveis recebidas - vr[J], as variáveis definidas - vd[J] e vd/D] e as variáveis livres $\operatorname{vl}[D]$ e vl[ $[P]$ são especificadas por indução estrutural na Figura 2.

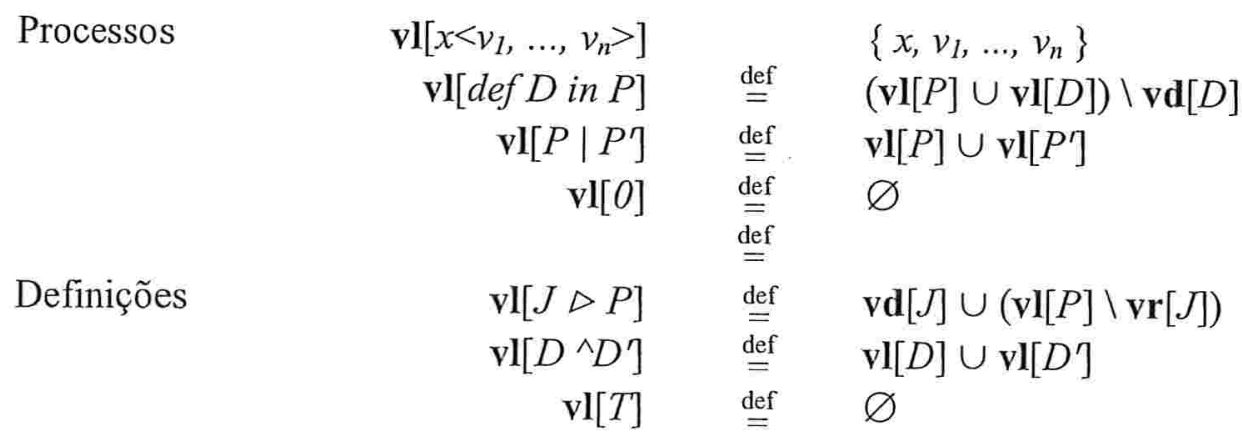




$\begin{array}{rll}\operatorname{vr}[J \Delta P] & \stackrel{\text { def }}{=} & \mathbf{v d}[J] \\ \operatorname{vr}\left[D^{\wedge} D^{\prime}\right] & \stackrel{\text { def }}{=} & \mathbf{v d}[D] \cup \mathbf{v d}\left[D^{\prime}\right] \\ \operatorname{vr}[T] & \stackrel{\text { def }}{=} & \varnothing\end{array}$

Padrões de união

$$
\begin{array}{rll}
\mathbf{v d}\left[x<y_{1}, \ldots, y_{n}>\right] & \stackrel{\text { def }}{=} & \{x\} \\
\mathbf{v d}\left[J \mid J^{\prime}\right] & \stackrel{\text { def }}{=} & \mathbf{v d}\left[J \uplus \mathbf{v d}\left[J^{\prime}\right]\right. \\
\mathbf{v r}\left[x<y_{1}, \ldots, y_{n}>\right] & \stackrel{\text { def }}{=} & \left\{y_{1}, \ldots, y_{n}\right\} \\
\mathbf{v r}[J \mid J] & \stackrel{\text { def }}{=} & \mathbf{v r}[J] \uplus \mathbf{v r}\left[J^{\prime}\right]
\end{array}
$$

\section{Figura 2 - Escopos do Join-Calculus}

As condições para as ocorrências de nomes nos padrões de união forçam duas restrições:

- nenhuma variável recebida pode aparecer duas vezes no mesmo padrão $J$, o que evita a comparação de nomes e garante que os padrões de união permaneçam lineares; e

- nenhum padrão pode unir várias mensagens para o mesmo nome definido, o que é menos importante mas simplifica algumas discussões.

Pode-se usar a conversão $\alpha$ para garantir que nenhum nome apareça duas vezes em qualquer padrão de união.

\subsubsection{Semântica Operacional}

Nesta seção, apresentamos a semântica operacional para o join-calculus.

\section{$\underline{\text { Soluções Reflexivas }}$}

O estado da computação é a solução química. Ela consiste em dois conjuntos separados, $D$ e $P$, de conjuntos de moléculas e é representado por $D \vdash P$. Do lado direito, $P$ é um conjunto de processos em execução e do lado esquerdo, $D$ é um conjunto de conjuntos de regras ativas. As definições ativas em $D$ são regras de reação que definem as possíveis reduções de processos. Os processos em execução em $P$ representam o estado da computação. Esses processos interagem de acordo com as regras de reação que são enfatizadas nomeando a máquina reflexiva. 


\title{
Regras químicas para o RCHAM
}

As semânticas estão definidas na Figura 3 como uma coleção de regras químicas que funciona em fragmentos de soluções reflexivas.

\author{
STR-JOIN \\ STR-NULL \\ STR-AND \\ STR-NODEF \\ STR-DEF
}

RED

Condições para as substituições:

STR-DEF $\sigma_{\mathrm{vd}}$ instancia a porta de variáveis vd[N] para distinto, nomes livres: $\operatorname{Dom}\left(\sigma_{\mathrm{vd}}\right) \cap \operatorname{vl}[D \vdash P]=\varnothing$ onde $D \vdash P$ é a solução inicial

RED $\sigma_{\mathrm{rv}}$ substitui os nomes transmitidos para variáveis recebidas distintas $\operatorname{vr}[J]$

\section{Figura 3 - A máquina química reflexiva (RCHAM)}

As primeiras quatro regras estruturais determinam que os operadores $\mid \mathrm{e}^{\wedge}$ sejam associativos e comutativos com unidades 0 e T. A regra estrutural STR-DEF estabelece reflexão com disciplina de escopo estático: na direção do aquecimento, um processo de definição pode ativar suas regras de reações locais, fornecendo novos nomes que são substituídos por suas variáveis definidas. No lado do resfriamento, as regras de reação podem ser dobradas no processo, desde que seus nomes definidos apareçam somente naquele processo e naquelas regras.

A regra de redução RED descreve o uso das regras de reações ativas $J \triangleright P$ que aparecem no lado esquerdo da solução química. Para toda regra de reação deste tipo, o passo de redução corresponde ao consumo de uma composição paralela de mensagens que compara $J$ e libera uma cópia do processo condicional e associado onde os nomes enviados são substituídos pelos parâmetros recebidos. A regra de reação $J \triangleright P$ é inalterada à esquerda e pode ser usada mais tarde nos passos de redução futuros.

\subsubsection{Exemplos}

Nesta seção, veremos alguns exemplos de processos e definições e uma descrição intuitiva de seus significados. Estes exemplos foram extraídos de [FGLMR96]. 
Este primeiro exemplo de definição retransmite mensagens de um nome para outro:

$$
P=\operatorname{def} x<u>\triangleright y<u>\text { in } Q
$$

O nome $y$ é livre em $P$, enquanto o nome $x$ é limitado. Operacionalmente, a regra $x<u>\Delta$ $y\langle u>$ recebe qualquer mensagem enviada para $x$ e envia a mensagem com o mesmo conteúdo para $y$. Assim, o nome $x$ comporta-se como um retransmissor para $y$. Ele pode ser usado em $Q$ através de $y$ enviando mensagens ou como valor nas mensagens. Independentemente do contexto, a semântica do join-calculus garante que toda mensagem emitida por $x$ será encaminhada para $y$ que transforma os nomes $x$ e $y$ em sinônimos. Estendendo nosso exemplo de retransmissão, podemos fazer uma transmissão múltipla de uma mensagem, encaminhando-a para vários nomes:

$$
P=\operatorname{def} x<u>\triangleright x_{1}<u>\left|x_{2}<u>\right| \ldots \mid x_{n}<u>\text { in } Q
$$

Toda mensagem $x<v>$ emitida em $Q$ produz $\mathrm{n}$ mensagens, para serem recebidas por $\mathrm{n}$ diferentes agentes na computação de fechamento.

Num segundo exemplo, assumimos a existência de valores básicos como inteiros. Assim, uma especificação pode ter a seguinte forma:

$$
\operatorname{def} \text { print }\langle x>\triangleright \ldots \text { in print }<3>
$$

Para imprimir alguns inteiros em ordem, precisamos que a impressora retorne alguma mensagem de conclusão de impressão. Assim, a impressora retorna um canal $k$ para cada trabalho:

$$
\text { def } \operatorname{print}<x, k>\triangleright \ldots k<>\text { in def } k<>\triangleright \text { print }<4, k^{\prime}>\text { in print }<3, k>
$$

Na prática, o controle seqüencial é tão comum que merece um refinamento sintático para tornar a continuação implícita. Assim, temos:

$$
\operatorname{def} \operatorname{print}(x) \triangleright \ldots \text { reply to } \operatorname{print} \ldots \text { in } \operatorname{print}(3) ; \operatorname{print}(4)
$$

Os nomes síncronos são escritos como "x" e "print" em vez de " $x$ " e "print" para sabermos que eles estão carregando um canal $k$ de continuação implícita. Ao longo do trabalho, usaremos $k_{\mathrm{x}}$ para nomes livres e as seguintes traduções:

$$
\begin{array}{rlll}
\mathrm{x}<v_{1}, \ldots, v_{n}> & \stackrel{\text { def }}{=} & x<v_{1}, \ldots, v_{n}, k_{\mathrm{x}}> & \text { em padrões de união J } \\
\text { reply } V_{1}, \ldots, V_{n} \text { to } \mathrm{x} & \stackrel{\text { def }}{=} & k_{\mathrm{x}}<V_{1}, \ldots, V_{n}> & \text { em processos condicionais } \mathrm{P}
\end{array}
$$

Para a chamada, são introduzidos o let, sequiências e chamadas aninhadas: 


$$
\begin{array}{rll}
x<V_{1}, \ldots, V_{n}> & \stackrel{\text { def }}{=} & \text { let } v_{1}, \ldots, v_{n}=V_{1}, \ldots, V_{n} \text { in } x<v_{1}, \ldots, v_{n}> \\
\text { let } u_{1}, \ldots, u_{n}=\mathrm{x}\left(V_{1}, \ldots, V_{n}\right) \text { in } P & \stackrel{\text { def }}{=} & \operatorname{def} k<u_{1}, \ldots, u_{n}>\triangleright P \text { in } x<V_{1}, \ldots, V_{n}, k> \\
\text { let } u=v \text { in } P & \stackrel{\text { def }}{=} & P\{u / v\} \\
\text { let } u_{1}, \ldots, u_{n}=V_{1}, \ldots, V_{n} \text { in } P & \stackrel{\text { def }}{=} & \text { let } u_{1}=V_{1} \text { in let } u_{2}=\ldots \text { in } P \\
\mathrm{x}\left(V_{1}, \ldots, V_{n}\right) ; P & \stackrel{\text { def }}{=} & \text { def } k<\triangleright P \text { in } x<V_{1}, \ldots, V_{n}, k>
\end{array}
$$

\subsubsection{Reduções}

As duas próximas subseções utilizam-se da observação $\boldsymbol{l}$ abaixo que prepara a identificação de processos e soluções simples de moléculas. A partir de soluções químicas abstratas, pode-se aplicar repetidamente as regras de aquecimento até se obter dois conjuntos de conjuntos uniformes de definições simples de condições e mensagens simples. Assim, pode-se resfriar esta solução usando as regras STR-JOIN e STR-AND e finalmente STR-DEF uma vez.

Observação 1: Toda solução química é equivalente estruturalmente:

- a uma solução completamente aquecida que contenha somente regras de reação simples e mensagens $\left\{\ldots J_{j} \triangleright J_{j}, \ldots\right\} \vdash\left\{\ldots x_{i}<u_{i l}, \ldots, u_{i n}>, \ldots\right\}$

- a soluções correspondentes que contenham um processo simples e resfriado $\varnothing \vdash$ $\left\{\right.$ def $\wedge J_{j} \triangleright P_{j}$ in $\left.\prod x_{i}<u_{i k}, \ldots, u_{i n}>\right\}$

A análise de reduções químicas é especialmente simples em soluções completamente aquecidas quando se deve unir algumas mensagens pela regra STR-JOIN para comparar um padrão de união.

\subsection{Distributed Join-Calculus}

Esta seção mostra uma forma de join-calculus mais explícita para a programação distribuída. As computações distribuídas, soluções químicas ou máquinas, podem se comunicar sobre uma rede assíncrona. Parte da computação pode migrar de uma máquina para outra.

O join-calculus é estendido com localidades e primitivas para mobilidade. O resultado distributed join-calculus - permite expressar agentes móveis que podem se deslocar entre as máquinas.

A novidade do distributed join-calculus é a introdução de localidades as quais contêm um grupo de processos e definições que podem se deslocar de uma máquina para outra. Os agentes móveis, representados por localidades, podem conter subagentes que são representados por localidades aninhadas. Quando uma localidade se desloca, todas as suas 
sublocalidades se deslocam com ela, por isso, as localidades são organizadas em uma árvore.

\subsubsection{Soluções Distribuídas}

Uma visão estática e uniforme de distribuição será apresentada. Processos e definições são agrupados em localidades. Informalmente, toda localidade é mapeada para uma máquina soluções químicas.

Uma máquina química reflexiva e distribuída (DRCHAM - Distributed Chemical Abstract Machines) é um conjunto de conjuntos de DRCHAMs. Em vez de usar notação de conjuntos de conjuntos aninhados, uma situação global do DRCHAM é representada como várias soluções $D \vdash \varnothing Q$ da DRCHAM separados por um operador $\|$ associativo e comutativo que representa composição global. Cada solução global é comentada com um rótulo $\varnothing$ diferente para referências no texto. Na próxima seção, estes rótulos serão mais bem detalhados.

Cada solução $D \vdash \varnothing Q$ da DRCHAM pode se desenvolver internamente pelo uso das mesmas regras químicas do join-calculus (Figura 1), ambos por rearranjamento estrutural e por passos de redução. Tecnicamente, a lei de contexto químico é estendida para possibilitar a computação em qualquer solução local. Partes inativas do contexto são mantidas implícitas. Assim, as mesmas regras químicas se aplicam sem alterações. Mas, as condições de substituições em STR-DEF (Figura 3) agora requerem que os nomes globais recentes sejam substituídos por nomes definidos.

As soluções locais podem interagir umas com as outras usando uma nova regra de redução química que opera para pares de soluções:

COMM $\vdash_{\varphi} x<v_{1}, \ldots, v_{n}>\left\|J \triangleright P \vdash_{\psi} \rightarrow \vdash_{\varphi}\right\| J \triangleright P \vdash_{\psi} x<v_{1}, \ldots, v_{n}>$ (quando $x \in \operatorname{vd}[J]$ )

Esta regra modela a comunicação global. Ela declara que uma mensagem emitida em uma dada solução $\varphi$ no nome da porta $x$, que é definido remotamente, possa ser encaminhada para a solução $\psi$ que contenha a definição de $x$. Mais tarde, esta mensagem pode ser usada na $\psi$ para unir uma composição paralela de mensagens que comparam $J$ e então consumida usando a regra $R E D$.

Agora será considerado somente o DRCHAM bem formado, ou seja, onde todo nome é definido em, no máximo, uma solução local. Se a regra $S T R-D E F$ afeta somente soluções locais então esta condição é claramente fechada pelas reduções químicas. Com esta condição, a regra COMM é determinística, estática e de comunicação direta.

O caminho das mensagens é mantido implícito no cálculo. Formalmente, há uma função parcial que mapeia todo nome para sua solução local de definições. Este mapeamento de 
nomes de portas para localidades não será afetado para nenhuma redução. No texto, a notação $\operatorname{loc}(x)$ é usada para representar a localidade de $x$. Agora veremos um exemplo simples de computação distribuída.

\section{Passagem remota de mensagem}

Neste exemplo, que envolve várias soluções locais, considera-se o exemplo de um programa de impressoras da Seção 2.1.3. Agora, assume-se que há três máquinas: uma máquina servidor $s$ que hospeda o programa de impressão, uma impressora laser $p$ que faz os registros para o servidor e uma máquina usuário $u$ onde alguns pedidos de impressão serão requisitados. Como na Seção 2.1.3, temos:

\section{$D=$ leitura $<$ impressora $>\mid$ trabalho $<$ arquivo $>\Delta$ impressora $<$ arquivo $>$}

e considere $P$ representando o código da impressora. Temos a série de passos químicos:

$$
\begin{aligned}
& \vdash_{\mathrm{s}} \| \text { laser }<\beta>P \vdash_{p} \text { leitura }<\text { 1aser }>\| \vdash_{u} \text { trabalho }<1> \\
& \underset{\mathrm{COMM}}{\rightarrow} \mathrm{D} \quad \vdash_{\mathrm{s}} \text { trabalho }<1>\| \text { laser }<f>P \vdash_{p} \text { leitura }<\text { laser }>\| \vdash_{u} \\
& \stackrel{\mathrm{COMM}}{\rightarrow} \mathrm{D} \vdash_{\mathrm{s}} \text { trabalho }<1>\text {, leitura }<\text { laser }>\| \text { laser }<\beta>P \vdash_{p} \| \vdash_{u} \\
& \stackrel{\text { JOIN, RED }}{\rightarrow} \mathrm{D} \quad \vdash_{\mathrm{s}} \text { laser }<1>\| \text { laser }<f>P \vdash_{p} \| \vdash_{u} \\
& \stackrel{\mathrm{COMM}}{\rightarrow} \mathrm{D} \vdash_{\mathrm{s}} \quad \| \text { laser }<\beta>P \vdash_{p} \text { laser }<1>\| \vdash_{u}
\end{aligned}
$$

O primeiro passo encaminha a mensagem trabalho $<1>$ da máquina usuário $u$ para a única máquina que define trabalho, o programa de impressão $s$. Por outro lado, o segundo passo encaminha a mensagem leitura $<$ laser $>$ para o programa de impressão. No próximo passo, ocorre sincronização dentro do programa de impressão entre estas duas mensagens como um passo de redução local. Como resultado, uma nova mensagem no programa de impressão é enviada para a impressora laser onde a mensagem pode ser encaminhada e então recebida.

\subsubsection{Localidades}

As localidades no distributed join-calculus são representadas como definições sintáticas (quando elas migram) ou como soluções químicas locais (quando elas interagem umas com as outras). Estas estruturas são chamadas nomes de localidades.

Os nomes de localidades são valores de primeira classe que identificam estaticamente uma localidade. Assim como nomes de canais, os nomes de localidades podem ser criados localmente, enviados e recebidos em mensagens. Para introduzir novas localidades, a sintaxe de definições do join-calculus é estendida com novo construtor de localidade: 
D $\quad::=$

definições

$\begin{array}{ll}J \triangleright P & \text { regra de reação } \\ D^{\wedge} D^{\prime} & \text { conjunção de definição } \\ \mathbf{T} & \text { definição nula } \\ a\left[D^{*}: P^{\prime}\right] & \text { (sub) localidade }\end{array}$

Figura 4 - Sintaxe de definições do distributed join-calculus

onde $\boldsymbol{D}^{*}$ liga todas as definições da localidade que são visíveis fora da localidade, $\boldsymbol{P} \boldsymbol{*}$ é o código de execução da localidade e $a$ é o nome definido que identifica unicamente a localidade. Informalmente, a definição $a\left[D^{\prime \prime}: P^{\prime}\right]$ corresponde à solução local $\left\{D^{*}\right\} \vdash_{\varphi} a$ $\left\{\boldsymbol{P}^{*}\right\}$.

A relação de sublocalidade é definida como: $\vdash_{\varphi}$ é uma sublocalidade de $\vdash_{\psi}$, onde $\psi$ é um prefixo de $\varphi$. Os DRCHAMs são conjunto de conjuntos de soluções rotuladas cujos rótulos $\varphi$ são todos distintos, prefixados e identificados unicamente por seu nome de localidade mais à direita, se existir. Estas condições asseguram que as soluções ordenadas pela relação de sublocalidade formem uma árvore.

Esta associação é representada pela nova regra estrutural STR-LOC:

STR-LOC $\quad a[D: P] \vdash_{\varphi} \quad \rightleftharpoons \quad \vdash_{\varphi} \|\{D\} \vdash_{\varphi a}\{P\} \quad(a$ resfriado)

A definição $D$ pode conter definições de sublocalidades resfriadas e a condição garante que $D$ captura, sintaticamente, toda a subárvore de sublocalidades na localidade $\boldsymbol{a}$.

Na direção do aquecimento, a semântica deste novo construtor de definição é criar uma sublocalidade da localidade atual que inicialmente contém uma definição simples $\boldsymbol{D}$ e um processo simples em execução $\boldsymbol{P}$.

Na direção do resfriamento, STR-LOC tem um efeito congelante sobre a localidade $\boldsymbol{a}$ e todas as suas sublocalidades.

\subsubsection{Migração}

A migração pode ser expressa como uma relocalização dos ramos na árvore de localidades. Para introduzir migrações, a sintaxe de processos do join-calculus é estendida com a nova primitiva de migração: 


\begin{tabular}{|c|c|c|}
\hline \multirow[t]{2}{*}{$\boldsymbol{P} \quad::=$} & \multicolumn{2}{|c|}{ processos } \\
\hline & $\begin{array}{l}x<v_{1}, \ldots, v_{n}> \\
\operatorname{def} D \text { in } P\end{array}$ & $\begin{array}{l}\text { mensagem } \\
\text { definição local }\end{array}$ \\
\hline & $P \mid P^{\prime}$ & composição paralela \\
\hline | & $\mathbf{0}$ & processo nulo \\
\hline | & $g o<b, k>$ & migração \\
\hline
\end{tabular}

Figura 5 - Sintaxe de processos do distributed join-calculus

e com uma nova regra de redução que opera sobre duas soluções químicas:

GO $\quad a[D: P \mid g o<b, k>] \vdash_{\varphi}\left\|\vdash_{\psi b} \quad \rightarrow \quad \vdash_{\varphi}\right\| a[D: P \mid k<] \vdash_{\psi} b$

Informalmente, a localidade $\boldsymbol{a}$ se locomove de sua posição inicial, $\varphi \boldsymbol{a}$, na árvore para uma nova posição, $\psi \boldsymbol{b} \boldsymbol{a}$, logo abaixo do nome de localidade $\boldsymbol{b}$ passado como argumento. A solução $\vdash_{\psi} \boldsymbol{b}$ é identificada pelo nome relativo $\boldsymbol{b}$. Uma vez que $\boldsymbol{a}$ chega, a continuação $\boldsymbol{k}<\boldsymbol{}$ é liberada e engatilha a computação local. No caso da regra STR-LOC ter sido usada anteriormente para resfriar a localidade $\boldsymbol{a}$ dentro de uma definição, sua condição ( $\boldsymbol{a}$ resfriado) força todas as sublocalidades de $a$ a migrarem ao mesmo tempo, como um todo. Isto é o suficiente para garantir que uma localidade não migre para uma de suas sublocalidades.

Na prática, o controle seqüencial é tão comum que algumas sintaxes tornam a continuação implícita. Assim, podemos escrever go(a) em vez de $\boldsymbol{g o}<\boldsymbol{a}, \boldsymbol{k}>$.

A sintaxe, o escopo e a semântica operacional completa do distributed join-calculus estão no Apêndice A.

\subsubsection{Exemplo}

O exemplo a seguir refere-se à arquitetura cliente-agente-servidor.

O oposto de trazer código é enviar a computação para um servidor remoto. O cliente define o pedido que vai até o servidor, o pedido é executado no servidor e o resultado é retornado ao cliente. Isto pode ser expresso pelo lado do cliente pelo seguinte processo:

$$
\operatorname{def} \mathrm{f}(x, s) \triangleright\{\text { go }(s) \text {; reply ... to } \mathrm{f}\} \text { in ... } \mathrm{f}(3, \text { servidor }) \ldots
$$

No código acima, como f é um nome síncrono, a computação remota retorna uma tripla de valores. No entanto, o resultado deve conter dados arbitrários alocados durante a computação ou mesmo dados ativos (processos com estado interno). Na arquitetura clienteagente-servidor genérico, o servidor não pode retornar um ponteiro para o dado, devendo 
também mover o dado e o retorno do código para a localidade do cliente. Para ilustrar isso, considere um agente que aloca e usa uma célula de referência, new_cell, que é um servidor de applet que cria uma nova célula e retorna seus dois conjuntos de métodos para atualizar e acessar.

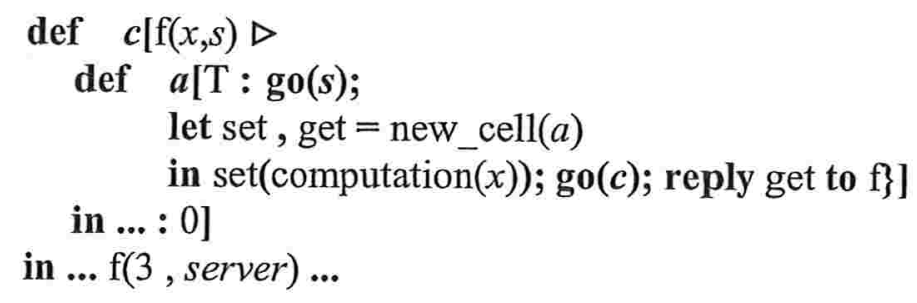

A célula de referência é alocada dentro do agente da localidade $\boldsymbol{a}$ durante sua permanência no servidor, podendo ser modificado como parte da computação do agente. Quando esta computação terminar, o agente retorna a estrutura de dado para o cliente usando a chamada da primitiva go(c).

\subsection{Linguagem do Distributed Join-Calculus}

Nas seções que se seguem, apresentamos como os agentes móveis são representados na linguagem do distributed join-calculus.

\subsubsection{Termos e Definições}

Definimos abaixo alguns termos e definições que serão utilizados ao longo deste texto.

Localidade - introduz um suporte para a programação distribuída para o distributed joincalculus.

Sublocalidade - uma localidade definida dentro de outra localidade.

Mobilidade - capacidade das localidades migrarem de um domínio para outro.

Processos - funções usadas num contexto onde algumas ações são desenvolvidas sem o retorno de resultados.

Expressões - funções usadas num contexto onde o retorno de um resultado é necessário.

Agentes - um agente contém um grupo de processos e definições sob o nome de uma localidade. 
Agentes Móveis - agentes com a capacidade de mobilidade.

Canais ou nomes de porta - principal valor da linguagem do distributed join-calculus. Eles podem ser vistos como canais que carregam argumentos.

Biblioteca padrão do Distributed Join-Calculus - é a biblioteca que contém funções prédefinidas.

Servidor de nomes - para desenvolver uma computação distribuída, se faz necessário a troca de alguns nomes. Isso é feito usando uma biblioteca construída chamada servidor de nomes.

Cliente - quando as execuções ocorrem em outro servidor de nomes diferente do servidor de nomes onde estão definidas.

Servidor - quando as execuções acontecem localmente no mesmo servidor de nomes onde está definido.

\subsubsection{Os Agentes}

No distributed join-calculus os agentes são representados por processos e expressões. Os processos são executados de forma assíncrona e não produzem resultados, enquanto que expressões são calculadas de forma síncrona e retornam valores. Assim, as expressões são usadas quando há necessidade de um resultado e os processos quando as ações são desenvolvidas sem a necessidade de haver um retorno.

Na biblioteca padrão do distributed join-calculus, temos definidos canais: nomes de porta dos agentes que são utilizados para identificação e comunicação entre agentes [FM99]. Usaremos no nosso trabalho os canais: echo (canal assíncrono que não retorna valor) e print (canal síncrono que retorna um valor). Além desses canais, podemos definir novos canais de acordo com a necessidade. Estes canais são usados para a comunicação com o mundo externo (terminal) e entre agentes.

Assim, considerando A uma constante, temos que print (A), que é uma expressão, e echo (A), que é um processo, são agentes no distributed join-calculus.

Novos canais podem ser definidos, como por exemplo um novo canal quadrado que retorna o cálculo do quadrado de um argumento e um canal cubo que retorna, da variável resultado, o cubo de um argumento quando invocado com cubo (quadrado). No distributed join-calculus, os novos canais a serem definidos são introduzidos pela palavra chave "let" e o retorno do resultado de uma função é definido por "reply". 


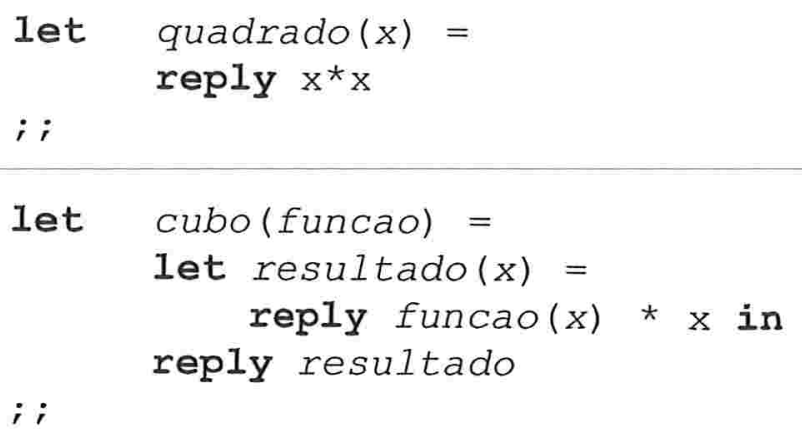

No distributed join-calculus existe uma biblioteca, servidor de nomes que, entre outras, consiste de duas funções: uma para registrar, ns.register e outra para procurar, ns.lookup, valores arbitrários numa tabela global indexada por uma cadeia de caracteres. Por exemplo, o seguinte programa contém dois processos em execução paralela, um deles define localmente um recurso (uma função $f$ que calcula o quadrado de dois inteiros) e o registra sob a cadeia de caracteres "quadrado". O outro processo não está dentro do escopo de f, ele procura por um valor registrado sob a mesma cadeia de caracteres "quadrado", o define localmente em quad e o usa para imprimir algum valor. No distributed join-calculus, os processos são introduzidos pela palavra-chave "spawn":

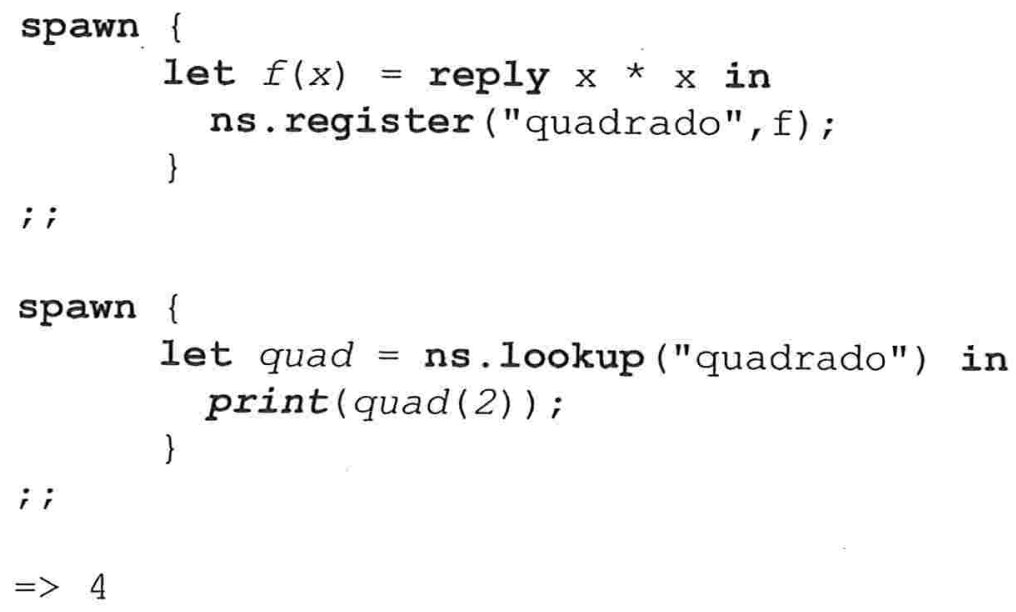

Para não precisar modificar o programa em execução no servidor toda vez que precisamos executar um tipo diferente de processo ou expressão que envolva várias chamadas de uma função, o distributed join-calculus introduz uma unidade de localidade chamada "Iocation".

Uma localidade contém um grupo de definições e processos em execução num mesmo lugar e para toda localidade é dado um nome. Este nome de localidade pode ser informado a outros processos e/ou agentes por meio de mensagens, registrado num servidor de nome, assim como os canais. Eles podem também ser usados em primitivas que dinamicamente mudam a organização das localidades. No distributed join-calculus, a definição de uma 
localidade é iniciada com a palavra-chave "Ioc" e terminada com a palavra-chave "end" e os processos ou expressões podem ser iniciados dentro de uma localidade pela palavra chave "init". Podemos, por exemplo, criar uma localidade chamada esta_localidade:

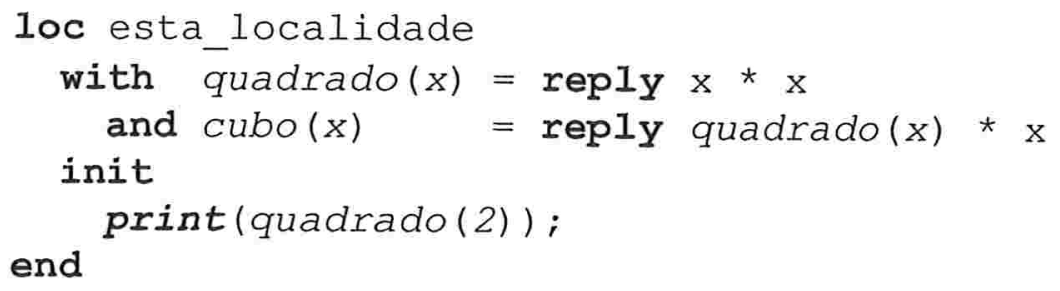

Esta declaração limita o nome de localidade esta_localidade e dois canais quadrado e cubo cujo escopo se estende dentro da localidade e na declaração seguinte, do print (cubo (2)). Ele também inicia um processo, print (quadrado (2)) $i$, na sua parte init. Este processo é executado dentro da localidade, em paralelo com o restante do programa, no nosso caso, print (cubo (2)). Como resultado, pode-se obter 84 ou 48, onde 8 é o resultado de print (cubo(2)) e 4 de print (quadrado (2)).

Computações distribuídas são organizadas como árvores de localidades aninhadas e toda definição e todo processo estão permanentemente anexados na localidade onde eles aparecem no programa fonte. Um processo pode criar novas sublocalidades com um conteúdo inicial que, uma vez criadas, impedem a introdução de novos conteúdos na localidade pelo seu exterior. Na biblioteca padrão do distributed join-calculus, o canal print_string está definido para a impressão de uma determinada cadeia de caracteres na tela. $\bar{A}$ seguir, apresentamos um exemplo de uma localidade com sublocalidades:

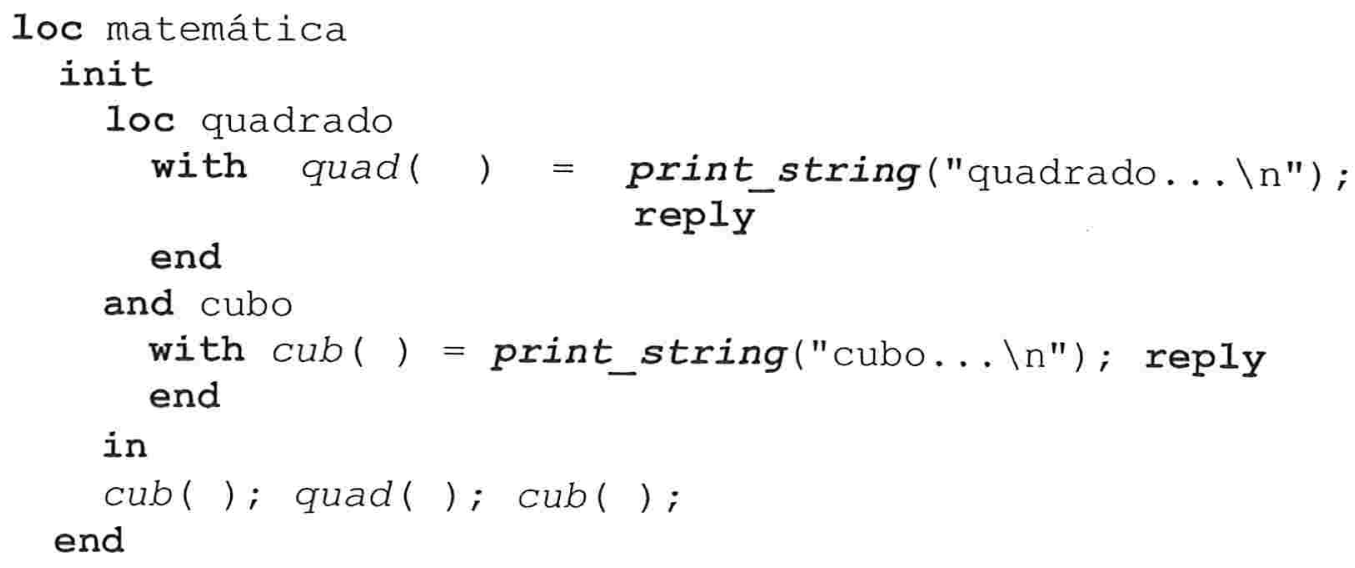


$\Rightarrow$ cubo...
$\Rightarrow>$ quadrado...

$\Rightarrow$ cubo...

Este programa define três localidades tais que as localidades chamadas quadrado e cubo são sublocalidades de matemática.

\subsubsection{Comunicação}

A comunicação dos processos ocorre por envio de mensagens através de canais. Os canais podem conter zero ou mais valores e eles próprios são valores, ou seja, objetos de primeira ordem.

Podemos exemplificar um processo simples de envio de uma mensagem por um canal usando um canal echo existente na biblioteca padrão da linguagem do distributed joincalculus. Enviando um argumento "i" por este canal, obtemos como resposta a impressão de "i" na tela:

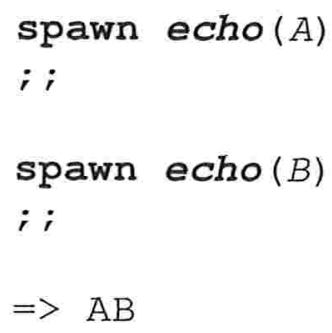

Podemos exemplificar uma expressão simples de envio de alguns valores através de um canal síncrono (print) existente na biblioteca padrão do distributed join-calculus. Enviando uma mensagem que consiste em um inteiro "i", o canal imprime o "i" na tela e retorna um resultado vazio para quem o enviou. No distributed join-calculus, as expressões são introduzidas pela palavra chave "do".

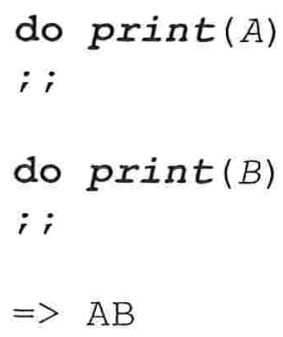

Os canais podem ser enviados como mensagens através de outros canais e retornados como resultados. É assim que ocorre a comunicação entre agentes. Para exemplificar isso, 
consideramos os canais cubo e quadrado dos agentes cubo(funçao) e quadrado(x) definidos na seção anterior e enviamos o canal quadrado como mensagem pelo canal cubo. O agente cubo (quadrado) é ativado quando o agente print ( $f(2))$ é executado. Neste momento, os argumentos 2 e quadrado são enviados para o agente cubo (função) que os utilizará para finalizar o cálculo da função cubo (quadrado) que terá como resultado 8.

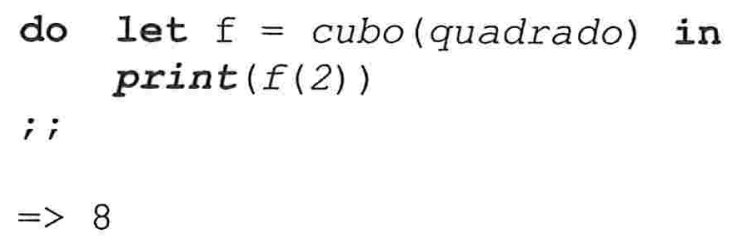

\subsubsection{Mobilidade de Agentes}

O distributed join-calculus introduz as localidades as quais contêm um grupo de processos e definições que podem se deslocar de um lugar para outro. Os agentes móveis, representados por localidades, podem conter subagentes que são representados por localidades aninhadas. Quando uma localidade se desloca, todas as suas sublocalidades se movem com ela, por isso, as localidades são organizadas em uma árvore, como ilustrado na Figura 6.

No distributed join-calculus, a comunicação ocorre por troca de mensagens e a mobilidade ocorre quando as localidades se deslocam de um lugar para outro.
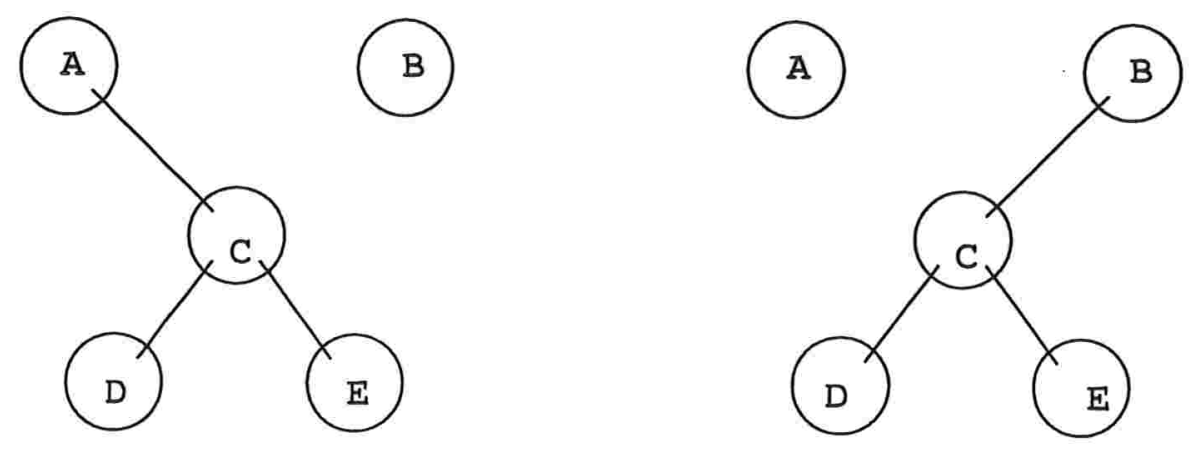

Figura 6 - Exemplo de Mobilidade de Localidade

A, B, C, D e E são localidades. As localidades D e E são sublocalidades de C e a localidade $C$ é uma sublocalidade de $A$. A localidade $C$ é um agente móvel que se desloca da localidade $A$ para a localidade $B$, com todas as suas sublocalidades. 
A execução dos programas no distributed join-calculus pode ser distribuída em um conjunto de máquinas heterogêneas que podem conter localidades, processos e definições (que são os servidores). Todo processo ou expressão está sendo executado em determinada máquina. No entanto, em determinado momento, eles podem migrar de uma máquina para outra, sob controle da linguagem.

Desde que as (sub)localidades e definições estejam hierarquicamente anexadas às suas localidades, as localidades podem se deslocar de um lugar para outro. Tais migrações são engatilhadas por um processo dentro desta localidade. Como resultado de uma migração, a localidade em movimento se torna uma sublocalidade da localidade destino.

Para exemplificar, vamos criar, no lado do servidor, uma nova localidade vazia "aqui" e a registramos no servidor de nomes. Este nome será usado como o endereço destino para um agente móvel:

$$
\begin{aligned}
& \text { loc aqui end } \\
& \text { do ns.register("aqui", aqui) }
\end{aligned}
$$

No lado do cliente, vamos criar uma localidade "movel" que define toda a computação que deve ser executada no lado do servidor. O processo dentro de movel pega o nome aqui, e então migra sua localidade para a localidade "aqui". Uma vez que isso acontece, ele desenvolve a computação:

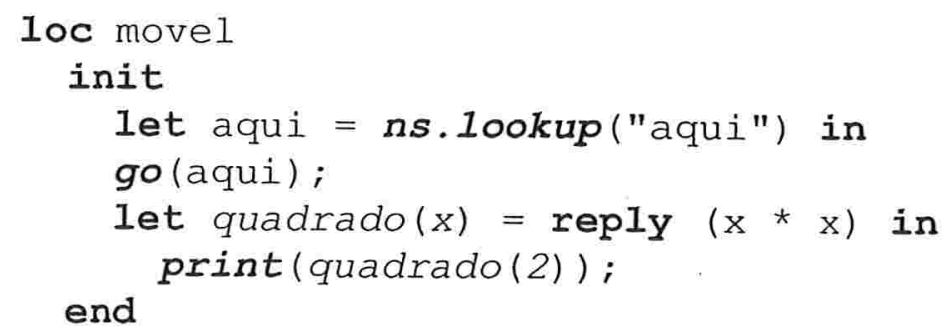

go é uma primitiva do distributed join-calculus e, na nossa especificação, a primitiva go(aqui) migra toda a localidade "movel" para o servidor aqui, como uma sublocalidade de "aqui" e então retorna. Depois disso, toda computação (chamada de quadrado) é local no servidor aqui. Há somente três mensagens trocadas entre os dois servidores: um para o pedido lookup(aqui), um para a resposta e outro para a migração.

A sintaxe completa da linguagem do distributed join-calculus está no Apêndice B. 


\subsection{Conclusão}

Neste capítulo sobre formalismos, a máquina química abstrata (CHAM), que descreve semânticas operacionais de sistemas concorrentes, foi apresentada para entender $o$ formalismo do join-calculus que usa uma analogia com a química.

Adicionando reflexão à CHAM, temos a máquina química abstrata reflexiva (RCHAM) que representa o join-calculus. Posteriormente, sua sintaxe de processos, definições e padrões de união, seu escopo e substituições de processos, definições e padrões de união e sua semântica operacional de soluções reflexivas e regras químicas para o RCHAM bem como suas reduções foram apresentados.

Adicionando distribuição à RCHAM, temos a máquina química reflexiva e distribuída (DRCHAM) que representa o distributed join-calculus. Posteriormente, uma nova regra estrutural de localidade é adicionada à sintaxe de definição e uma nova regra de redução sobre migração é adicionada à sintaxe de processos, completando assim a sintaxe e a semântica operacional do distributed join-calculus.

Por fim, a linguagem do distributed join-calculus é apresentada, mostrando como é o comportamento dos agentes, que podem ser móveis, e como é feita a comunicação e a mobilidade entre agentes. 


\section{Capítulo 3 - Especificação do RDP (Result Delivery Protocol)}

O Result Delivery Protocol [ESO98] é um protocolo proposto para a entrega confiável de respostas às requisições de aplicações clientes localizadas em estações móveis. Este protocolo é apropriado para serviços de rede baseados num estilo de interação pedidoresposta e com processamento de pedido demorado.

\subsection{Termos e Definições}

Definimos abaixo alguns termos que serão utilizados ao longo deste texto.

Rede Fixa - porção da rede formada por máquinas conectadas fisicamente.

Máquina Fixa - máquina conectada fisicamente à rede, com localização geográfica e endereço de rede fixo.

Unidade Móvel (UM) - máquina da rede cuja localização e ponto de conexão (endereço) pode variar; é conectada à rede por meio de um canal sem fio.

Estação Base (EB) - máquina conectada fisicamente à rede e responsável por manter conectados à rede fixa todas as UMs, dentro de uma determinada região (célula). Chamaremos a EB responsável pela célula onde se encontra uma UM de EB responsável pela UM.

Célula - área geográfica sob a responsabilidade de uma EB.

Handoff - troca de dados entre duas EBs que transfere a responsabilidade sobre uma UM quando esta se desloca de uma célula para outra.

Mensagens - as mensagens greet, dereg, deregAck, update, request, forwardresult e forwresAck serão mantidas em inglês, pois são assim utilizadas no protocolo original e padronizadas para outros protocolos de comunicação.

\subsection{Modelo do Sistema}

O Result Delivery Protocol [ESO98] é apropriado para serviços de rede baseados no estilo de interação pedido e resposta que exigem algum tempo no processamento do pedido. 
O protocolo RDP é baseado em um modelo indireto [BBIM93] em que as estações de apoio à mobilidade atuam como representantes para todas as unidades móveis dentro de sua célula, mantém parte do estado da UM e faz a tradução entre a comunicação com e sem fio.

O protocolo handoff é ativado quando a UM migra de uma célula para outra, ou seja, é a parte do protocolo RDP que trata da mobilidade e, portanto, a parte que estamos interessados em especificar e analisar.

No modelo do sistema em que o protocolo RDP atua existem dois tipos de máquinas: as unidades estáticas (EB - Estações Base de suporte à mobilidade) e as unidades móveis (UM). As unidades estáticas estão conectadas entre si por uma rede estática e confiável e assume-se que as EBs nunca falham. Cada EB pode se comunicar somente com as unidades móveis dentro de sua célula. A EB guarda numa estrutura de dados, UM_local, as informações sobre as UMs dentro de sua célula.

As unidades móveis são computadores portáteis (desconectados da rede) que têm um sistema de identificação único e que podem estar em um dos dois estados: ativo ou inativo. No estado inativo as unidades móveis não conseguem enviar e nem receber mensagens. As unidades móveis são capazes de migrar de uma célula para outra e quando entram em uma nova célula, a UM envia uma mensagem para a EB da célula em que a UM está entrando, com a identificação da EB da célula onde a UM estava. Com esta informação, a EB, da nova célula, é capaz de iniciar o protocolo handoff com a EB da célula antiga.

O RDP é baseado na noção de proxy. Um proxy é criado na EB para uma UM que quer interagir com servidores dentro de uma rede sem fio. Os principais objetivos do proxy são prover uma localização fixa para a qual as respostas do servidor devem ser enviadas, controlar e armazenar os pedidos pendentes e entregá-los à UM. O proxy é um objeto que existe até que todos os pedidos enviados sejam recebidos pela UM correspondente, depois disso ele é destruído. Durante o protocolo handoff, a nova localização da UM é atualizada no proxy. A partir de então, a mesma UM pode causar a criação de um novo proxy na mesma ou em outra EB, dependendo se ela migrou ou não. Entretanto, a UM tem, no máximo, um proxy.

\subsection{Hipóteses do RDP}

Assim como definido no artigo original [ESO98], o RDP possui as seguintes hipóteses:

1. A comunicação entre as EBs é confiável e a entrega da mensagem não tem uma ordem específica.

2. Todos as EBs são confiáveis e nunca falham.

3. Em qualquer momento, cada UM ativa está associada com exatamente uma EB. 
4. Quando a UM está ativa ela deve enviar uma confirmação para todas as mensagens recebidas da EB responsável pela célula corrente, e enquanto estiver inativa, não pode responder a nenhuma mensagem. Quando uma UM migra entre células, ela pode ser considerada inativa tanto para a $\mathrm{EB}$ que está deixando quanto para a $\mathrm{EB}$ em que está entrando, o período em que o protocolo handoff está ativado.

5. A UM é capaz de saber se uma mensagem da EB, que é responsável pela UM, é nova ou uma retransmissão.

6. A UM deixa o sistema somente quando todas as mensagens recebidas pela EB responsável pela célula corrente forem recebidas.

\subsection{Visão Geral do RDP}

O RDP é baseado na noção de proxy. Para saber para qual EB ele deve encaminhar o resultado de um pedido, o proxy guarda uma variável chamada LocCorr que é atualizada com o endereço da EB responsável pela UM, sempre que a UM migrar. O proxy também guarda uma ListaPedidos contendo identificadores de todos os pedidos pendentes emitidos pela UM.

Para atualizar a LocCorr sempre que a UM migra, cada UM tem uma referência de proxy (pRef) associada à ela, que é gerada pela EB responsável pela UM. A pRef contém uma referência (endereço da EB e um proxyID) para o proxy atual associado com a UM. Entretanto, quando a UM não tem um proxy (ou seja, quando a UM não tem pedidos pendentes), a pRef guarda um endereço nulo. Uma pRef também contém um indicador, RKpR - Ready to Kill pRef, que indica se o proxy encaminhou o resultado de seu último pedido pendente.

Toda vez que uma EB recebe um novo pedido de uma de suas UMs locais, ela checa se a correspondente $\mathbf{p R e f}$ tem o endereço nulo. Neste caso, um novo proxy é criado localmente em nome da UM e a EB atualiza a pRef com seu próprio endereço e o proxyID do proxy. Caso contrário, a EB encaminha o pedido para o proxy cujo endereço é mencionado na pRef.

Quando a UM migra de uma EBa para uma EBn, a pRef é manipulada pelo protocolo handoff e assim que completado, a nova localização da UM no proxy será atualizada. Isto acontece porque a EBn enviou a mensagem update LocCorr para o proxy. Quando a mensagem update chega ao proxy, o proxy atualiza a variável LocCorr e reenvia, para a nova localidade todos os pedidos pendentes cujo resultado foi enviado para a UM e a confirmação de recebimento do pedido pela UM não tenha chegado ao proxy. 
Quando o resultado de qualquer pedido pendente chegar ao proxy, ele é encaminhado pela EB responsável pela UM para o endereço mencionado na LocCorr e então entregue à UM através de uma comunicação sem fio.

Em condições normais, ou seja, quando a UM está ativa e está em sua célula por um período de tempo suficientemente longo, a chegada do resultado do pedido é reconhecido pela UM através de uma mensagem forwresAck, que é encaminhada pela EB responsável pela UM para a EB onde está o proxy. Uma vez que a mensagem tenha chegado, o proxy marca que o pedido foi recebido e o remove da lista de pedidos.

Se a EB responsável pela UM não for capaz de detectá-la porque a UM está migrando, a EB não reenvia o resultado do pedido, pois é o proxy que reenviará o resultado assim que ele receber a próxima atualização do endereço da UM.

Para cada EB, é prioridade o encaminhamento das mensagens de confirmação da UM para a EB responsável do que iniciar uma nova transação do handoff. Isto evita que resultados já recebidos pela UM sejam reenviados para a nova célula. Além disso, assim que a EB responsável recebe de outra $\mathrm{EB}$ uma mensagem de que a UM está migrando, a EB responsável passa a ignorar mensagens futuras desta UM.

Pelo ponto de vista do proxy, até que ele não receba uma mensagem de confirmação de recebimento do pedido pela UM, ele continua reenviando o resultado para toda EBn que lhe enviar a mensagem de atualização de endereço da UM. Assim, existe a garantia de que todo resultado de um pedido chegará à UM, pois a UM não deixa o sistema com um pedido pendente. $\mathrm{O}$ único preço a pagar por esta confiabilidade é que, eventualmente, um resultado pode ser enviado mais que uma vez para uma UM.

\subsubsection{Exemplo de funcionamento do protocolo RDP}

Nesta seção apresentamos um exemplo para ilustrar como o RDP trabalha.

A Figura 7 mostra uma estrutura onde uma unidade móvel UM emite um simples pedido para um servidor através da EBp, então migra para a EBa e mais tarde para a EBn. Assumindo que este é o primeiro pedido da UM, seu pRef não contém nenhum endereço. A partir daí, um novo proxy é criado na EBp com sua variável LocCorr atualizada para a EBp e também o endereço na pRef atualizado para a EBp.

Toda vez que a UM migra e depois que o protocolo handoff está completo, a nova EB responsável pela UM envia uma mensagem, update LocCorr, para o proxy que atualiza a variável LocCorr.

Quando a resposta do pedido chega no proxy, a EBp entrega o resultado para a EB mencionado na LocCorr, mesmo se durante o processo, a UM tenha migrado, como 
sugere o ponto de interrogação na Figura 7. Assim, que o resultado é entregue, del_pRef é atualizado para verdadeiro, porque a lista de pedidos do proxy tem somente um pedido. Como a UM migrou para outra célula, o proxy não recebe da $\mathrm{EBa}$ a confirmação de recebimento do pedido pela UM, por isso, o proxy reenvia o resultado do pedido toda vez que a variável LocCorr for atualizada, até que finalmente receba a confirmação de recebimento do pedido pela UM.

Quando a EBn recebe o resultado do pedido com del_pRef = verdadeiro, ela atualiza RKpR para verdadeiro no pRef da UM, entrega o resultado do pedido para a UM e espera pela confirmação de recebimento pela UM. Assim que receber essa mensagem e se RKpR ainda for verdadeiro, a EBn apaga o endereço da pRef da UM e envia para a EBp uma mensagem de confirmação de recebimento do pedido pela UM com del_proxy = verdadeiro. Finalmente, quando esta mensagem chega à EBp, o proxy é destruído.

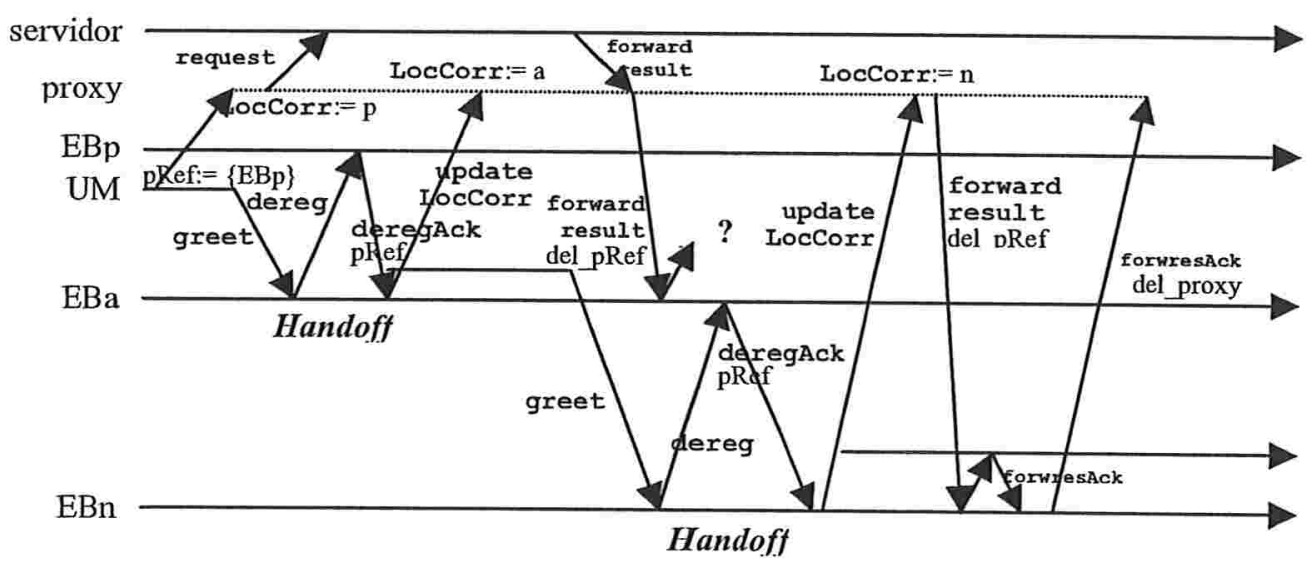

Figura 7 - Exemplo de funcionamento do protocolo RDP

\subsection{Protocolo Handoff}

O handoff é um protocolo de comunicação entre EBs que é executado quando uma UM migra. No caso do RDP, seu principal objetivo é o de atualizar a informação sobre a localização da UM.

O protocolo handoff é executado entre duas EBs, a EBo (EB de origem) e a EBn (EB de destino) que, respectivamente, correspondem à EB que define a célula que a UM está deixando e a EB que define a célula que a UM está entrando.

Quando a UM entra em uma nova célula, ela registra-se, com a correspondente EBn, enviando uma mensagem greet, contendo a identificação da última EBo responsável por 
ela. Anunciada para a nova EBn, a UM passa a responder somente às mensagens da EBn e de nenhuma outra EB.

Quando a EBn recebe a mensagem greet, ela envia uma mensagem dereg para a antiga EBo, requisitando a referência de proxy (pRef) da UM e o desregistro da UM naquela EB. No recebimento da mensagem dereg, a EBo responde para a EBn com uma mensagem deregAck, contendo a pRef da UM, e então apaga a UM da sua lista de UMs locais.

De posse da lista de referência de proxy da UM, a EBn se torna responsável pela UM, colocando-a na sua lista de UMs locais e atualiza a nova localidade da UM com seu proxy, enviando uma mensagem update LocCorr para o proxy, cujo endereço está na pRef.

A UM não receberá a resposta do servidor se, durante o envio de forwardresult, ele migrar de célula. Neste caso, o envio de forwardresult é reiniciado quando for recebida uma nova mensagem update LocCorr. Isto garante que, em algum instante futuro, a UM irá receber o resultado.

\subsection{Mensagens}

A seguir, apresentamos todas as mensagens que fazem parte do sistema, separadas em mensagens do protocolo handoff e mensagens do protocolo RDP quando não há execução do protocolo handoff.

\subsubsection{Protocolo Handoff}

- greet - mensagem enviada da unidade móvel para a nova estação base

- dereg - mensagem enviada da nova estação base para a estação base antiga

- deregAck - mensagem enviada da estação base antiga para a nova estação base

- update (atualização 1) - mensagem enviada da nova estação base para a estação base do proxy

- update (atualização 2) - mensagem enviada da estação base onde o proxy está para o proxy da unidade móvel

\subsubsection{Protocolo RDP sem Handoff}

- forwardresult (resultado do pedido 1) - mensagem enviada do servidor para o proxy da unidade móvel

- forwardresult (resultado do pedido 2) - mensagem enviada do proxy da unidade móvel para a estação base onde o proxy está 
- forwardresult (resultado do pedido 3) - mensagem enviada da estação base onde o proxy está para a estação base onde a unidade móvel está

- forwardresult (resultado do pedido 4) - mensagem enviada da estação basè onde a unidade móvel está para a unidade móvel

- forwresAck (reconhecimento do resultado do pedido 1) - mensagem enviada da unidade móvel para a estação base onde a unidade móvel está

- forwresAck (reconhecimento do resultado do pedido 2) - mensagem enviada da estação base onde a unidade móvel está para a estação base onde o proxy está

- forwresAck (reconhecimento do resultado do pedido 3) - mensagem enviada da estação base onde o proxy está para o proxy

- request (novo pedido 1) - mensagem enviada da unidade móvel para a estação base onde a unidade móvel está

- request (novo pedido 2) - mensagem enviada da estação base onde a unidade móvel está para o novo proxy

- request (novo pedido 2) - mensagem enviada da estação base onde a unidade móvel está para a estação base onde o proxy está

- request (novo pedido 3) - mensagem enviada da estação base onde o proxy está para o proxy

- request (novo pedido 4) - mensagem enviada do proxy para o servidor

\subsection{Especificação do RDP no Distributed Join-Calculus}

Nesta seção, apresentamos a especificação do protocolo Handoff e de partes relevantes do protocolo RDP no distributed join-calculus. Para um melhor entendimento, enumeramos cada linha da especificação e fazemos breve comentários de cada parte da especificação. Observe que algumas partes do protocolo não estão especificadas, mas explicadas, uma vez que não são relevantes para o estudo proposto por este trabalho.

\subsubsection{Especificação do protocolo handoff}

Para um melhor entendimento do funcionamento do protocolo RDP, apresentamos graficamente o funcionamento do protocolo handoff, com as mensagens envolvidas no sistema e a seqüência de procedimentos. Posteriormente, a especificação do protocolo handoff no distributed join-calculus será apresentada.

\subsubsection{Diagrama do protocolo handoff}

Cada retângulo do diagrama representa uma localidade e cada seta representa a comunicação de mensagens entre localidades. A localidade da UM que estava anexada na localidade EB antiga, agora está anexada (representada por uma linha que liga EB nova 
com UM) na localidade da EB nova e a localidade do proxy está anexada (representada por uma linha que liga EB proxy com proxy) na localidade da EB proxy para representar que a localidade da UM está sob o domínio da EB UM e a localidade do proxy está sob responsabilidade da localidade $\mathbf{E B}$ proxy, respectivamente.

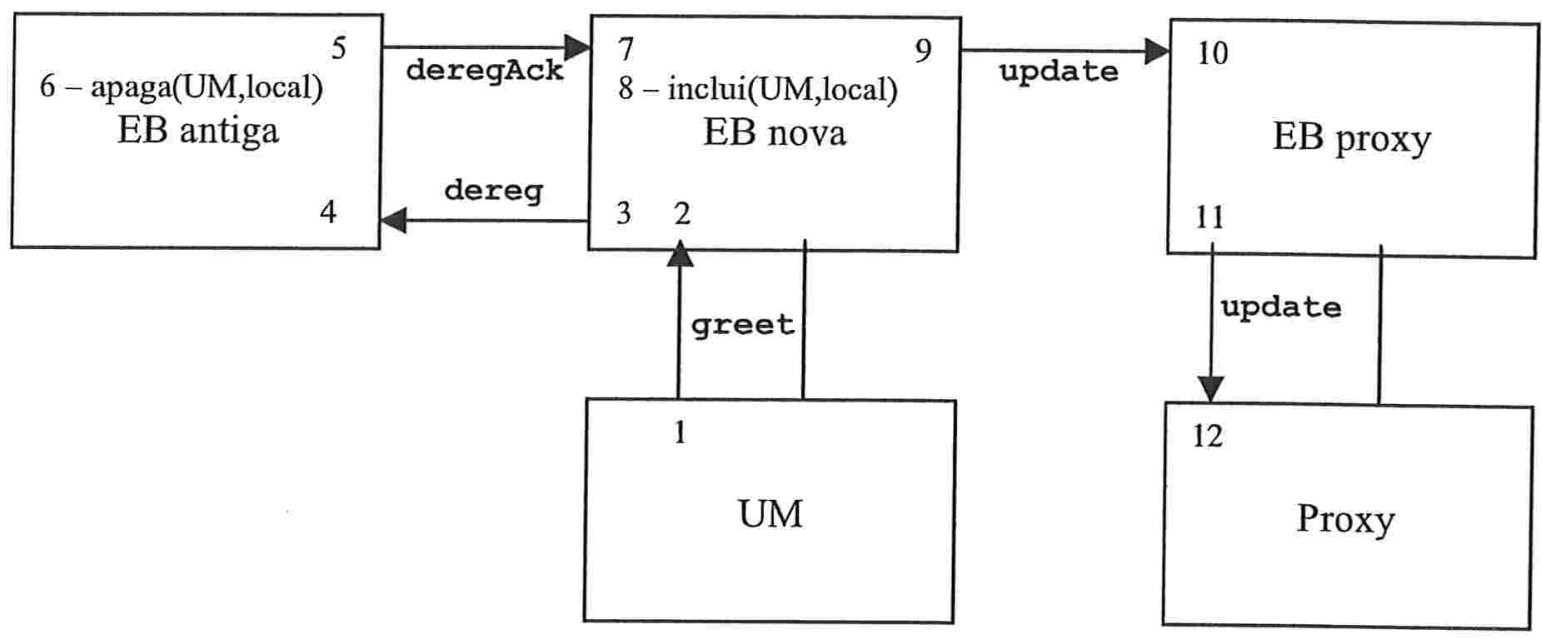

\section{Comunicações:}

$1 \rightarrow 2$-EB_nova_inicial(greet,UM,oldEB)

$3 \rightarrow 4-$ EB_antiga(dereg,UM)

$5 \rightarrow 7$ - EB_nova_retorno(deregAck,UM,pRef)

$9 \rightarrow 10-$ EB_atualiza(update,pRef,UM,EB_proxy)

$11 \rightarrow 12$ - Proxy_atualiza(update,pRef,UM)

\section{Ações:}

1 - Quando a UM entra em uma nova célula, ela se registra com a EB, enviando para a EB uma mensagem greet contendo a identificação da sua EB antiga (oldEB).

2 - EB nova recebe a mensagem greet da EB antiga com o nome da EB antiga.

3 - EB nova envia mensagem dereg para a EB antiga pedindo para deregistrar a UM da sua lista local de UMs e para enviar a pRef da UM.

4 - EB antiga recebe a mensagem dereg da EB nova com os pedidos.

5 - EB antiga envia mensagem deregAck para a nova EB com a pRef da UM.

6 - EB antiga apaga a UM da sua lista local de UMs (UM local).

7 - EB nova recebe a mensagem deregAck com a pRef da UM.

8 - EB nova inclui a UM na sua lista local de UMs.

9 - EB nova envia mensagem update com a LocCorr para o Proxy.

10 - EB onde o Proxy está recebe a mensagem update com a LocCorr.

11 - EB onde o Proxy está envia a mensagem update com a LocCorr para o Proxy.

12 - Proxy recebe a mensagem update com a LocCorr. 


\subsubsection{Especificação do protocolo handoff}

As funções a seguir são funções de implementação para o protocolo handoff que não serão especificadas, mas utilizadas nas demais definições da especificação. Podemos dizer que estas definições estão na solução do sistema.

[001] Apaga_LocalUM(UM,EB)

[002] <Apaga a UM da lista local de unidades móveis da EB>

[003] Inclui_LocalUM(UM,EB)

[004] <Inclui a UM na lista local de unidades móveis da EB>

[005] Verifica $p \operatorname{Ref}(U M, p R e f)$

[006] <Verifica qual é a pRef da UM e retorna a pRef>

[007] Atualiza_LocCorr(Proxy,LocCorr)

[008] <Atualiza, no proxy, a LocCorr com a atual localização da unidade móvel>

[009] Reenvia_pedidos(Proxy,UM)

[010] <Reenvia os pedidos pendentes da unidade móvel>

A seguir estão as localidades para a especificação do protocolo handoff. Estas localidades são soluções separadas por || (isto é, UM || EB || Proxy) e que estão dentro da solução do sistema:

[011] def Proxy[Proxy_atualiza(mens_update,pRef_EB,UM)|hand_verdadeiro() $\triangleright$

[016] Atualiza_LocCorr("Proxy",pRef_EB); Reenvia_pedidos("Proxy",UM)

[017] in hand_falso()

A localidade Proxy está definida como uma conjunção de definições e um processo inerte, ativando um processo condicional hand_falso(). Nas definições, temos uma reação [011] que liga Proxy_atualiza composto com hand_verdadeiro com Atualiza_LocCorr e Reenvia_pedidos, atualizando a localidade atual da unidade móvel no proxy e reenviando os pedidos pendentes da unidade móvel. Temos outra reação [014] que liga Proxy_atualiza composto com hand_falso com Atualiza_LocCorr, atualizando a localidade atual da unidade móvel no proxy.

[018] def EB[EB_antiga(mens_dereg,UM) $\triangleright$

[019]

Verifica_pRef(UM,pRef); 
A localidade EBn está definida como uma conjunção de definições e um processo inerte, ativando um processo inerte.

$\mathrm{Na}$ definição temos quatro reações. A primeira reação [018] liga EB_antiga com Verifica_pRef, EB_nova_retorno e Apaga_LocalUM, verificando a pRef da unidade móvel, engatilhando uma nova reação e apagando a unidade móvel da lista da estação base.

A segunda reação [022] liga EB_nova_inicial com EB_antiga, engatilhando uma nova reação.

A terceira reação [024] liga EB_nova_retorno com Inclui_LocalUM e EB_atualiza, incluindo a unidade móvel na lista da estação base e engatilhando uma nova reação.

A quarta reação [027] liga EB_atualiza com Proxy_atualiza, engatilhando uma nova reação.

[032] def UM[T

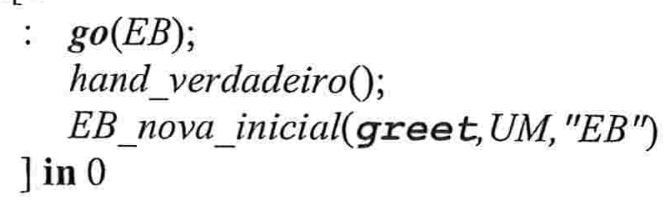

A localidade UM é um agente móvel definido como uma definição inerte e um processo em execução que engatilha a migração, ativando um processo inerte.

\subsubsection{Especificação do protocolo RDP}

Para um melhor entendimento do funcionamento do protocolo RDP, apresentamos graficamente o funcionamento do protocolo RDP, com as mensagens envolvidas no sistema e a seqüência de procedimentos. Posteriormente, a especificação do protocolo RDP no distributed join-calculus será apresentada. 


\subsubsection{Diagrama do protocolo RDP sem handoff}

Cada retângulo do - diagrama representa uma localidade e cada seta representa a comunicação de mensagens entre localidades. A localidade da UM está anexada (representada por uma linha que liga EB UM com UM) na localidade da EB UM para representar que a localidade UM está sob o domínio da EB UM. A localidade do proxy está anexada (representada por uma linha que liga EB proxy com proxy) na localidade da EB proxy para representar que a localidade do proxy está sob responsabilidade da localidade EB proxy. Uma outra localidade proxy está anexada (representada por uma linha que liga EB UM com proxy) na localidade EB UM para representar que um novo proxy foi criado para uma unidade móvel que ainda não tinha um proxy e fez um pedido e está sob responsabilidade da EB UM.

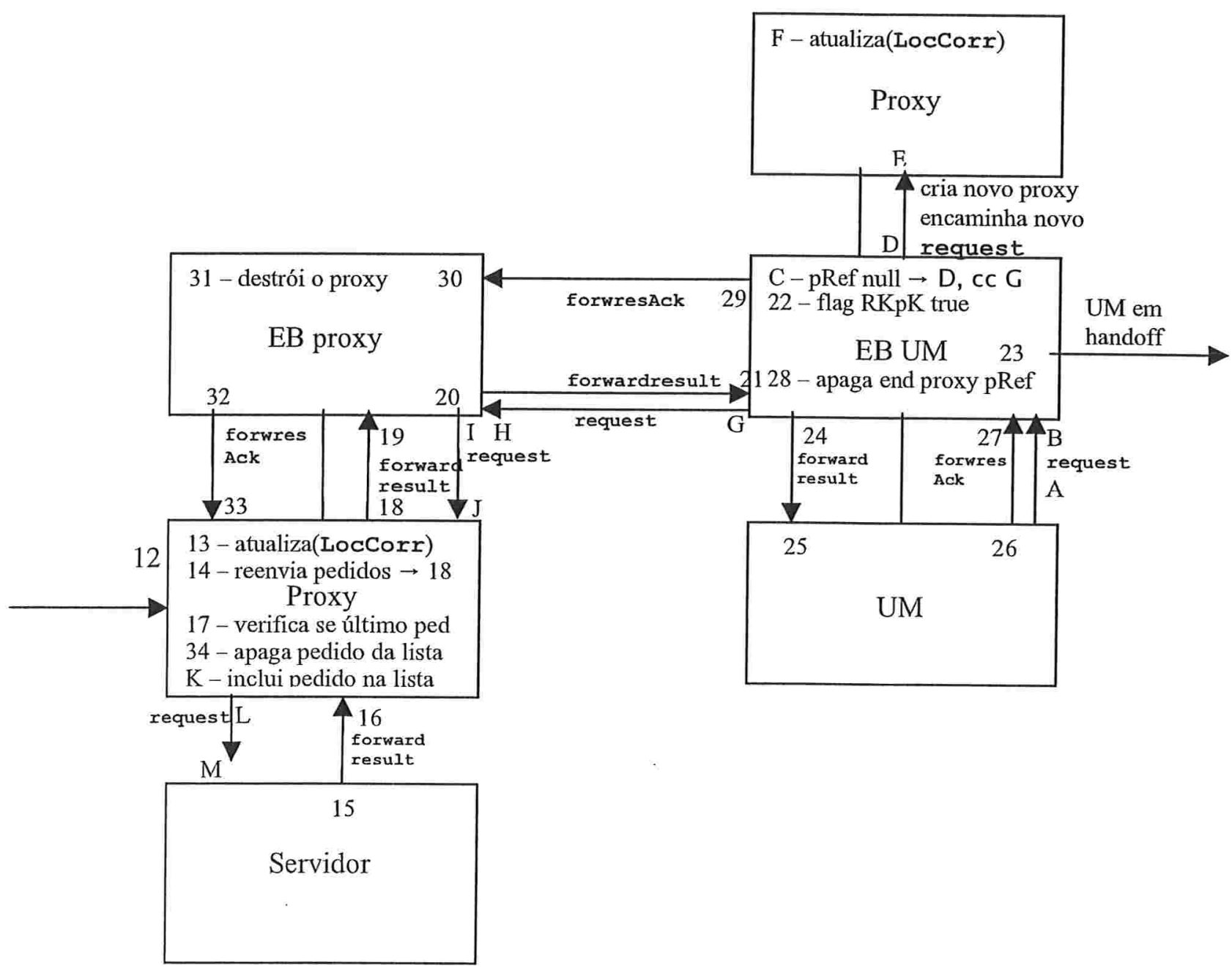




\section{Comunicações:}

$\mathrm{A} \rightarrow \mathrm{B}-$ EB_novo_pedido(request,pedido,UM,proxy)

$\mathrm{D} \rightarrow \mathrm{E}$ - Cria_novo_proxy(request,pedido,UM,proxy)

$\mathrm{G} \rightarrow \mathrm{H}-\mathrm{EB}$ _novo_pedido_proxy(request,pedido,proxy)

$\mathrm{I} \rightarrow \mathrm{J}$ - Proxy_novo_pedido(request,pedido)

$\mathrm{L} \rightarrow \mathrm{M}$ - Servidor_pedido(request,pedido)

$16 \rightarrow 17$ - Proxy_res_pedido(forwardresult,pedido)

$18 \rightarrow 19$-EB_res_pedido_proxy(forwardresult,pedido,UM,EB,Proxy)

$20 \rightarrow 21$ - EB_res_pedido(forwardresult,UM,EB,pedido)

$24 \rightarrow 25$ - UM_pedido(forwardresult,pedido,EB,UM)

$26 \rightarrow 27$-EB_ackp_UM(forwresAck,ackp,UM,Proxy)

$29 \rightarrow 30$-EB_ackp_proxy(forwresAck,ackp,UM,Proxy)

$33 \rightarrow 33$ - Proxy_ackp(forwresAck)

\section{Ações:}

12 - O Proxy recebe a mensagem update da estação base com a LocCorr.

13 - O Proxy atualiza a localização atual da UM com a LocCorr.

14 - O Proxy reenvia para a nova localidade todos os resultados dos pedidos que não confirmaram recebimento pela UM. (vai para a 14).

15 - O servidor envia para o proxy o resultado de algum pedido.

16 - O Proxy recebe o resultado de algum pedido pendente da UM.

17 - O Proxy verifica se o resultado do pedido recebido é o último, se é o último envia del_pRef como verdadeiro, caso contrário, como falso.

18 - O Proxy envia o resultado do pedido para a estação base do proxy e o del_pRef.

19 - A estação base onde o Proxy está recebe o resultado do pedido e o del_pRef.

20 - A estação base onde o Proxy está envia o resultado do pedido para a estação base da UM cujo endereço está na LocCorr e o del_pRef.

21 - A estação base onde a UM está recebe o resultado do pedido e o del_pRef.

22 - Se del_pRef é verdadeiro, seta pRef_RKpR como verdadeiro, caso contrário, como falso, no pRef da UM.

23 - Se a UM estiver em handoff, a EB não entrega o pedido.

24 - A estação base onde a UM está envia o resultado do pedido e o pRef_RKpR para a UM.

25 - Se a UM não está em período de handoff, a UM recebe o resultado do pedido e o pRef_RKpR.

26 - A UM envia mensagem de confirmação de recebimento do resultado do pedido, forwresAck, para a estação base onde a UM está.

27 - A estação base onde a UM está recebe a mensagem forwresAck.

28 - Se pRef_RKpR continuar verdadeiro, a estação base onde a UM está apaga o endereço de proxy da pRef.

29 - A estação base onde a UM está envia a mensagem forwresAck para a estação base onde o Proxy está e envia também del_pRef.

30 - A estação base onde o Proxy está recebe a mensagem forwresAck e o del_pRef. 
31 - Se del_pRef é verdadeiro, a estação base onde está o Proxy destrói o Proxy (acaba aqui).

32 - Se del_pRef é falso, a estação base onde o Proxy está envia a mensagem forwresAck para o Proxy.

33 - O Proxy recebe a mensagem forwresAck.

34 - O Proxy apaga o pedido da lista local de pedidos (ListaPedidos) da UM.

A - A UM envia um novo pedido para a estação base onde a UM está.

B - A estação base onde a UM está recebe um novo pedido da UM.

C - Verifica se já existe um Proxy da UM pela pRef da UM.

D - Se a UM não tem um Proxy, a estação base onde está a UM cria um novo Proxy para a

UM, encaminha o pedido para o novo Proxy e envia mensagem update com o LocCorr.

E - O Proxy recebe o pedido da UM e o LocCorr.

F - O Proxy atualiza a LocCorr com o endereço da EB onde a UM está.

G - Se a UM já tem um Proxy, a estação base onde a UM está encaminha o pedido para a Estação Base onde o Proxy está.

H - A Estação Base onde o Proxy está recebe o pedido.

I - A Estação Base onde o Proxy está envia o pedido para o proxy.

$\mathrm{J}$ - O Proxy recebe o pedido.

$\mathrm{K}$ - O Proxy inclui o pedido em sua ListaPedidos.

$\mathrm{L}$ - O Proxy envia o pedido para o servidor.

$\mathrm{M}-\mathrm{O}$ servidor recebe $\mathrm{o}$ pedido.

\subsubsection{Especificação de partes necessárias do protocolo $R D P$}

As funções a seguir são funções de implementação para o protocolo RDP que não serão especificadas, mas utilizadas nas demais definições da especificação. Podemos dizer que estas definições estão na solução do sistema.

[001] Apaga_LocalUM(UM,EB)

[002] <Apaga a UM da lista local de unidades móveis da EB>

[003] Inclui_LocalUM(UM,EB)

[004] <Inclui a UM na lista local de unidades móveis da EB>

[005] Verifica_pRef(UM,pRef)

[006] < Verifica qual é a pRef da UM e retorna a pRef $>$

[007] Cria_novo_proxy $(E B, U M)$

[008] <Cria um novo proxy na EB para a UM>

[009] Inclui_pedido_proxy(pedido,proxy) 
[010] <Inclui o pedido da unidade móvel na lista de pedidos (ListaPedidos) do proxy>

[011] Processa_pedido(pedido)

[012] <O servidor processa o pedido da unidade móvel $>$

[013]Apaga_end_proxy(UM,proxy)

[014] <Apaga o endereço de proxy da pRef>

[015] Deleta_proxy(Proxy, UM)

[016] <Deleta (destrói) o proxy da UM>

[017] Apaga_pedido_proxy(pedido,Proxy)

[018] <Apaga o pedido da unidade móvel da lista de pedidos (ListaPedidos) do proxy>

[019] Atualiza_LocCorr(Proxy,LocCorr)

[020] <Atualiza, no proxy, a LocCorr com a atual localização da unidade móvel>

[021] Reenvia_pedidos(Proxy, UM)

[022] <Reenvia os pedidos pendentes da unidade móvel>

A seguir estão as localidades para a especificação das partes do protocolo RDP. Estas localidades são soluções separadas por || (isto é, UM || EB || Proxy || Servidor) e que estão dentro da solução do sistema:

[023] def UM[UM_pedido(mens_forwardresult,pedido, $E B, U M) \mid$

$$
R K \bar{p} R \text { verdadeiro }() \triangleright
$$

del_proxy_verdadeiro();

$E B \_a c k p \_U M(" f o r w r e s A c k ", a c k p, U M$, Proxy); RKpR falso()

$\wedge$ UM_pedido(mens_forwardresult,pedido, $E B, U M) \mid R K p R \_$falso() $\triangleright$ EB_ackp_UM("forwresAck",ackp,UM,Proxy)

$\wedge$ UM_novo_pedido(pedido,UM,proxy) $\triangleright$ EB_novo_pedido("request",pedido,UM,proxy) |

$U M$ novo_pedido("pedido",UM,proxy)

: $g o(\bar{E} B)$;

RKpR_falso();

$E B \_n o v a \_$inicial( $"$ greet",UM,EB)

] in UM_novo_pedido("pedido",UM,proxy)

A localidade UM está definida como uma conjunção de definições e um processo em execução que engatilha a migração, ativando a solicitação de pedido da unidade móvel. 
Na definição temos três reações. A primeira reação [023] liga a composição UM_pedido e RKpR_verdadeiro com del_proxy_verdadeiro, EB_ackp_UM e RKpR_falso, engatilhando uma nova reação.

A segunda reação [027] liga a composição UM_pedido e RKpR_falso com EB_ackp_UM, engatilhando uma nova reação.

A terceira reação [029] liga UM_novo_pedido com a composição EB_novo_pedido e UM_novo_pedido, engatilhando uma nova reação e podendo emitir um novo pedido.

[036] def Proxy[Proxy_atualiza(mens_update,pRef_EB,UM) |hand_verdadeiro() $\triangleright$ Atualiza_LocCorr("Proxyn",pRef_EB); Reenvia_pedidos("Proxyn",UM); hand falso()

$\wedge$ Proxy_atualiza(pRef_EB,UM)|hand_falso() $\triangleright$ Atualiza_LocCorr ("Proxyn",pRef_EB)

$\wedge$ Proxy_ackp(mens_forwres_Ack,ackp) $\triangleright$ Apaga_pedido_proxy(ackp, "Proxyn")

$\wedge$ Proxy_res_pedido(mens_forwardresult,pedido $) \mid$ ultimo_pedido ()$\triangleright$ del_pRef_verdadeiro()

EB_res_pedido_proxy(mens_forwardresult,pedido,UM_aux, $E \bar{B} \_a u x$, "Proxyn")

$\wedge$ Proxy_res_pedido(mens_forwardresult,pedido) | nao_ultimo_pedido() $\triangleright$

del_pRef_falso();

EB_res_pedido_proxy(mens_forwardresult,pedido,UM_aux,

ultimo pedido() $E \bar{B} \_$aux, "Proxyn") |

$\wedge$ Proxy_novo_pedido(mens_request,pedido) $\triangleright$

Inclui_pedido_proxy(pedido);

nao_ultimo_pedido();

Servidor_pedido(mens_request,pedido)

: 0]

in hand_falso()

A localidade Proxy está definida como uma conjunção de definições e um processo inerte, ativando um processo condicional hand_falso().

Nas definições, temos seis reações das quais as duas primeiras reagem como no protocolo handoff. A terceira reação [042] liga Proxy_ackp com Apaga_pedido_proxy, apagando do proxy um pedido cujo resultado já foi recebido pela unidade móvel. 
A quarta reação [044] liga a composição de Proxy_res_pedido e ultimo_pedido com del_pRef_verdadeiro e EB_res_pedido_proxy, engatilhando uma nova reação.

A quinta reação [047] liga a composição de Proxy_res_pedido e nao_ultimo_pedido com del_pRef_falso e EB_res_pedido_proxy, engatilhando uma nova reação.

A sexta reação [051] liga Proxy_novo_pedido com Inclui_pedido_proxy, nao_ultimo_pedido e Servidor_pedido, incluindo um pedido da unidade móvel no proxy e engatilhando uma nova reação.

[057] def $\mathrm{EB}\left[E B \_a n t i g a\left(m e n s \_d e r e g, U M\right) \triangleright\right.$

[061]

[063]

[064]

$[065]$

[066]

$\wedge E B \_$nova_inicial(mens_greet,UM,oldEB) $\triangleright$ $E \bar{B}$ _antiga(dereg, $U M$ )

$\wedge E B$ nova_retorno (mens_deregAck,UM,pRef) $\triangleright$ Inclui_LocalUM(UM, "EBn"); hand_verdadeiro(); $E B \_$atualiza(update, "EBn", $U M$ )

$\wedge E B$ atualiza(mens_update,pRef,UM) $\triangleright$ Proxy_atualiza(mens_update,pRef,UM)

$\wedge E B \_$novo_pedido(mens_request,pedido,UM,proxy) |

Cria_novo_proxy ("EBn", UM);

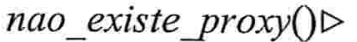
existe_proxy();

Proxy_atualiza(update,pRef,UM);

Proxy_novo_pedido(mens_request,pedido)

$\wedge$ EB_novo_pedido(mens_request,pedido,UM,proxy) | existe_proxy ()$\triangleright$ $E \bar{B} \_$novo_pedido_proxy(mens_request,pedido,proxy)

$\wedge$ EB_novo_pedido_proxy(mens_request,pedido,proxy) $\triangleright$

Proxy_novo_pedido(mens_request,pedido)

${ }^{\wedge} E B$ res_pedido(mens_forwardresult, UM,EB,pedido)| $R K p R \_$verdadeiro(); del_pRef_verdadeiro() | hand_falso() $\triangleright$

$U M$ _pedido(mens_forwardresult,pedido, $E B, U M$ )

$\wedge$ EB_res_pedido(mens_forwardresult, UM,EB,pedido)| del_pRef_falso()|hand_falso() $\triangleright$

$U M$ pedido(mens_forwardresult,pedido, $E B, U M)$

$\wedge E B \_a c k p \_U M\left(m e n s \_\right.$forwresAck, ackp,UM,Proxy) | del_proxy_verdadeiro()\

Apaga_end_proxy(UM,Proxy);

EB_ackp_proxy(mens_forwresAck, ackp,UM,Proxy); del proxy falso(); 
[091] $\wedge$ EB_ackp_UM(mens_forwresAck,ackp,UM,Proxy) |

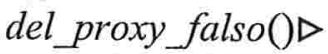

[092] EB_ackp_proxy(mens_forwresAck,ackp,UM,Proxy)

[093] $\wedge$ EB_res_pedido_proxy(mens_forwardresult,pedido,UM,EB,Proxy) $\triangleright$

[094] EB_res_pedido(mens_forwardresult, $U M, E B$,pedido)

[095] $\wedge E B \_a c k p \_p r o x y\left(m e n s \_f o r w r e s A c k, a c k p, U M, P r o x y\right) \mid$

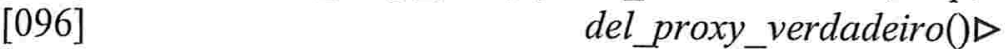

[097] Deleta_proxy(Proxy, UM);

[098] nao_existe_proxy();

[099] del_proxy_falso()

[100] $\wedge E B \_a c k p \_p r o x y\left(m e n s \_f o r w r e s A c k, a c k p, U M, P r o x y\right) \mid$

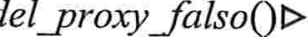

[102] Proxy_ackp(mens_forwres_Ack,ackp)

[103] in não_existe_proxy() |

[104] del proxy_falso()।

[105] del_pRef_falso()

[106] RKpR_falso()

A localidade EB está definida como uma conjunção de definições e um processo inerte, ativando um processo condicional.

Na definição temos quatorze reações das quais as quatro primeiras reagem como no protocolo handoff. A quinta reação [069] liga a composição EB_novo_pedido e nao_existe_proxy com Cria_novo_proxy, existe_proxy, Proxy_atualiza e Proxy_novo_pedido, criando um novo proxy para a unidade móvel e engatilhando duas novas reações.

A sexta reação [074] liga a composição EB_novo_pedido e proxy_existe com EB_novo_pedido, engatilhando uma nova reação.

A sétima reação [076] liga EB_novo_pedido_proxy com Proxy_novo_pedido, engatilhando uma nova reação.

A oitava reação [078] liga a composição EB_res_pedido, del_pRef_verdadeiro e hand_falso com RKpR_verdadeiro e UM_pedido, engatilhando uma nova reação.

A nona reação [082] liga a composição EB_res_pedido, del_pRef_falso e hand_falso com UM_pedido, engatilhando uma nova reação.

A décima reação [085] liga a composição EB_ackp_UM e del_proxy_verdadeiro com del_proxy_falso, Apaga_end_proxy e EB_ackp_proxy, del_proxy_falso e del_pRef_falso, apagando o endereço do proxy da pRef e engatilhando uma nova reação. 
A décima primeira reação [091] liga a composição EB_ackp_UM e del_proxy_falso com EB_ackp_proxy, engatilhando uma nova reação.

A décima segunda reação [093] liga EB_res_pedido_proxy com EB_res_pedido, engatilhando uma nova reação.

A décima terceira reação [095] liga a composição EB_ackp_proxy e del_proxy_verdadeiro com Deleta_proxy, nao_existe_proxy e del_proxy_verdadeiro, destruindo o proxy da unidade móvel.

A décima quarta reação [100] liga a composição EB_ackp_proxy e del_proxy_falso com Proxy_ackp, engatilhando uma nova reação.

[107] def Servidor[Servidor_pedido(mens_request,pedido) $\triangleright$

[108] Processa_pedido(pedido)

[109]

[110]

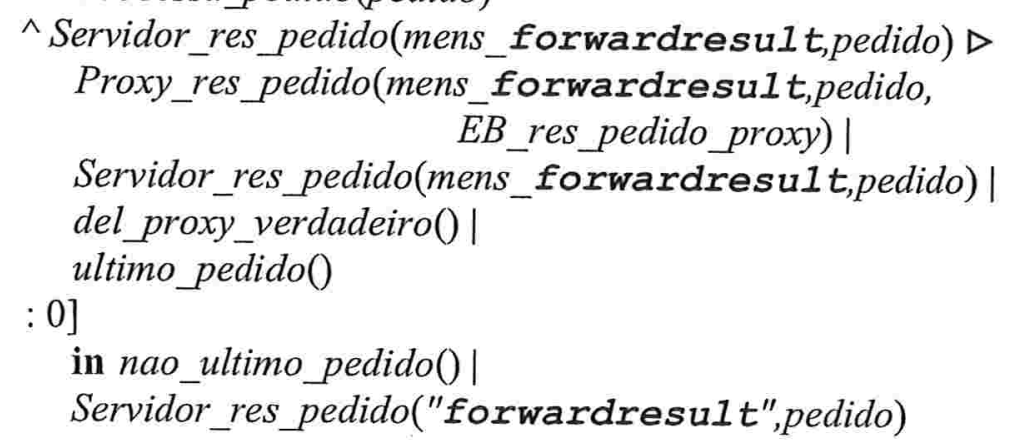

A localidade Servidor está definida como uma conjunção de definições e um processo inerte, ativando um processo condicional que engatilha o retorno do resultado do pedido da unidade móvel.

Na definição temos duas reações das quais a primeira [107] liga Servidor pedido e Processa_pedido, processando o pedido da unidade móvel. A segunda reação [109] liga Servidor_res_pedido com a composição de Proxy_res_pedido, Servidor_res_pedido, del_proxy_verdadeiro e último_pedido, enviando o resultado de um pedido para o proxy e esperando um novo resultado.

\subsection{Análise do uso do distributed join-calculus para agentes móveis}

O campo da computação móvel é novo e desenvolve-se rapidamente de diferentes formas. O distributed join-calculus não foi desenvolvido com o propósito de abranger uma pesquisa completa na área, mas para ter alguns pontos de comparação com trabalhos já existentes. 
Como o distributed join-calculus une a teoria da concorrência com sistemas distribuídos, ele é muito mais complexo do que o join-calculus, mas visa a simplicidade e enfoca um modelo particular de comunicação distribuída. O distributed join-calculus não se dirige às inúmeras questões importantes e muitas vezes encontradas nos modelos mais complexos para sistemas distribuídos. Por exemplo, o distributed join-calculus não é adequado para tratar técnicas baseadas em replicação, computação móvel como um todo ou ligação intermitente.

O distributed join-calculus foi desenvolvido para estudos tradicionais do cálculo de processos que está mais interessado nas especificações de protocolos do que em outros programas. Mas, também é adequado para escrever programas paralelos cujas propostas sejam gerais.

Para tratar as equivalências, foram desenvolvidas algumas técnicas como, por exemplo, equivalências observacionais, assincronismo e congruências "barbed bisimulation".

Os critérios de avaliação se baseiam nos conceitos gerais e propriedades de agentes móveis que normalmente aparecem nas pesquisas desta área [Hua01]. Assim, o estabelecimento desses critérios tem como objetivo prover um meio de avaliar o distributed join-calculus em relação à mobilidade.

Os critérios a serem usados na avaliação do distributed join-calculus, para agentes móveis, são:

- Mobilidade: capacidade de migrar por si próprio de um domínio para outro dentro de uma rede;

- Inteligência: a habilidade de interagir com o ambiente e aprender a partir dele a tomar decisões;

- Autonomia: tem total controle sobre suas próprias ações;

- Lealdade: desenvolve a computação em nome do seu usuário;

- Recursão: cria subagentes para subtarefas, se necessário;

- Colaboração: coopera e negocia com outros agentes;

- Assincronismo: capacidade de desenvolver uma computação assíncrona.

\subsubsection{Mobilidade}

A mobilidade é a propriedade essencial que diferencia o agente móvel de outros tipos de agentes. Um agente móvel carrega sua identidade, estado de execução e código.

A facilidade de especificação de mobilidade no distributed join-calculus vem do fato do uso de localidades e primitivas para mobilidade. Isso permite expressar agentes móveis que podem migrar entre diferentes máquinas. Além disso, quando uma localidade migra, ela leva consigo seu grupo de processos e definições. 


\subsubsection{Inteligência}

Um agente móvel é capaz de decidir suas ações baseadas no conhecimento e na informação do caminho percorrido por ele e é capaz de gerar novos conhecimentos de sua experiência.

No distributed join-calculus, um agente móvel não consegue guardar informações dos caminhos percorridos por ele e muito menos utilizar esses conhecimentos.

\subsubsection{Autonomia}

Um agente móvel deve ser capaz de executar, migrar e parar independentemente, sem supervisão, mesmo em uma execução longa.

Uma localidade controla seu próprio movimento e pode migrar para outra localidade tendo somente o nome desta localidade. A execução de processos é independente da distribuição e esta transparência de localidade simplifica o modelo dos agentes móveis e ajuda na prova de suas propriedades.

\subsubsection{Lealdade}

Um agente móvel é responsável pela tarefa de um usuário, representando um usuário para obter recursos e serviços para terminar uma tarefa.

No distributed join-calculus, um agente móvel possui seus próprios processos e definições que podem ser definidos para representar exclusivamente um usuário na manipulação de suas tarefas.

\subsubsection{Recursão}

Um agente móvel tem a capacidade de criar subagentes para subtarefas, se necessário.

No distributed join-calculus, uma localidade pode ter seus processos e definições expressados como sublocalidades, podendo, por exemplo, desenvolver parte da computação em outros domínios. Quando uma localidade migra, ela carrega consigo todas as suas sublocalidades. 


\subsubsection{Colaboração}

As tarefas complicadas podem ser executadas em colaboração com outros agentes.

Como o distributed join-calculus considera a programação distribuída, há várias situações onde alguns níveis de recursos de mobilidade são necessárias. Por exemplo, um agente pode, naturalmente, usar seus subagentes para desenvolver alguma parte da computação em outros domínios.

\subsubsection{Assincronismo}

Num ambiente de computação distribuída, a cooperação de agentes móveis pode desenvolver sua computação concorrentemente e possivelmente em localidades diferentes.

No distributed join-calculus, por definição, um processo pode ser uma emissão assíncrona de uma mensagem poliádica. Além disso, o distributed join-calculus tem a característica de colaboração dos agentes móveis e desenvolve uma computação concorrente podendo ser em localidades diferentes.

\subsection{Conclusão}

Neste capítulo sobre a especificação do RDP, o modelo do sistema, que utiliza estações base, unidades móveis e proxies, foi apresentado, juntamente com suas hipóteses conforme artigo original do RDP. Além disso, uma visão geral do RDP e seu funcionamento, desde a solicitação de um pedido pela unidade móvel até a chegada do resultado desse pedido à unidade móvel, considerando que a unidade móvel pode ter migrado, também foram apresentados.

O protocolo handoff, parte do protocolo RDP que trata a mobilidade, foi apresentado. Considerando as mensagens referentes ao protocolo handoff, este foi especificado informalmente através de um diagrama para verificarmos suas comunicações e ações e, posteriormente, especificado no distributed join-calculus.

O protocolo RDP, considerando somente as partes necessárias para este trabalho, também foi especificado informalmente, da mesma forma que o protocolo handoff $\mathrm{e}$, posteriormente, especificado no distributed join-calculus.

Analisando o uso do distributed join-calculus para agentes móveis e considerando alguns critérios de avaliação que se baseiam nos conceitos gerais e propriedades de agentes móveis, concluímos que o distributed join-calculus satisfaz os critérios de mobilidade, 
autonomia, lealdade, recursão, colaboração e assincronismo e não satisfaz o critério de inteligência. 


\section{Capítulo 4 - Análise do RDP}

Nesta fase de análise, verificamos algumas propriedades inerentes aos protocolos handoff e RDP utilizando a lógica temporal e as especificações dos protocolos apresentadas no Capítulo 3, Seção 3.7. Para isso, apresentamos parte da lógica temporal com definições de fórmulas temporais, conjuntos pré-definidos e predicados do sistemas que são necessárias para a prova das propriedades. As hipóteses e propriedades escritas na lógica temporal são apresentadas em seguida e posteriormente a prova de cada propriedade.

Além disso, realizamos uma análise do distributed join-calculus e de sua linguagem em relação a agentes móveis para saber quais critérios são ou não abordados pelo cálculo e pela linguagem. Analisamos também o uso do distributed join-calculus para a prova das propriedades e a facilidade da tradução para a linguagem dada a especificação.

\subsection{Notações e Definições}

O modelo computacional que usamos refere-se ao modelo de Manna e Pnueli definido em [MP91]. Esse modelo é mais genérico por fornecer um modelo para variáveis associadas e passagem de mensagem. A noção de computação neste trabalho é dada por um conjunto infinito de ações atômicas.

$$
\sigma=s_{0}, s_{1}, \ldots
$$

\subsubsection{Lógica temporal}

Uma fórmula temporal é construída de uma fórmula de estado para que operadores temporais, conectivos boleanos e quantificadores sejam aplicados. Neste trabalho são aplicados alguns operadores de futuro e de passado.

\section{Fórmulas Temporais sobre V}

- Toda fórmula de estado está em $\boldsymbol{V}$.

- $\neg p, p \wedge q, p \vee q, p \Rightarrow q$ e $p \leftrightarrow \mathrm{q}$, se $p$ e $q$ são fórmulas temporais sobre $V$.

- $\quad$ p se $p$ é uma fórmula temporal sobre $V$. $\bigcirc p$ é válido na posição (passo) $j$ se e somente se $p$ é válido na próxima posição $(j+1)$.

- $\square p$, se $p$ é uma fórmula temporal sobre $V$. $\square p$ é válido na posição (passo) $j$ se e somente se $p$ é válido na posição $j$ e em todas as posições seguintes (a partir de agora).

- $\diamond p$, se $p$ é uma fórmula temporal sobre $\boldsymbol{V}$. $\diamond p$ é válido na posição (passo) $j$ se e somente se $p$ é válido em alguma posição $k \geq j$. 
- $\odot p$, se $p$ é uma fórmula temporal sobre $V$. ๑ $p$ é válido na posição (passo) $j$ se e somente se $p$ foi válido na última posição $(j-1)$.

- $\diamond p$, se $p$ é uma fórmula temporal sobre $V$. $\diamond p$ é válido na posição (passo) $j$ se e somente se $p$ foi válido em alguma posição $k<j$.

\subsubsection{Conjuntos pré-definidos}

Alguns elementos do sistema devem ser distinguidos para conseguirmos certas propriedades. Assim, descrevemos um conjunto de elementos pré-definidos:

- $c$ conj-UM $=\left\{U M_{1}, U M_{2}, \ldots\right\}:$ conjunto de todas as unidades móveis inerentes ao sistema.

- $c o n j-E B=\left\{E B_{1}, E B_{2}, \ldots\right\}:$ conjunto de todas as estações base (estações de serviço de mensagem) inerentes ao sistema.

- conj-Proxy $=\left\{\operatorname{Proxy}_{1}, \operatorname{Proxy}_{2}, \ldots\right\}$ : conjunto de todos os proxies inerentes ao sistema.

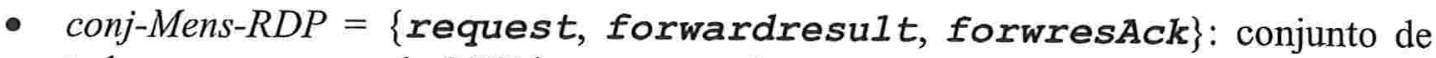
todas as mensagens do RDP inerentes ao sistema.

- $\quad$ conj-Mens-Hand $=\{$ greet, dereg, deregAck, update $\}$ : conjunto de todas as mensagens do handoff inerentes ao sistema.

- conj-Mens-UM = \{forwardresult, forwresAck $\}$ : conjunto de todas as mensagens da unidade móvel quando não está no período de handoff.

\section{Funcões}

- UMovel(EB): conjunto de todas as unidades móveis do sistema que estão sob o domínio da $E B$.

- $\operatorname{Proxy}(U M)$ : conjunto de todos os proxies do sistema que estão sob o domínio da $U M$, tal que o número de elementos deste conjunto é 0 ou 1.

- ProxyEB(EB): conjunto de todos os proxies do sistema que estão sob o domínio da EB.

\subsubsection{Predicados do sistema}

Alguns predicados do sistema são necessários para conseguirmos escrever as hipóteses e propriedades do sistema, bem como suas provas. Atentamos por determinar somente os predicados necessários para escrever as hipóteses, propriedades e suas provas e não todos os predicados envolvidos no sistema, minimizando, ao máximo, o número de predicados.

$\forall m_{1}, m_{2} \in($ conj-UM $\cup$ conj-EB $\cup$ conj-Proxy $)$

- ativo $\left(m_{1}\right)$ : é verdadeiro se $m_{1}$ responde efetivamente para o sistema. 
- $\operatorname{enviar}\left(m_{1}, m_{2}, M\right)$ : é verdadeiro se $m_{1}$ envia a mensagem $M$ para $m_{2}$.

- receber $\left(m_{1}, m_{2}, M\right)$ : é verdadeiro se a mensagem $M$, de $m_{2}$, chega a $m_{1}$ com segurança.

- responder $\left(m_{1}, m_{2}, M\right)$ : é verdadeiro se $m_{1}$ envia para $m_{2}$ o resultado do pedido que está junto com a mensagem $\mathrm{M}$.

- apagar_UM( $\left.m_{1}, m_{2}\right)$ : é verdadeiro se a unidade móvel $m_{1}$ é removida da lista interna de unidades móveis da estação base $m_{2}$.

- incluir_UM( $\left.m_{1}, m_{2}\right)$ : é verdadeiro se a unidade móvel $m_{1}$ é incluída na lista interna de unidades móveis da estação base $m_{2}$.

- verificar $p R e f\left(m_{1}\right)$ : é verdadeiro se a pRef da unidade móvel $m_{1}$ é verificada.

- criar $\operatorname{proxy}\left(m_{1}, m_{2}\right)$ : é verdadeiro se o proxy $m_{1}$ é criado na estação base $m_{2}$.

- incluir_proxy $\left(m_{1}\right)$ : é verdadeiro se um pedido é incluído no proxy $m_{1}$

- processar(): é verdadeiro se um pedido está sendo processado.

- apagar proxy $\left(m_{1}\right)$ : é verdadeiro se a unidade móvel $m_{1}$ apaga o endereço de proxy de sua pRef.

- destruir_proxy $\left(m_{1}\right)$ : é verdadeiro se o proxy $m_{1}$ é destruído.

- apagar_proxy_pedido $\left(m_{1}\right)$ : é verdadeiro se um pedido é apagado do proxy $m_{1}$.

- atualizar_proxy $\left(m_{1}, m_{2}\right)$ : é verdadeiro se o proxy $m_{1}$ é atualizado com a nova localidade $m_{2}$ da unidade móvel.

- handoff $\left(m_{1}\right)$ : é verdadeiro se a unidade móvel $m_{1}$ estiver no período do protocolo handoff.

- existe $\operatorname{proxy}()$ : é verdadeiro se existe um proxy para uma unidade móvel.

- del_proxy_verdadeiro(): é verdadeiro se um proxy pode ser destruído.

- del_pRef_verdadeiro(): é verdadeiro se uma referência de proxy pode ser apagada.

- último_pedido(): é verdadeiro se um proxy entrega o resultado do último pedido da unidade móvel.

\subsection{Hipóteses e Propriedades do RDP e do Protocolo Handoff}

Nesta seção apresentamos as hipóteses e propriedades do protocolo RDP e do protocolo handoff escritos na lógica temporal. As hipótese foram retiradas do artigo que descreve o protocolo RDP e handoff. As propriedades foram determinadas visando verificar pontos importantes dos protocolos e garantia de resultados. A maioria destas propriedades foram apontadas como desejáveis ao protocolo no artigo original.

\subsubsection{Hipóteses}

A seguir, apresentamos as hipóteses dos protocolos handoff e RDP separadas por hipóteses referentes às unidades móveis, às estações base e do handoff, para um melhor entendimento de cada hipótese. Nem todas as hipóteses apresentadas no artigo original foram 
consideradas, ou porque não as consideramos como hipóteses e sim com propriedades ou porque não eram relevantes para o desenvolvimento de nossa análise.

\section{Das unidades móveis}

1. Hipótese do sistema. O conjunto de UMs é constante nas computações:

$\forall U M \in$ conj-UMO .

$\square U M \in$ conj-UM

Esta hipótese garante que o número de unidades móveis no sistema é constante, não podendo haver inclusões ou exclusões de unidades móveis no sistema. Esta não é uma hipótese do artigo original que descreve o RDP, mas facilita nas provas e não afeta efetivamente o comportamento do protocolo no propósito de nossa análise.

2. Hipótese do protocolo RDP. As UMs respondem a todas as mensagens recebidas: $\forall E B \in$ conj-EB, $U M \in U$ Movel $(E B)$. receber $(U M, E B$, forwardresullt $) \Rightarrow \diamond$ enviar $(E B, U M$, forwresAck)

Hipótese extraída do artigo original que descreve o protocolo RDP.

3. Hipótese do protocolo RDP. As UMs não recebem e não enviam mensagens se seu estado é inativo:

$\forall E B \in$ conj-EB, $U M \in U M$ Movel(EB) .

$\neg$ ativo $(U M) \Rightarrow$

$(\neg$ enviar $(U M, E B, M) \wedge \neg \operatorname{receber}(U M, E B, M))$

Hipótese extraída do artigo original que descreve o protocolo RDP.

4. Hipótese parcial do protocolo RDP. No passo 0, ou seja, assim que a UM entra no sistema, cada UM ativa está sob o domínio de uma única EB:

$\forall U M \in$ conj- $U M_{0}$.

$\exists ! E B \in$ conj-EB $B_{0}$.

$\left(U M \in U_{M}\right.$ ovel $\left._{0}(E B) \wedge \operatorname{ativa}(U M)\right)$

No artigo que descreve o protocolo RDP e handoff [ESO98], esta hipótese 4 é considerada sempre verdadeira em qualquer tempo. No entanto, acreditamos que o protocolo é quem deve garantir que uma unidade móvel ativa está sempre sob o domínio de uma única estação base. Isso porque, quando ocorre o handoff, a unidade móvel está migrando de uma estação base antiga para uma estação base nova e poderia acontecer da unidade móvel continuar sob o domínio da estação base antiga e passar a estar também sob o domínio da estação base nova. Portanto, para esta hipótese, consideramos que, inicialmente, ou seja, somente no passo 0, a unidade móvel está sob o domínio de uma única estação base. 


\section{Das estacões base}

5. Hipótese do sistema. O conjunto de EBs é constante nas computações:

$\forall E B \in$ conj- $E B_{0}$.

$\square E B \in$ conj-EB

Esta hipótese garante que o número de estações base no sistema é constante, não podendo haver inclusões ou exclusões de estações base no sistema. Esta não é uma hipótese do artigo original que descreve o RDP, mas facilita nas provas e não afeta efetivamente $o$ comportamento do protocolo no propósito de nossa análise.

6. Hipótese do protocolo RDP. As EBs não falham:

$$
\begin{array}{r}
\forall E B \in \text { conj-EB } . \\
\square \text { ativo }(E B)
\end{array}
$$

Hipótese extraída do artigo original que descreve o protocolo RDP.

7. Hipótese do protocolo RDP. A comunicação entre cada dois elementos é confiável:

$$
\begin{aligned}
& \left(\forall E B_{1}, E B_{2} \in \operatorname{conj}-E B \cdot\right. \\
& \quad \text { enviar }\left(E B_{1}, E B_{2}, M\right) \Rightarrow \diamond \operatorname{receber}\left(E B_{2}, E B_{1}, M\right) \\
& (\forall E B \in \operatorname{conj}-E B, U M \in U M \operatorname{Movel}(E B) \cdot \\
& \quad(\text { ativo }(U M) \wedge \\
& \quad(\text { enviar }(E B, U M, M) \Rightarrow \diamond \operatorname{receber}(U M, E B, M) \vee \\
& \quad \text { enviar }(U M, E B, M) \Rightarrow \diamond \operatorname{receber}(E B, U M, M))) \quad \wedge \\
& (\forall E B \in \operatorname{conj}-E B, \operatorname{Proxy} \in \operatorname{Proxy} E B(E B) \cdot \\
& \quad(\text { enviar }(\operatorname{Proxy}, E B, M) \Rightarrow \diamond \operatorname{receber}(E B, \operatorname{Proxy}, M) \vee \\
& \quad \text { enviar }(E B, \operatorname{Proxy}, M) \Rightarrow \diamond \operatorname{receber}(\operatorname{Proxy}, E B, M))
\end{aligned}
$$

No artigo original que descreve o protocolo RDP, há a hipótese de que a comunicação entre as estações base é confiável. No entanto, para verificar as propriedades dos protocolos, é necessário que qualquer comunicação entre cada dois elementos do sistema seja confiável. Caso contrário, não poderíamos garantir que qualquer mensagem enviada por um elemento seja recebida pelo elemento que deveria receber a mensagem, não garantindo a entrega de pedido da unidade móvel até o servidor e do resultado desse pedido do servidor até a unidade móvel.

\section{Do handoff}

8. Hipótese do protocolo RDP. As UMs ativas só enviam uma mensagem greet se responderem a todas as mensagens recebidas.

$$
\begin{aligned}
& \forall E B_{1}, E B_{2} \in \text { conj- } E B, U M \in U M \text { Movel }\left(E B_{1}\right), E B_{1} \neq E B_{2} . \\
& \quad\left(\operatorname{receber}\left(U M, E B_{1}, \text { forwardresult }\right) \wedge\right. \\
& \left.\quad \text { ᄀenviar }\left(U M, E B_{1}, \text { forwresAck }\right)\right) \Rightarrow
\end{aligned}
$$


As unidades móveis só respondem as mensagens, com o resultado de um pedido, recebidas da estação base responsável por ela. Para evitar que a unidade móvel receba novamente o mesmo resultado de um pedido, ela deve responder essa mensagem, de recebimento do resultado, para a estação base responsável por ela antes de entrar no período de handoff. Isto é descrito no artigo original que descreve o RDP mas não como hipótese.

9. Hipótese do protocolo RDP As UMs iniciam o handoff quando enviam a mensagem greet para uma nova EB:

$\forall U M \in$ conj-UM, $E B \in$ conj-EB,$U M \notin U M \operatorname{Uovel}(E B)$. enviar $(U M, E B$, greet $) \Rightarrow$ Ohandoff $(U M)$

A necessidade de saber exatamente o início do handoff nos levou a determinar esta hipótese que não está clara no artigo original que descreve o protocolo RDP.

10. Hipótese do protocolo RDP As UMs permanecem inativas durante o handoff (a migração)

$$
\begin{aligned}
& \forall U M \in \text { conj-UM } \\
& \quad \text { handoff }(U M) \Rightarrow \neg \text { ativo }(U M)
\end{aligned}
$$

Hipótese extraída do artigo original que descreve o protocolo RDP.

\subsubsection{Propriedades do Protocolo Handoff}

A seguir, apresentamos as propriedades do protocolo handoff escritas na lógica temporal:

1. As UMs não enviam e não recebem mensagens durante o handoff (migração)

$\forall U M \in$ conj-UM,$E B \in \operatorname{conj-EB}$.

$$
\text { handoff }(U M) \Rightarrow(\neg \text { enviar }(U M, E B, M) \wedge \neg \operatorname{receber}(U M, E B, M))
$$

Como as unidades móveis ficam inativas durante a migração, ou seja, no período do handoff, é importante verificar se as unidades móveis realmente não enviam e não recebem mensagem nesse período. Neste período, as unidades móveis não respondem a nenhuma estação base e se enviassem alguma mensagem, provavelmente esta se perderia, e se recebessem alguma mensagem, não seria possível garantir de qual estação base é a procedência desta mensagem.

2. Após o handoff, cada UM continua a ter, no máximo, um proxy:

$\forall U M \in \operatorname{conj}-U M$.

$\diamond$ handoff $(U M) \Rightarrow$

$(\operatorname{Proxy}(U M)=\{\} \vee(\exists ! \operatorname{Proxy} \in \operatorname{conj}-\operatorname{Proxy} \cdot \operatorname{Proxy} \in \operatorname{Proxy}(U M)))$ 
O proxy é um elemento que existe para administrar os pedidos de uma unidade móvel, por isso, a unidade móvel necessita de, no máximo, um proxy. A existência de mais de um proxy poderia causar confusões de pedidos. Um proxy é criado quando uma unidade móvel faz um pedido e não tem um proxy, destruído quando o resultado do último pedido pendente chega à unidade móvel e continua o mesmo quando sua unidade móvel migra. Desta forma, é importante garantirmos que, a qualquer tempo, a unidade móvel tenha, no máximo, um proxy.

3. Após o handoff, os proxies reenviam o resultado de um pedido cuja confirmação não foi recebida:

$$
\begin{aligned}
& \forall E B_{1}, E B_{2} \in \text { conj-EB }, U M \in U M \text { Movel }\left(E B_{1}\right) \cdot \\
& E B_{1} \neq E B_{2} \wedge \exists \operatorname{Proxy} \in \operatorname{Proxy}(U M) \cdot \\
& \text { enviar }\left(\text { Proxy, } E B_{1}, \text { forwardresult }\right) \wedge \\
& \neg \text { receber }\left(U M, E B_{1}, \text { forwardresult }\right) \wedge \\
& \text { ○handoff }(U M) \wedge U M \in U M \text { Movel }\left(E B_{2}\right) \Rightarrow \\
& \diamond \text { enviar }\left(\text { Proxy, } E B_{2}, \text { forwardresult }\right)
\end{aligned}
$$

Esta propriedade garante que, se o proxy enviou o resultado de um pedido para sua unidade móvel e esta migrou antes de receber o resultado, o proxy reenvia o resultado deste pedido assim que a unidade móvel terminar de migrar. Esta propriedade é importante para garantir que o resultado de um pedido feito pela unidade móvel sempre lhe é entregue.

4. Após o handoff, cada UM ativa está sob o domínio de uma única $E B$ :

$\forall U M \in$ conj-UM

$\diamond$ handoff $(U M) \Rightarrow \exists ! E B \in \operatorname{conj}-E B$.

$(U M \in U M o v e l(E B) \wedge \operatorname{ativa}(U M))$

Como comentado na hipótese 4 , é importante que o protocolo garanta que uma unidade móvel ativa esteja sempre sob o domínio de uma única estação base. Esta propriedade verifica se, mesmo após a migração da unidade móvel, ela continua sob o domínio de uma única estação base.

\subsubsection{Propriedades do Protocolo RDP}

A seguir, apresentamos as propriedades do protocolo RDP escritas na lógica temporal:

1. Cada UM pode se comunicar somente com a EB em cujo domínio está incluída:

$\forall U M \in$ conj-UM, EB $\in$ conj-EB .

$(\operatorname{receber}(U M, E B, M) \vee$ enviar $(U M, E B, M)) \Rightarrow$

$U M \in$ conj-UMovel $(E B)$

Esta propriedade garante que uma unidade móvel se comunica somente com a estação base responsável por ela. A veracidade desta propriedade é importante pois se a unidade móvel 
se comunicar com outras estações base, ela pode não receber o resultado de um pedido, pois o proxy entrega o resultado de um pedido somente para a estação base responsável pela unidade móvel. E também não haveria a possibilidade do proxy entregar o resultado de um pedido para todas as estações base com que a unidade móvel se comunicou, pois, neste caso, a unidade móvel receberia a quantidade de cópias do resultado de um mesmo pedido na quantidade de estações base com que ela se comunicou.

2. Nenhuma mensagem espontânea é gerada:

$$
\begin{gathered}
\forall m_{1} \text { e } m_{2} \in(\text { conj-UM } \cup \text { conj-EB } \cup \text { conj-Proxy }) \\
\operatorname{receber}\left(m_{1}, m_{2}, M\right) \Rightarrow \diamond \operatorname{enviar}\left(m_{2}, m_{1}, M\right)
\end{gathered}
$$

Para garantir que o funcionamento do protocolo seja controlado, toda emissão de mensagem vem da solicitação de um pedido, retorno do resultado de um pedido ou da resposta de alguma mensagem enviada, é necessário que o protocolo saiba exatamente qual elemento do sistema e quando uma mensagem foi enviada. Por isso, a importância de se verificar se nenhuma mensagem espontânea é gerada.

3. O resultado de um pedido é sempre entregue:

$$
\begin{aligned}
& \forall E B_{1}, E B_{2} \in \text { conj-EB }, U M \in U M \operatorname{Uovel}\left(E B_{I}\right) \text {. } \\
& E B_{1} \neq E B_{2} \wedge \exists \text { Proxy } \in \operatorname{Proxy}(U M) \text {. } \\
& \text { enviar(Proxy, } E B_{1} \text {, forwardresult) } \Rightarrow \\
& \diamond \text { receber }\left(U M, E B_{1} \text {, forwardresul } t\right) \vee \\
& \left(\odot \text { handoff }(U M) \wedge U M \in U M \text { Movel }\left(E B_{2}\right) \wedge\right. \\
& \diamond \text { enviar(Proxy, } E B_{2} \text {, forwardresu1t)) }
\end{aligned}
$$

Esta é uma das propriedades mais importantes do protocolo: a garantia da entrega do resultado de um pedido. Se o protocolo garante que o resultado de um pedido é sempre entregue, aumenta a confiabilidade deste protocolo. Mesmo que o resultado de um pedido seja eventualmente entregue mais de uma vez, teremos a certeza de que o resultado chegará à unidade móvel que solicitou o pedido.

4. Uma mensagem enviada é sempre entregue:

$$
\begin{gathered}
\forall m_{1} \text { e } m_{2} \in(\text { conj-UM } \cup \text { conj-EB } \cup \text { conj-Proxy }) \\
\quad \text { enviar }\left(m_{1}, m_{2}, M\right) \Rightarrow \diamond \operatorname{receber}\left(m_{2}, m_{1}, M\right)
\end{gathered}
$$

Para garantir que um pedido de uma unidade móvel chega ao servidor e que o resultado de um pedido chega à unidade móvel, é importante garantir que todas as mensagens envolvidas até o pedido chegar no servidor e o resultado de um pedido chegar na unidade móvel sejam entregues. Caso contrário, o protocolo não consegue garantir que o resultado de um pedido solicitado chegue à unidade móvel. Além disso, no período do handoff, é importante garantir a entrega de todas as mensagens pois, caso contrário, o handoff pode não terminar ou terminar com alguns erros como, por exemplo, a unidade móvel ativa estar sob domínio de duas estações base. 


\subsection{Análise das Propriedades}

Nesta seção, provamos cada uma das propriedades acima descritas, usando a especificação dos protocolos handoff e RDP.

\subsubsection{Propriedades do Handoff}

1. As UMs não enviam e não recebem mensagens durante o handoff (migração)

$\forall U M \in$ conj-UM, $E B \in$ conj-EB .

handoff $(U M) \Rightarrow(\neg$ enviar $(U M, E B, M) \wedge \neg \operatorname{receber}(U M, E B, M))$

Durante todo o período do Handoff (migração), as unidades móveis permanecem no estado inativo, portanto, não enviam e não recebem mensagens nesse período.

Prova:

\begin{tabular}{lr}
\hline$\forall U M \in$ conj- $U M, E B \in$ conj-EB & \\
\hline handoff $(U M) \Rightarrow \neg \operatorname{ativo}(U M)$ & Hipótese 10 \\
\hline$\neg$ ativo $(U M) \Rightarrow(\neg$ enviar $(U M, E B, M) \wedge \neg \operatorname{receber}(U M, E B, M))$ & Hipótese 03 \\
\hline$\therefore$ handoff $(U M) \Rightarrow$ & \\
$\quad(\neg$ enviar $(U M, E B, M) \wedge \neg \operatorname{receber}(U M, E B, M))$ & \\
\hline
\end{tabular}

2. Após o handoff, cada UM continua a ter, no máximo, um proxy:

$\forall U M \in$ conj-UM .

$\diamond \operatorname{handoff}(U M) \Rightarrow$

$(\operatorname{Proxy}(U M)=\{\} \vee(\exists !$ Proxy $\in$ conj-Proxy $\cdot \operatorname{Proxy} \in \operatorname{Proxy}(U M)))$

Um novo proxy é criado somente quando um novo pedido é solicitado pela unidade móvel (0). Quando a unidade móvel solicita um novo pedido, este pedido é enviado para a estação base responsável pela unidade móvel. Quando o pedido chega à estação base (1), (3), esta verifica a pRef do proxy. Se a pRef contiver o valor null é porque a unidade móvel não tem um proxy e somente neste caso um proxy é criado e o novo pedido encaminhado para ele (3). Neste caso, o proxy atualiza o endereço atual da unidade móvel com a mesma estação base que a criou (4). Se a pRef não contiver o valor null é porque existe um proxy para esta unidade móvel e, neste caso, o pedido é encaminhado para a estação base onde o proxy está (1) e posteriormente para o proxy já existente (1). Quando o pedido da unidade móvel chega ao seu proxy, o pedido é incluído no proxy e enviado para o servidor (5). Se a unidade móvel inicia um período de handoff (6) antes da chegada do resultado do seu pedido, a unidade móvel migra de uma estação base para outra (7), (8) e o endereço do 
proxy é atualizado com a nova estação base responsável pela unidade móvel (9), (10). E se houver resultados de pedidos pendentes, estes são reenviados para a unidade móvel (10).

Prova:

$\forall U M \in$ conj-UM .

(0) receber $(U M, U M$, request $) \Rightarrow \diamond$ enviar $(U M, E B$, request) $\quad$ linhas 029 e 030

do Apêndice D

Se já existe um proxy

enviar $(U M, E B$, request $) \Rightarrow \diamond \operatorname{receber}(E B, U M$, request $)$

Hipótese 7

(1) receber $(E B, U M$, request $) \Rightarrow \diamond$ enviar $\left(E B, E B_{p}\right.$, request) linhas 074,075 do

enviar $\left(E B, E B_{p}\right.$, request $) \Rightarrow \diamond$ receber $\left(E B_{p}, E B\right.$, request $)$

Apêndice D

(2) $\operatorname{receber}\left(E B_{p}, E B\right.$, request) $\Rightarrow$

$\diamond$ enviar(EB $B_{p}$ Proxy, request)

Hipótese 7

enviar $\left(E B_{p}\right.$, Proxy, request $) \Rightarrow$

$\diamond$ receber(Proxy, $E B_{p}$, request)

Se não existe proxy

\begin{tabular}{rrr}
\hline enviar $(U M, E B$, request $)$ & $\Rightarrow \diamond \operatorname{receber}(E B, U M$, request $)$ & Hipótese 7 \\
\hline (3) $\operatorname{receber}(E B, U M$, request $)$ & $\Rightarrow \diamond \operatorname{criar}(\operatorname{Proxy}, E B) \wedge$ & linhas 069,070, \\
& $\diamond$ enviar $(E B$, Proxy, update $) \wedge$ & 072,073 do \\
& $\diamond$ enviar $(E B$, Proxy, request $)$ & Apêndice D \\
\hline enviar $(E B$, Proxy, update $)$ & $\Rightarrow \diamond \operatorname{receber}($ Proxy, $E B$, update $)$ & Hipótese 7 \\
\hline enviar $(E B$, Proxy, request $) \Rightarrow$ & Hipótese 7 \\
& $\diamond$ receber $(\operatorname{Proxy}, E B$, request $)$ & \\
\hline
\end{tabular}

Se não ocorreu handoff

(4) receber(Proxy, EB, update) $\Rightarrow \diamond$ atualizar_proxy(Proxy, EB) $\quad$ linhas 040, 041 do

Apêndice D

(5) receber(Proxy, $E B$, request) $\Rightarrow$

$\diamond$ incluir_pedido(Proxy) $\wedge$

linhas 051, 052,

$\diamond$ enviar(Proxy, servidor, request)

054 do Apêndice

(6) $\operatorname{receber}\left(E B_{n}, U M\right.$, greet $) \Rightarrow \diamond$ enviar $\left(E B_{n}, E B_{a}\right.$, dereg) linhas 022,023 do

Apêndice C

\begin{tabular}{lr}
\hline enviar $\left(E B_{n}, E B_{a}\right.$, dereg $) \Rightarrow \diamond \operatorname{receber}\left(E B_{a}, E B_{n}\right.$, dereg $)$ & Hipótese 7 \\
\hline$(7)$
\end{tabular}

(7) $\operatorname{receber}\left(E B_{a}, E B_{n}\right.$, dereg $) \Rightarrow \diamond$ enviar $\left(E B_{a}, E B_{n}\right.$, deregAck $)$ linhas 018,020 do

enviar $\left(E B_{a}, E B_{n}\right.$, deregAck $) \Rightarrow$

Apêndice C

$\diamond$ receber $\left(E B_{n}, E B_{a}\right.$, deregAck $)$

Hipótese 7

(8) receber $\left(E B_{n}, E B_{a}\right.$, deregAck $) \Rightarrow \diamond$ enviar $\left(E B_{n}, E B_{p}\right.$, update) linhas 024, 026 do

\begin{tabular}{lrr}
\hline & enviar $\left(E B_{n}, E B_{p}\right.$, update $) \Rightarrow \diamond \operatorname{receber}\left(E B_{p}, E B_{n}\right.$, update $)$ & Hipótese 7 \\
\hline (9) $\quad$ receber $\left(E B_{p}, E B_{n}\right.$, update $) \Rightarrow \diamond$ enviar $\left(E B_{p}\right.$, Proxy, update $)$ & linhas 027,028 do \\
\hline
\end{tabular}

Apêndice C 


\begin{tabular}{|c|c|}
\hline enviar $\left(E B_{n}\right.$, Proxy, update $) \Rightarrow$ & $\begin{array}{c}\text { Apêndice C } \\
\text { Hinótese } 7\end{array}$ \\
\hline \multicolumn{2}{|l|}{$\diamond$ receber(Proxy, $E B_{p}$, update) } \\
\hline Se ocorreu handoff & \\
\hline $\begin{aligned}\text { (10) receber(Proxy, EB, update }) & \Rightarrow \diamond \text { atualizar } \operatorname{proxy}(\text { Proxy, EB }) \\
& \diamond \text { responder }(\text { Proxy, EB, mens })\end{aligned}$ & $\begin{array}{r}\text { linhas 036, 037, } \\
038 \text { do Apêndice }\end{array}$ \\
\hline $\begin{aligned} \therefore & (\operatorname{Proxy}(U M)=\{\} \vee \\
& (\exists ! \operatorname{Proxy} \in \text { conj-Proxy } \cdot \operatorname{Proxy} \in \operatorname{Proxy}(U M)))\end{aligned}$ & ㅁ \\
\hline
\end{tabular}

3. Após o handoff, os proxies reenviam o resultado de um pedido cuja confirmação não foi recebida:

$\forall E B_{a}, E B_{n} \in$ conj-EB,$U M \in \operatorname{UMovel}\left(E B_{a}\right) \cdot$

$E B_{a} \neq E B_{n} \wedge \exists$ Proxy $\in \operatorname{Proxy}(U M)$.

enviar(Proxy, $E B_{a}$, forwardresult) $\wedge$

$\neg$ receber(UM, $E B_{a}$, forwardresult) $\wedge$

○ handoff $(U M) \wedge U M \in U M \operatorname{Uovel}\left(E B_{n}\right) \Rightarrow$

$\diamond$ enviar(Proxy, $E B_{n}$, forwardresult)

Assim que o período do handoff se inicia, ou seja, quando a unidade móvel envia uma mensagem greet para a nova estação base (1), a unidade móvel fica inativa, não podendo mais enviar e receber mensagens (2). Para garantir que o resultado de um pedido enviado pelo proxy chegue à unidade móvel, assim que o período do handoff termina (3) e a mensagem update chega ao Proxy, este reenvia todos os resultados de pedidos enviados e cuja confirmação não foi recebida (4).

Prova:

\begin{tabular}{|c|c|c|}
\hline & $\begin{aligned} & \forall E B_{a}, E B_{n}, E B_{p} \in \operatorname{conj}-E B, U M \in \operatorname{Umovel}\left(E B_{a}\right) \cdot \\
& E B_{a} \neq E B_{b} \wedge \exists \operatorname{Proxy} \in \operatorname{Proxy}(U M)\end{aligned}$ & \\
\hline (1) & enviar $\left(U M, E B_{n}\right.$, greet $) \Rightarrow$ Ohandoff(UM) & $\begin{array}{r}\text { linha } 035 \text { do } \\
\text { Apêndice C e } \\
\text { Hipótese } 9 \\
\end{array}$ \\
\hline (2) & handoff $(U M) \Rightarrow(\neg$ enviar $(U M, E B, M) \wedge \neg \operatorname{receber}(U M, E B, M))$ & $\begin{array}{r}\text { Propriedade } 1 \text { do } \\
\text { handoff }\end{array}$ \\
\hline & enviar $\left(U M, E B_{n}\right.$, greet $) \Rightarrow \diamond \operatorname{receber}\left(E B_{n}, U M\right.$, greet $)$ & Hipótese 7 \\
\hline & receber $\left(E B_{n}, U M\right.$, greet $) \Rightarrow \diamond$ enviar $\left(E B_{n}, E B_{a}\right.$, dereg $)$ & $\begin{array}{r}\text { linhas } 022,023 \text { do } \\
\text { Apêndice C }\end{array}$ \\
\hline & enviar $\left(E B_{n}, E B_{a}\right.$, dereg $) \Rightarrow \diamond \operatorname{receber}\left(E B_{a}, E B_{n}\right.$, dereg $)$ & Hipótese 7 \\
\hline & receber $\left(E B_{a}, E B_{n}\right.$, dereg $) \Rightarrow \diamond$ enviar $\left(E B_{a}, E B_{n}\right.$, deregAck $)$ & $\begin{array}{r}\text { linhas } 018,020 \text { do } \\
\text { Apêndice C } \\
\end{array}$ \\
\hline & $\begin{aligned} \text { enviar }\left(E B_{a}, E B_{n}, \text { deregAck }\right) \Rightarrow & \\
& \text { ○receber }\left(E B_{n}, E B_{a}, \text { deregAck }\right)\end{aligned}$ & Hipótese 7 \\
\hline & receber $\left(E B_{n}, E B_{a}\right.$, deregAck $) \Rightarrow \diamond$ enviar $\left(E B_{n}, E B_{p}\right.$, update $)$ & linhas 024,026 do \\
\hline
\end{tabular}




\begin{tabular}{|c|c|c|}
\hline & & Apêndice C \\
\hline & enviar $\left(E B_{n}, E B_{p}\right.$, update $) \Rightarrow \diamond \operatorname{receber}\left(E B_{p}, E B_{n}\right.$, update $)$ & Hipótese 7 \\
\hline & receber $\left(E B_{p}, E B_{n}\right.$, update $) \Rightarrow \diamond$ enviar $\left(E B_{p}\right.$, Proxy, update $)$ & linhas 027,028 do \\
\hline & & Apêndice C \\
\hline (3) & enviar $\left(E B_{p}\right.$, Proxy, update $) \Rightarrow$ & Hipótese 7 \\
\hline & Oreceber(Proxy, $E B_{p}$, update) & \\
\hline (4) & receber(Proxy, $E B_{p}$, update) $\Rightarrow$ & linhas 011,013 do \\
\hline & จresponder(Proxy, $E B_{p}$, forwardresult) & Apêndice C \\
\hline & enviar(Proxy, $E B_{a}$, forwardresult) $\wedge$ & \\
\hline & $\neg$ receber $\left(U M, E B_{a}\right.$, forwardresult $) \wedge$ & \\
\hline & ○ handoff $(U M) \wedge U M \in U M \operatorname{Uovel}\left(E B_{n}\right) \Rightarrow$ & \\
\hline & $\diamond$ enviar(Proxy, $E B_{n}$, forwardresult $)$ & 므 \\
\hline
\end{tabular}

4. Após o handoff, cada UM ativa está sob o domínio de uma única EB:

$\forall U M \in$ conj-UM .

$\diamond$ handoff $(U M) \Rightarrow \exists ! E B \in \operatorname{conj}-E B$.

$(U M \in U M o v e l(E B) \wedge$ ativo $(U M))$

No início do sistema, cada unidade móvel está sob o domínio de uma única estação base (1) e somente no período do handoff poderia acontecer duplicidade de domínio. No entanto, no período do handoff que se inicia com o envio da mensagem greet da unidade móvel para a nova estação base (2), a unidade móvel envia, junto com a mensagem, o endereço da estação base antiga. Na comunicação da nova estação base com a estação base antiga, a estação base nova solicita o endereço de proxy da unidade móvel para a estação base antiga (3) e esta envia este endereço para a nova estação base (4) e exclui a unidade móvel de sua lista de unidades móveis (5). A nova estação base recebe este endereço (6) e inclui a unidade móvel em sua lista de unidades móveis (7). Como a inclusão da unidade móvel na nova estação base somente acontece depois de sua exclusão na estação base antiga (8), então a unidade móvel continua sob o domínio de uma única estação base (9).

Prova:

$\forall U M \in c o n j-U M, E B_{a}, E B_{n}, E B_{p} \in c o n j-E B$, Proxy $\in$ conj-Proxy .

(1) $\exists ! E B_{a} \in$ conj-EB $-U M \in$ Umovel $_{0}\left(E B_{a}\right)$.

(2) enviar $\left(U M, E B_{n}\right.$, greet $) \Rightarrow$ Ohandoff $(U M) \quad$ linha 035 do

Apêndice $\mathrm{C}$ e

\begin{tabular}{llr}
\hline & enviar $\left(U M, E B_{n}\right.$, greet $) \Rightarrow \diamond \operatorname{receber}\left(E B_{n}, U M\right.$, greet $)$ & Hipótese 9 \\
\hline (3) & receber $\left(E B_{n}, U M\right.$, greet $) \Rightarrow \diamond$ enviar $\left(E B_{n}, E B_{a}\right.$, dereg $)$ & Hipótese 7 \\
\hline & enviar $\left(E B_{n}, E B_{a}\right.$, dereg $) \Rightarrow \diamond \operatorname{receber}\left(E B_{a}, E B_{n}\right.$, dereg $)$ & linhas 022, 023 do \\
Apêndice C \\
\hline (4) $\quad$ receber $\left(E B_{a}, E B_{n}\right.$, dereg $) \Rightarrow\left(\diamond\right.$ enviar $\left(E B_{a}, E B_{n}\right.$, deregAck $)$ & Hipótese 7 \\
$\wedge$ & linhas 018, 020, & 021 do Apêndice \\
\hline
\end{tabular} 


\begin{tabular}{|c|c|c|}
\hline \multirow[t]{3}{*}{$(5)$} & $\left.\diamond \operatorname{apagar}\left(U M, E B_{a}\right)\right)$ & $\mathrm{C}$ \\
\hline & enviar $\left(E B_{a}, E B_{n}\right.$, deregAck $) \Rightarrow$ & Hipótese 7 \\
\hline & $\diamond$ receber $\left(E B_{n}, E B_{a}\right.$, deregAck $)$ & \\
\hline$(6)$ & receber $\left(E B_{n}, E B_{a}\right.$, deregAck $) \Rightarrow$ & linhas 024,025 do \\
\hline (7) & $\diamond$ incluir $\left(U M, E B_{n}\right)$ & Apêndice C \\
\hline (8) & $\diamond \operatorname{apagar}\left(U M, E B_{a}\right) \wedge \diamond \operatorname{incluir}\left(U M, E B_{n}\right) \Rightarrow$ & \\
\hline (9) & $U M \notin U M o v e l\left(E B_{a}\right) \wedge U M \in U M \operatorname{Movel}\left(E B_{n}\right)$ & \\
\hline & $\begin{array}{l}\diamond \text { handoff }(U M) \Rightarrow \\
\quad \exists ! E B \in \operatorname{conj}-E B \cdot(U M \in U M \operatorname{Movel}(E B) \wedge \operatorname{ativo}(U M))\end{array}$ & 口 \\
\hline
\end{tabular}

\subsubsection{Propriedades do RDP}

1. Cada UM pode se comunicar somente com a EB em cujo domínio está incluída:

$\forall U M \in$ conj-UM, $E B \in$ conj-EB .

$(\operatorname{receber}(U M, E B, M) \vee$ enviar $(U M, E B, M)) \Rightarrow$

$U M \in$ conj-UMovel $(E B)$

A unidade móvel se comunica somente com a estação base responsável por ela e as comunicações que envolvem uma unidade móvel são somente quatro: quando a unidade móvel está migrando e envia a mensagem greet (1) para a nova estação base; quando a unidade móvel faz um novo pedido, com a mensagem request (2), e a envia para a estação base responsável por ela para que esta encaminhe para o proxy da unidade móvel; quando a unidade móvel recebe o resultado do pedido da estação base responsável por ela, com a mensagem forwardresult (3); e quando a unidade móvel envia uma mensagem de recebimento do resultado do pedido, com a mensagem forwresAck (4), para a estação base responsável por ela encaminhar para o proxy.

Prova:

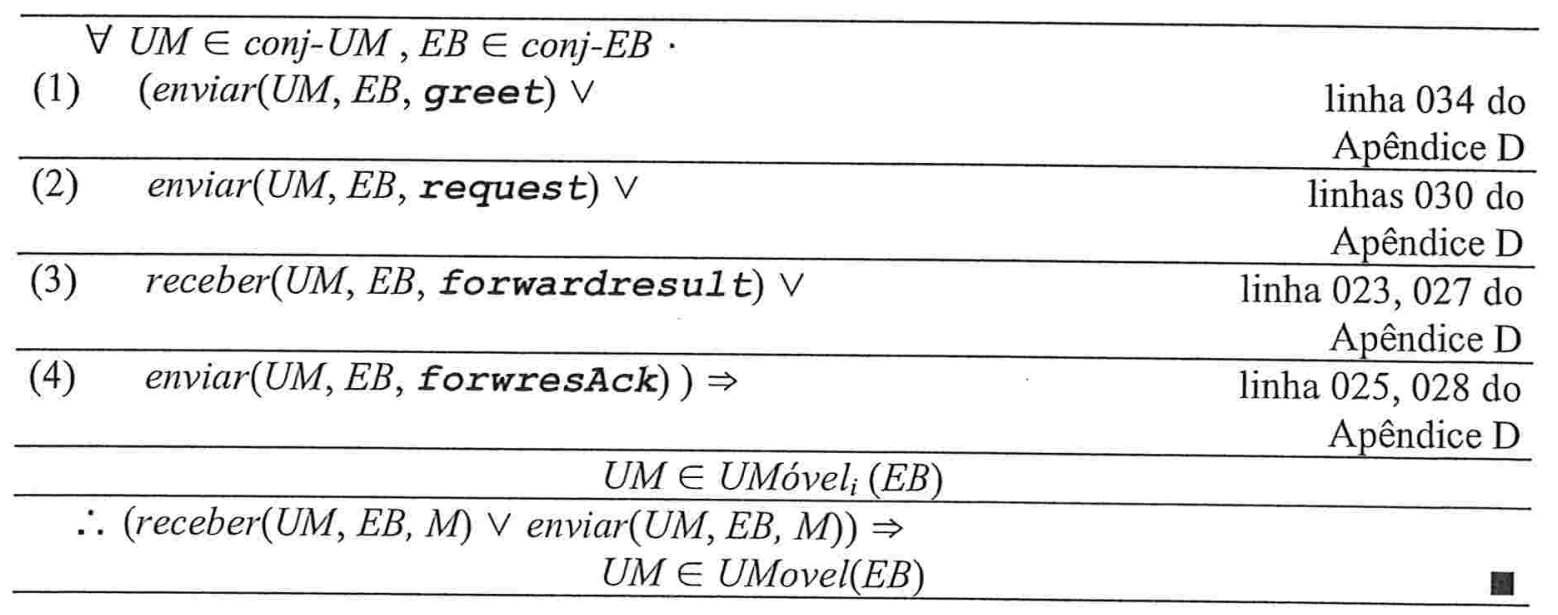


2. Nenhuma mensagem espontânea é gerada:

$\forall m_{1}$ e $m_{2} \in($ conj-UM $\cup$ conj-EB $\cup$ conj-Proxy $) \cdot$ $\operatorname{receber}\left(m_{1}, m_{2}, M\right) \Rightarrow \diamond \operatorname{enviar}\left(m_{2}, m_{1}, M\right)$

Como as mensagens que estão envolvidas no sistema são as que estão nos conjuntos de mensagens do RDP e do handoff, conj-Mens-RDP e conj-Mens-Hand, e para cada uma destas mensagens existe um elemento que envia a mensagem, então nenhuma mensagem espontânea é gerada.

Prova:

\begin{tabular}{|c|c|}
\hline $\begin{array}{l}\forall m_{1} \text { e } m_{2} \in(\text { conj-UM } \cup \text { conj-EB } \cup \text { conj-Proxy }) \cdot \\
\quad\left(\text { enviar }\left(m_{1}, m_{2}, \text { greet }\right)\right.\end{array}$ & $\begin{array}{l}\text { linha } 034 \text { do } \\
\text { Apêndice D } \\
\end{array}$ \\
\hline enviar $\left(m_{1}, m_{2}\right.$, dereg $)$ & $\begin{array}{l}\text { linha } 062 \text { do } \\
\text { Apêndice D } \\
\end{array}$ \\
\hline enviar $\left(m_{1}, m_{2}\right.$, deregAck) & $\begin{array}{l}\text { linha } 059 \text { do } \\
\text { Apêndice D } \\
\end{array}$ \\
\hline enviar $\left(m_{1}, m_{2}\right.$, update $)$ & $\begin{array}{r}\text { linhas } 066 \text { do } \\
\text { Apêndice D } \\
\end{array}$ \\
\hline enviar $\left(m_{1}, m_{2}\right.$, update $)$ & $\begin{array}{r}\text { linha } 068,072 \text { do } \\
\text { Apêndice D } \\
\end{array}$ \\
\hline enviar $\left(m_{1}, m_{2}\right.$, forwardresult $)$ & $\begin{array}{r}\text { linhas } 110 \text { do } \\
\text { Apêndice D } \\
\end{array}$ \\
\hline enviar $\left(m_{1}, m_{2}\right.$, forwardresult $)$ & $\begin{array}{r}\text { linhas } 046,049 \text { do } \\
\text { Apêndice D } \\
\end{array}$ \\
\hline enviar $\left(m_{1}, m_{2}\right.$, forwardresult $)$ & $\begin{array}{l}\text { linha } 094 \text { do } \\
\text { Apêndice D } \\
\end{array}$ \\
\hline enviar $\left(m_{1}, m_{2}\right.$, forwardresult $)$ & $\begin{array}{r}\text { linhas } 081,084 \text { do } \\
\text { Apêndice D } \\
\end{array}$ \\
\hline enviar $\left(m_{1}, m_{2}\right.$, forwresAck) & $\begin{array}{r}\text { linha } 025,028 \text { do } \\
\text { Apêndice D } \\
\end{array}$ \\
\hline enviar $\left(m_{1}, m_{2}\right.$, forwresAck) & $\begin{array}{r}\text { linhas } 088,092 \text { do } \\
\text { Apêndice D } \\
\end{array}$ \\
\hline enviar $\left(m_{1}, m_{2}\right.$, forwresAck) & $\begin{array}{l}\text { linha } 101 \text { do } \\
\text { Apêndice D } \\
\end{array}$ \\
\hline enviar $\left(m_{1}, m_{2}\right.$, request $)$ & $\begin{array}{r}\text { linhas } 030 \text { do } \\
\text { Apêndice D } \\
\end{array}$ \\
\hline enviar $\left(m_{1}, m_{2}\right.$, request $)$ & $\begin{array}{r}\text { linhas } 075 \text { do } \\
\text { Apêndice D } \\
\end{array}$ \\
\hline enviar $\left(m_{1}, m_{2}\right.$, request $)$ & $\begin{array}{r}\text { linha } 073,077 \text { do } \\
\text { Apêndice D } \\
\end{array}$ \\
\hline enviar $\left(m_{1}, m_{2}\right.$, request $)$ & $\begin{array}{l}\text { linha } 054 \text { do } \\
\text { Apêndice D } \\
\end{array}$ \\
\hline
\end{tabular}


$\Rightarrow \operatorname{receber}\left(m_{1}, m_{2}, M\right) \Rightarrow \diamond \operatorname{enviar}\left(m_{2}, m_{1}, M\right)$

$\therefore \operatorname{receber}\left(m_{1}, m_{2}, M\right) \Rightarrow \otimes \operatorname{enviar}\left(m_{2}, m_{1}, M\right)$

3. O resultado de um pedido é sempre entregue:

$\forall E B_{a}, E B_{n} \in$ conj-EB,$U M \in U M$ Movel $\left(E B_{a}\right)$.

$E B_{a} \neq E B_{b} \wedge \exists$ Proxy $\in \operatorname{Proxy}(U M)$.

enviar(Proxy, $E B_{a}$, forwardresult $) \Rightarrow$

$\diamond \operatorname{receber}\left(U M, E B_{a}\right.$, forwardresult $) \vee$

$\left(\odot\right.$ handoff $(U M) \wedge U M \in U M \operatorname{Movel}\left(E B_{n}\right) \wedge$

$\diamond$ enviar(Proxy, $E B_{n}$, forwardresult))

Como a comunicação entre dois elementos do sistema é confiável, então uma mensagem enviada sempre chega ao seu destinatário. Então se o resultado do pedido for enviado do servidor para o proxy (1) e depois enviado do proxy para a unidade móvel, passando pelas respectivas estações bases, e se esta não estiver no período de handoff (2), então a unidade móvel receberá o resultado do pedido (3). Se a unidade móvel estiver no período de handoff (4), então ela não receberá o resultado (5) mas assim que o handoff estiver terminado, o proxy reenvia o resultado do pedido para a unidade móvel (6). Assim, o resultado de um pedido é sempre entregue para a unidade móvel.

Prova:

\begin{tabular}{|c|c|c|}
\hline (1) & $\begin{array}{c}\forall E B_{a}, E B_{n}, E B_{p} \in \text { conj-EB }, U M \in U M o v e l\left(E B_{a}\right) \\
E B_{a} \neq E B_{n} \wedge \exists \operatorname{Proxy} \in \operatorname{Proxy}(U M) \\
\text { enviar }(\text { Servidor, Proxy, forwardresul } t)\end{array}$ & $\begin{array}{l}\text { linha } 110 \text { do } \\
\text { Apêndice D }\end{array}$ \\
\hline & $\begin{array}{l}\text { enviar(Servidor, Proxy, forwardresul } t) \Rightarrow \\
\qquad \text { receber(Proxy, Servidor, forwardresult) }\end{array}$ & Hipótese 7 \\
\hline & $\begin{array}{c}\text { receber(Proxy, Servidor, forwardresult) } \Rightarrow \\
\text { ○reponder(Proxy, } E B_{p} \text {, forwardresult) }\end{array}$ & $\begin{array}{r}\text { linhas } 044,046, \\
047,049 \text { do } \\
\text { Apêndice D } \\
\end{array}$ \\
\hline & $\begin{aligned}\left.\text { enviar(Proxy, } E B_{p}, \text { forwardresult }\right) \Rightarrow & \\
& \text { } \text { receber }\left(E B_{p}, \text { Proxy, forwardresult }\right)\end{aligned}$ & Hipótese 7 \\
\hline & $\begin{aligned} \text { receber }\left(E B_{p}, \text { Proxy, }\right. & \text { forwardresult }) \Rightarrow \\
& \diamond \text { enviar }\left(E B_{p}, E B_{a}, \text { forwardresult }\right)\end{aligned}$ & $\begin{array}{r}\text { linhas 093, } 094 \text { do } \\
\text { Apêndice D } \\
\end{array}$ \\
\hline & $\begin{aligned} \text { enviar }\left(E B_{p}, E B_{a}, \text { forwardresult }\right) \Rightarrow & \\
& \quad \text { receber }\left(E B_{a}, E B_{p}, \text { forwardresult }\right)\end{aligned}$ & Hipótese 7 \\
\hline \multicolumn{3}{|c|}{ (2) Se não estava em handoff } \\
\hline & receber $\left(E B_{a}, E B_{p}\right.$, forwardresult $) \Rightarrow$ & $\begin{array}{r}\text { linha } 078,082 \text { do } \\
\text { Apêndice D }\end{array}$ \\
\hline & ๖enviar $\left(E B_{a}, U M\right.$, forwardresult $)$ & $\begin{array}{r}\text { linha } 081,084 \text { do } \\
\text { Apêndice D } \\
\end{array}$ \\
\hline (3) & $\begin{aligned} \text { enviar }\left(E B_{a}, U M, \text { forwardresul } t\right) \Rightarrow & \\
& \diamond \text { receber }\left(U M, E B_{a}, \text { forwardresult }\right)\end{aligned}$ & Hipótese 7 \\
\hline
\end{tabular}




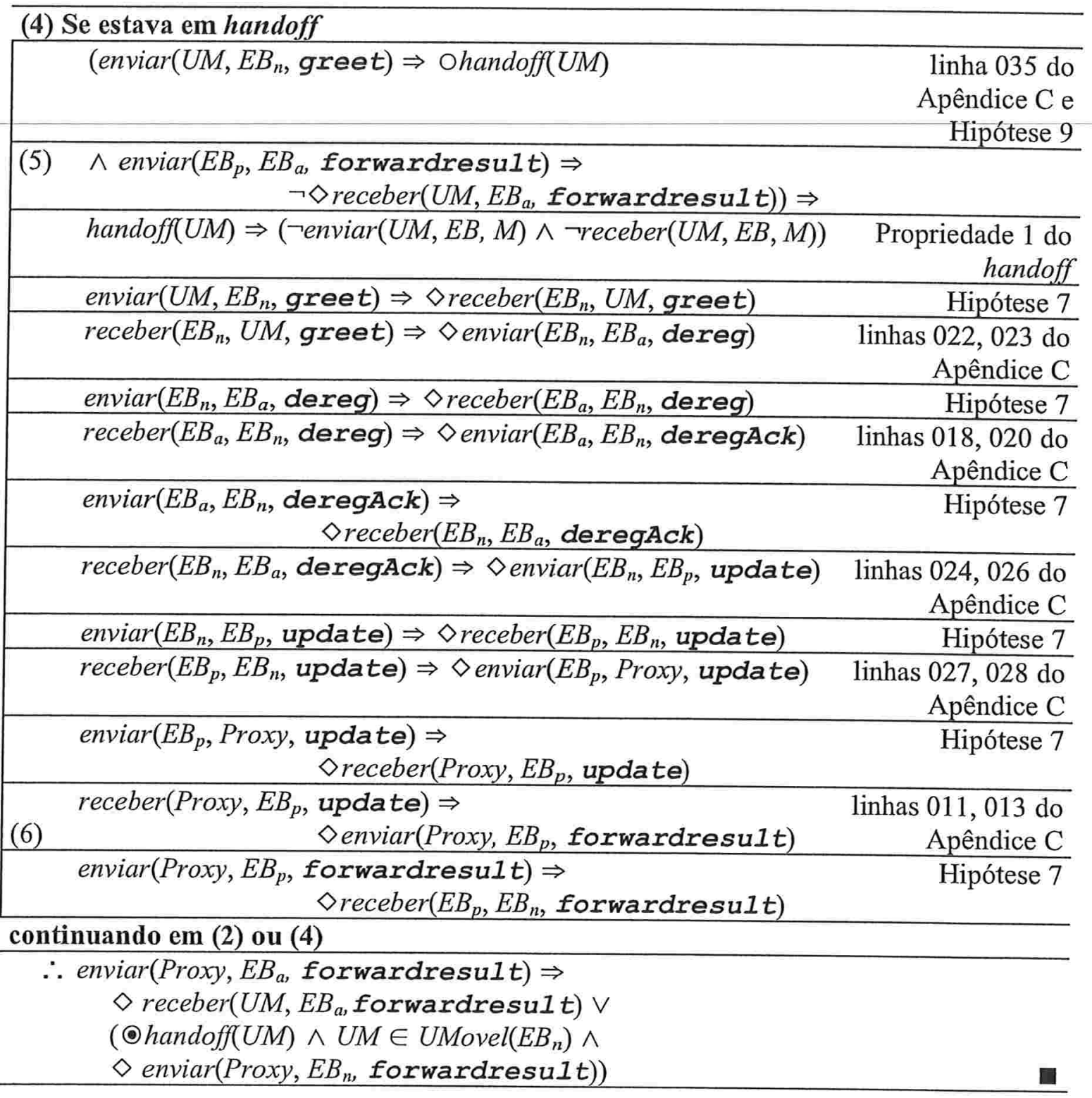

4. Uma mensagem enviada é sempre entregue:

$\forall m_{1}$ e $m_{2} \in($ conj-UM $\cup$ conj-EB $\cup$ conj-Proxy $)$. $\operatorname{enviar}\left(m_{1}, m_{2}, M\right) \Rightarrow \diamond \operatorname{receber}\left(m_{2}, m_{1}, M\right)$

Como para todas as mensagens envolvidas no sistema existe um elemento que envia estas mensagens (1) e como a comunicação entre cada dois elementos é confiável (2), então uma mensagem enviada é sempre entregue.

Prova: 


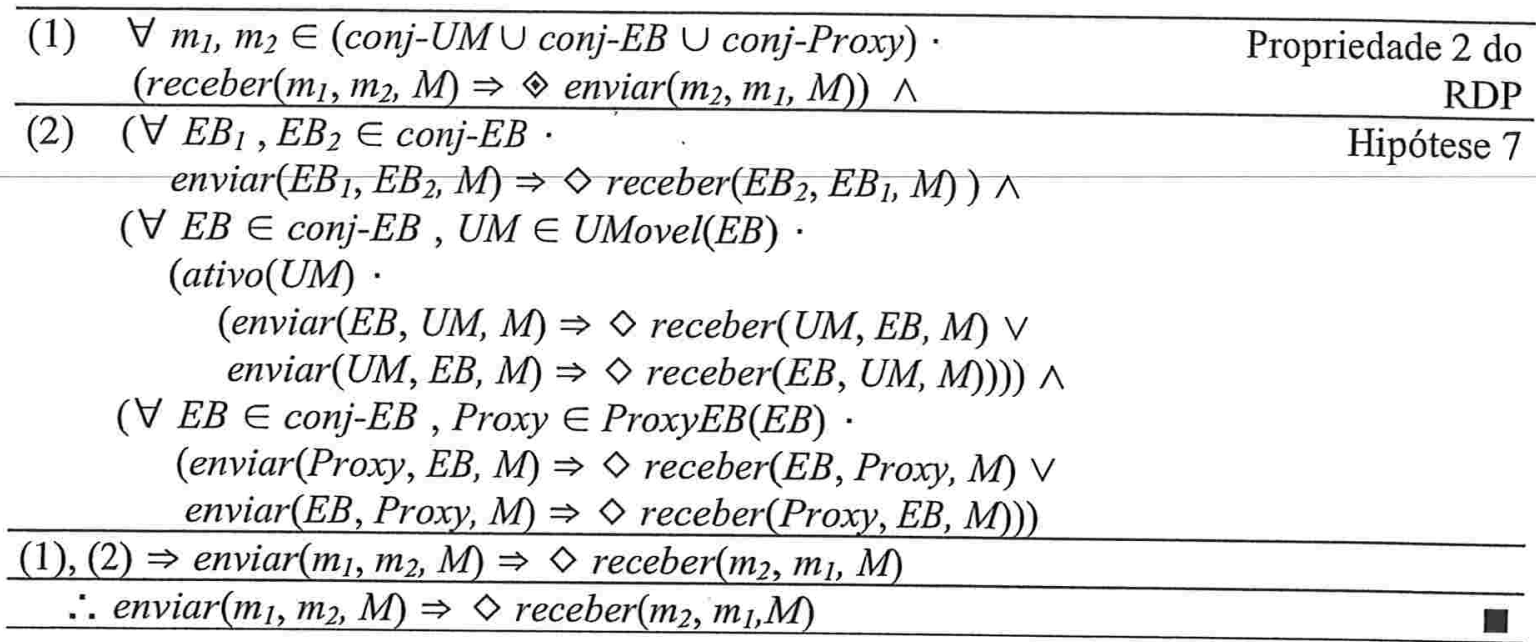

\subsection{Análise do uso do distributed join-calculus para a prova das propriedades}

A especificação do protocolo no distributed join-calculus foi utilizada para auxiliar na análise das propriedades inerentes ao protocolo. Para a análise das propriedades utilizamos: a lógica temporal para aplicarmos os operadores temporais, os conectivos boleanos e os quantificadores; e a especificação do protocolo no distributed join-calculus para verificarmos se determinada propriedade é ou não satisfeita pelo protocolo especificado.

Inicialmente tínhamos a expectativa de uma ferramenta que ajudasse nas provas, conforme mencionado pelos autores do join-calculus, mas acabamos fazendo as provas manualmente, dado que as ferramentas ainda não estão prontas.

Da lógica temporal determinamos as fórmulas temporais, conjuntos, funções e predicados do sistema necessários para a prova. Tentamos minimizar a quantidade de cada um deles, colocando somente os necessários, principalmente, para os predicados do sistema, para facilitar o processo de prova das propriedades.

Utilizamos as hipóteses do protocolo e RDP escritas na lógica temporal para provar as propriedades, mas utilizamos também a especificação dos protocolos no distributed joincalculus.

Como utilizamos a especificação do protocolo no distributed join-calculus para as provas das propriedades, fizemos uma tabela que caracteriza cada comando da especificação no distributed join-calculus para a lógica temporal descrita para a prova das propriedades. Essa tabela está no Apêndice C para o protocolo handoff e no Apêndice D para o protocolo RDP. 
Assim, quando precisamos da especificação no distributed join-calculus para provar as propriedades, caminhamos pela especificação, passo a passo. Como a propriedade está sendo provada usando a lógica temporal, a tabela facilita no entendimento do processo de prova da propriedade.

Se fizéssemos a prova de uma propriedade, que necessita o uso da especificação, usando a especificação na lógica temporal sem a tabela, seria mais fácil cometer erros durante a prova e ficaria mais difícil de entendê-la posteriormente.

Além disso, como o distributed join-calculus trata as localidades como uma subsolução de uma solução maior, que é o sistema, a prova de suas propriedades foi simplificada, pela facilidade de perceber quando ocorre uma comunicação, uma migração e uma reação.

\subsection{Conclusão}

Neste capítulo sobre a análise do RDP, introduzimos a lógica temporal necessária para a prova das propriedades definindo os conjuntos pré-definidos, funções e predicados do sistema.

As hipóteses e propriedades dos protocolos handoff e RDP foram, dessa foram, escritas na lógica temporal e a análise dessas propriedades foi realizada no uso conjunto da lógica temporal, da especificação dos protocolos no distributed join-calculus e das hipóteses.

Dentre as hipóteses consideradas neste trabalho, algumas foram extraídas do artigo original que descreve o protocolo RDP, outras foram incluídas para facilitar a prova das propriedades sem que afetassem efetivamente o comportamento do protocolo no propósito de nossa análise e outras foram modificadas, pois não concordamos que foram consideradas como hipóteses e sim como propriedades.

Concluímos, a partir desta análise, que todas as propriedades analisadas foram satisfeitas pelos protocolos. 


\section{Capítulo 5 - Implementação do RDP}

Além da especificação no cálculo, implementamos o RDP na linguagem do distributed join-calculus para que pudéssemos simular o comportamento do protocolo.

Neste capítulo, escrevemos o protocolo handoff e o RDP na linguagem do distributed joincalculus. Para isso, usaremos a sintaxe da linguagem do distributed join-calculus apresentada na Figura 11 do Apêndice B.

\subsection{Implementação do protocolo Handoff}

Nesta seção, apresentaremos uma implementação simplificada e restrita do protocolo handoff na linguagem do distributed join-calculus, para um melhor entendimento do funcionamento da linguagem. Posteriormente, a implementação completa do protocolo será apresentada com uma explicação menos detalhada. O resultado da simulação desta implementação no Apêndice E.

\subsubsection{Implementação particular do protocolo handoff}

Para a especificação que se segue, consideramos uma EBo, uma EBn, uma EBp, que é a estação base onde está o proxy, uma UM e um proxy. O que queremos especificar é a mobilidade da UM da EBo para a EBn que é controlado pelo protocolo handoff. Consideramos também as demais hipóteses do modelo apresentados na Seção 3.3.

Para o nosso exemplo inicial consideraremos que o proxy, está sempre com a EBp, ou seja, nunca é destruído. Inicialmente, a UM estará dentro da célula que é definido pela EBo, ou seja, a EBo já é a responsável pela UM e sua identificação já consta da estrutura de dados (UM_local) da EBo. A UM ficará inativa somente no período do handoff, ou seja, quando a UM está migrando entre células.

Vamos especificar o movimento da UM da célula 1 para a célula $\mathrm{a}_{2}$, respectivamente definidos pela EBo e EBn. Quando a UM entra numa nova célula, envia uma mensagem greet com uma variável oldEB, onde oldEB é a identidade da EB recém-deixada pela UM, para a $\mathrm{EBn}$, o que define a nova célula. É o envio da mensagem greet que inicia o protocolo handoff.

Especificação da EBo

A especificação no distributed join-calculus é a seguinte: 
Esta declaração define o nome da localidade EB_old (*0) e um canal, EBo_antiga (*1), que podem ser utilizados dentro da localidade e nas demais declarações.

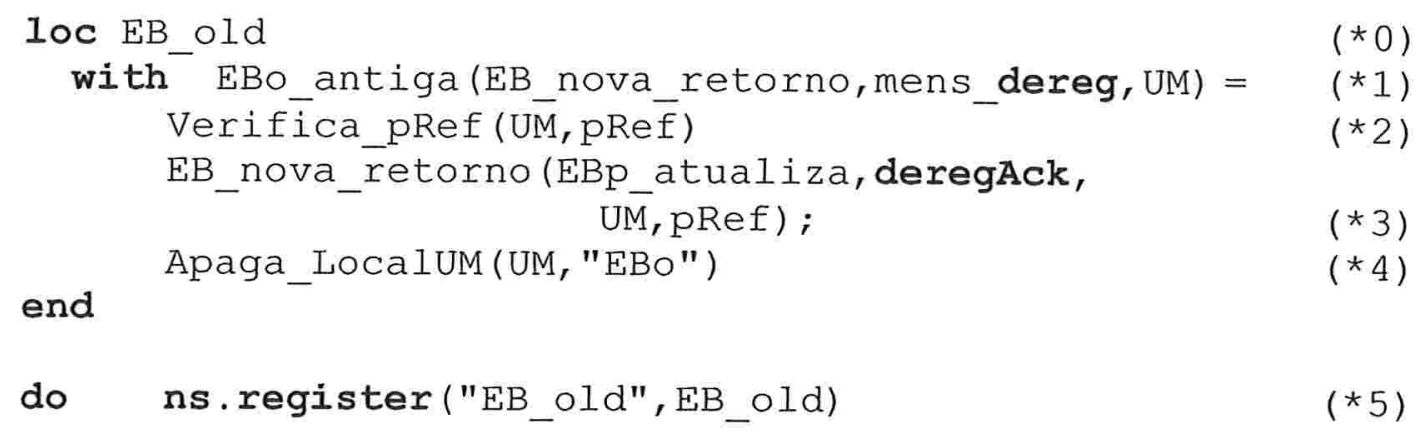

do ns.register("EB_old", EB_old)

Quando a UM migra da EBo para a EBn, a EBo recebe uma mensagem, dereg (*1), da EBn, solicitando a referência de proxy, pRef, da UM e que a EBo retire o registro da UM. Então, a EBo verifica a pRef da UM (*2), retorna uma mensagem, deregAck, contendo o pRef da UM (*3), para a EBn e apaga a UM da sua lista UM_Iocal (*4).

A localidade criada "EB_old" foi registrada no nome de servidor EB_old (*5) que será usada como um endereço de destino para o nosso agente móvel UM.

\section{Especificação da EBn}

A especificação no distributed join-calculus é a seguinte:

Esta declaração define o nome da localidade EB_new $(* 0)$ e dois canais, EBn_nova_inicial (*1) e EBn_nova_retorno (*⿻一乛]), que podem ser utilizados dentro da localidade e nas demais declarações.

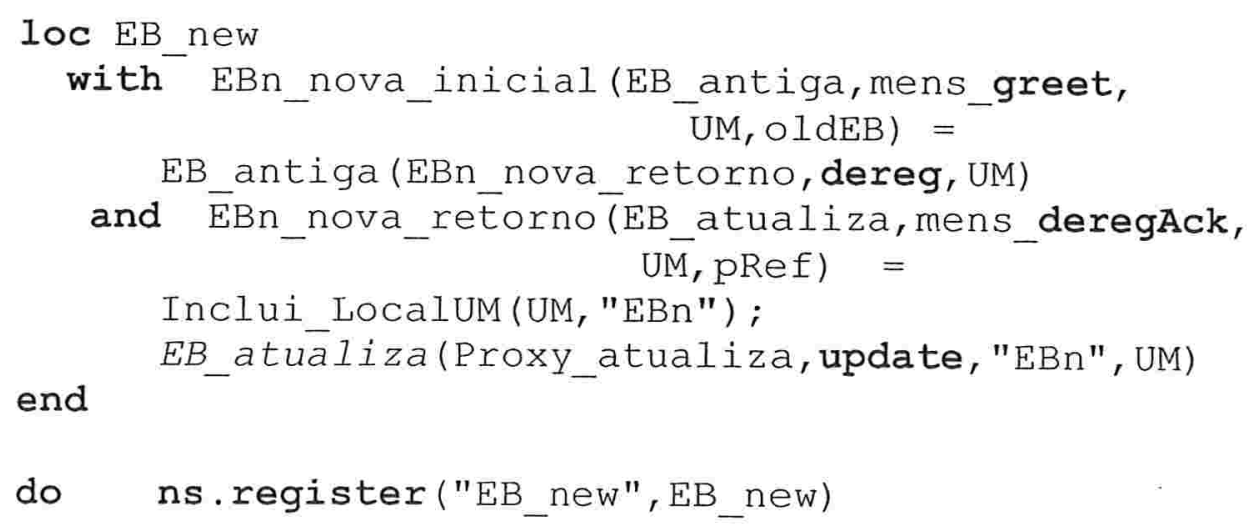


Quando a UM migra da EBo para a EBn, a EBn recebe uma mensagem, greet (*1), da UM. Então, a EBn envia para a EBo uma mensagem, dereg (*2), solicitando a referência de proxy da UM e a retirada do seu registro de acesso.

Quando a EBn recebe da EBo a mensagem de reconhecimento, deregAck (*3), com o pRef da UM, a responsabilidade da UM agora passa a ser da EBn, além disso, a EBn inclui a UM na sua lista UM_Iocal (*4) e atualiza a localização da UM junto ao seu proxy enviando uma mensagem update, com a LocCorr e o pRef, para a EBp (*5).

A localidade criada "EB_new" foi registrada no nome de servidor EB_new (*6) que será usada como um endereço de destino para o nosso agente móvel UM.

\section{Especificação da UM}

A especificação no distributed join-calculus é a seguinte:

Esta declaração define o nome da localidade mobile_host $\left({ }^{*} 0\right)$, que é o nosso agente móvel.

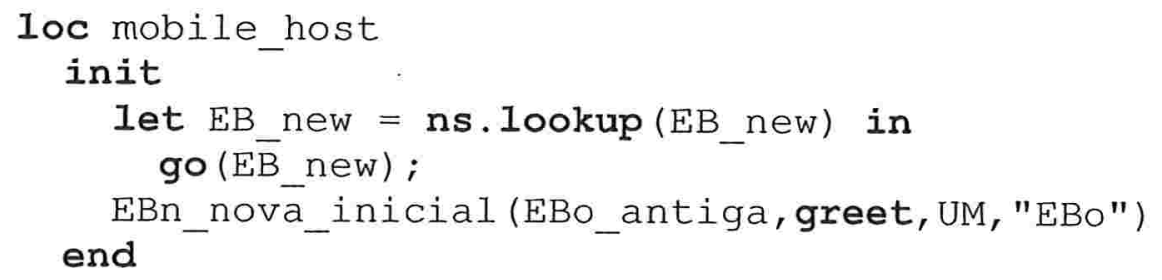

do

$$
\text { ns.register("mobile_host", mobile_host) }
$$

A princípio, a UM está na célula que é definida pela EBo. Quando a UM muda de célula, ela envia uma mensagem greet, com a identificação da $\mathrm{EB}$ em que estava (EBo), para a EB que define a nova célula $(\mathrm{EBn})(* 3)$. A partir deste momento, a UM só responde a mensagens da nova EB.

A localidade criada "mobile_host" obtém o nome EB_new, por ns.10okup (EB_new) (*1) e então migra sua localidade para dentro de "EB_new", por go (EB_new) (*2). Uma vez migrado, ele desenvolve a computação atual.

A primitiva go(EB_new) migra toda a localidade "mobile_host" para "EB_new", como uma sublocalidade da localidade "EB_new". A localidade criada "mobile_host" foi registrada no nome de servidor mobile_host (*4) que será usada como um endereço de referência para as estações base. 


\section{Especificação da EBp}

A especificação no distributed join-calculus é a seguinte:

Esta declaração define o nome da localidade EB_proxy $\left({ }^{*} 0\right)$ e um canal, EBP_atualiza, que pode ser utilizado dentro da localidade e nas demais declarações.

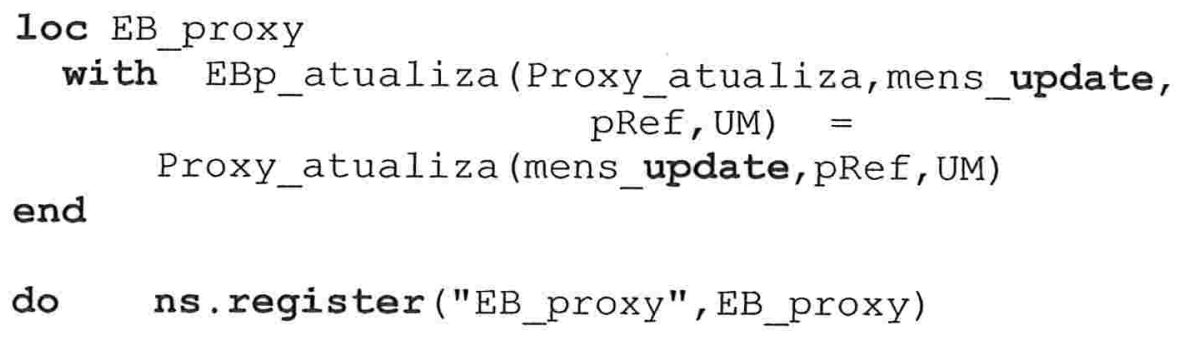

Quando a UM migra de uma célula para outra, a EBp recebe uma mensagem update, com a nova localidade pRef (*1), da EB que define a nova célula com a nova localização da UM, para que a EBp possa atualizar no proxy a nova localidade da UM (*2).

A localidade criada "EB_proxy" foi registrada no nome de servidor EB_proxy (*3) que será usada como um endereço de localização do proxy pelas estações base.

\section{Especificação do Proxy}

A especificação no distributed join-calculus é a seguinte:

Esta declaração define o nome da localidade Proxy (*0) e um canal, Proxy_atualiza, que pode ser utilizado dentro da localidade e nas demais declarações.

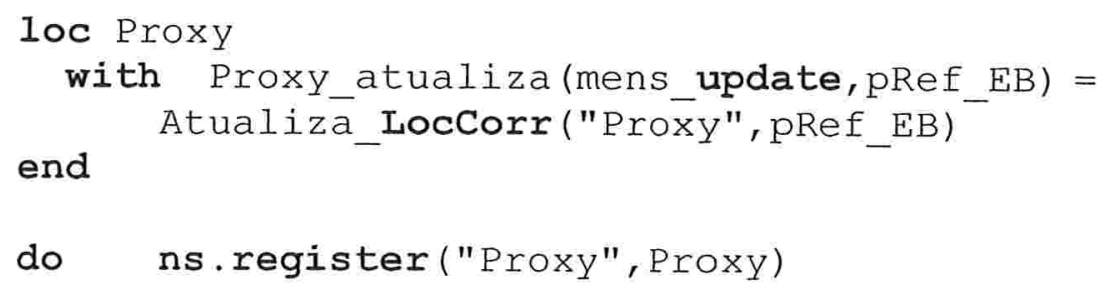

Quando a EBp recebe a mensagem update, ela envia esta mensagem para o proxy, juntamente com a nova localidade, pRef_EB, da UM. Quando o proxy recebe a mensagem update (*1), ele atualiza a localidade atual da UM (*2).

A localidade criada "Proxy" foi registrada no nome de servidor Proxy (*3) que será usada como um endereço de localização do proxy pelas estações base. 


\subsubsection{Implementação geral do protocolo handoff}

Para a especificação que se segue, podemos considerar $n$ estações base, $m$ unidades móveis e $k$ proxies, todos aqueles que pertençam ao sistema, para $n, m, k>=1$ e $n, m, k \in \mathbb{N}$. As funções são únicas, mas para cada estação base, unidades móveis e proxies, haverá uma localidade, por exemplo, se há cinco unidades móveis no sistema, haverá cinco localidades loc EBn, onde n será o número de identificação de cada unidade móvel.

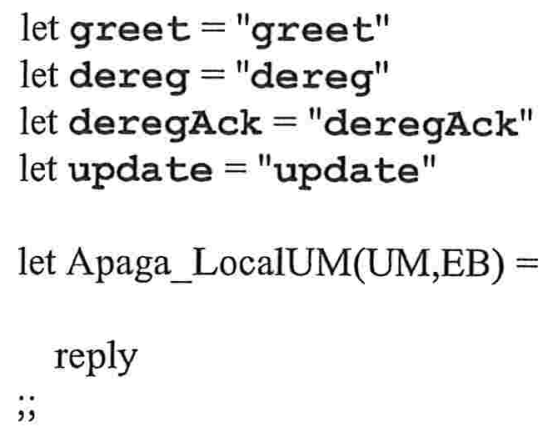

Esta função, considerada confiável, apaga a unidade móvel UM da lista local de unidades móveis (UM_local) da estação base EB.

let Inclui_LocalUM(UM,EB) =

reply

;

Esta função, considerada confiável, inclui a unidade móvel UM na sua lista local de unidades móveis (UM_local) da estação base EB.

let Verifica_pRef(UM,pRef) = reply $<$ pRef $>$ to $\mathrm{pRef}$ ;

Esta função, considerada confiável, verifica a pRef da unidade móvel e a retorna.

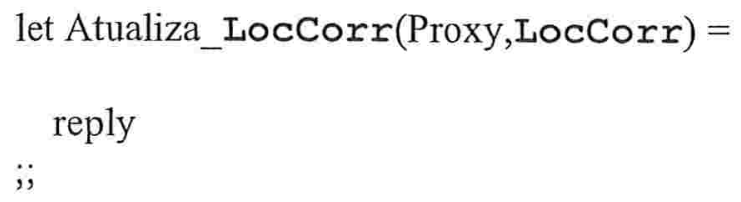

Esta função, considerada confiável, atualiza a localização atual da unidade móvel, que está na LocCorr, no Proxy. 
let Reenvia_pedidos(Proxy,, $\mathrm{UM})=$

reply

Esta função, considerada confiável, reenvia os resultados dos pedidos da unidade móvel que estão no Proxy e que não receberam confirmação de recebimento do resultado pela unidade móvel.

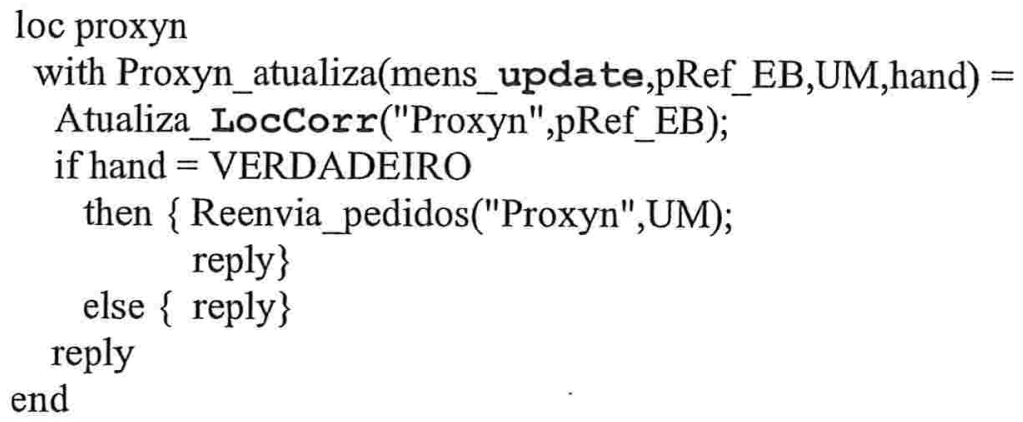

Esta função, considerada confiável, atualiza a localização atual da unidade móvel UM, ou seja, qual estação base é responsável pela UM. Ver itens 12 , ou 13 e 14 do diagrama do RDP sem handoff.

do ns.register("proxy",proxy)

;

loc EBn

with EBn_antiga(EB_nova_retorno,mens_dereg,UM,Proxy_atualiza) $=$

Verifica pRef(UM,pRef);

EB_nova_retorno(EBn_atualiza,deregAck,UM,pRef,Proxy_atualiza);

Apaga_LocalUM(UM,"EBn");

reply

Ver itens 4, 5, 6 do diagrama do handoff.

and EBn_nova_inicial(EB_antiga,mens_greet,UM,oldEB, Proxy_atualiza $)=$ EB_antiga(EBn_nova_retorno,dereg,UM,Proxy_atualiza); reply

Ver itens 2, 3 do diagrama do handoff.

and EBn_nova_retorno(EB_atualiza,mens_deregAck,UM,pRef,Proxy_atualiza $)=$ Inclui_LocalUM(UM,"EBn"

EB_atualiza(Proxyn_atualiza,update,"EBn",UM,VERDADEIRO); 
reply

Ver itens 7, 8, 9 do diagrama do handoff.

and EBn_atualiza(Proxy_atualiza,mens_update,pRef,UM,hand) = Proxy_atualiza(mens_update,pRef,UM,hand); reply

Ver itens 10, 11 do diagrama do handoff.

end

do ns.register("EBn",EBn)

;;

loc agente_moveln

init

let $\mathrm{EBx}=\mathrm{ns}$. lookup $(" \mathrm{EBx} ")$ in

go(EBx);

EBx_nova_inicial(EBy_antiga,greet,"UM1","EBy",Proxy1_atualiza); end

do ns.register("agente_moveln",agente_moveln)

;

\subsection{Implementação de partes necessárias do protocolo RDP}

Nesta seção, apresentaremos a implementação de partes necessárias do protocolo RDP. O resultado da simulação desta implementação está no Apêndice F.

let greet $=$ "greet"

let dereg = "dereg"

let deregAck = "deregAck"

let request = "request"

let forwardresult = "forwardresult"

let forwresAck = "forwresAck"

let update = "update"

let NULL $=0$

let VERDADEIRO $=0$

let FALSO $=1$

let ULTIMO $=0$

let Apaga_LocalUM(UM,EB) = 
reply

Mesmo que do handoff.

let Inclui_LocalUM(UM,EB) =

reply

;

Mesmo que do handoff.

let Verifica_pRef(UM,pRef) =

reply

;

Mesmo que do handoff.

let Cria_novo_proxy $(\mathrm{EB}, \mathrm{UM})=$

reply

;

Esta função, considerada confiável, cria um novo Proxy para a unidade móvel UM na Estação Base EB.

let Inclui_pedido_proxy(pedido,proxy) =

reply

;

Esta função, considerada confiável, inclui um novo pedido da unidade móvel, no Proxy.

let Processa_pedido(pedido $)=$

reply

;

Esta função, considerada confiável, processa o pedido da Unidade Móvel.

let Apaga_end_proxy(UM,proxy) = 
reply

;

Esta função, considerado confiável, apaga o endereço do Proxy na pRef da UM.

let Deleta_proxy $(\operatorname{Proxy}, \mathrm{UM})=$

reply

;

Esta função, considerada confiável, destrói o Proxy da unidade Móvel UM.

let Apaga_pedido_proxy(pedido,Proxy $)=$

reply

;

Esta função considerada confiável, apaga um pedido, cujo resultado foi entregue para a unidade móvel, da sua lista de pedidos (ListaPedidos).

let Atualiza_LocCorr(Proxy,LocCorr $)=$

reply

;

Esta função, considerada confiável, atualiza a localização atual da unidade móvel, que está na LocCorr, no Proxy.

let Reenvia_pedidos $(\operatorname{Proxy}, \mathrm{UM})=$

reply

;

Esta função, considerada confiável, reenvia os resultados dos pedidos da unidade móvel que estão no Proxy e que não receberam confirmação de recebimento do resultado pela unidade móvel.

loc UMn

with UMn_pedido(EB_ackp_UM,mens_forwardresult,pedido,EB,UM,RKpR) = if $\mathrm{RKpR}=$ VERDADEIRO

then \{ EB_ackp_UM(EBn_ackp_proxy,ackp,UM,VERDADEIRO,proxy); reply; \}

else \{EB_ackp_UM(EBn_ackp_proxy,ackp,UM,FALSO,proxy); reply; 
and UMn_novo_pedido(EB_novo_pedido,pedido,UM,proxy) $=$

EB_novo_pedido(request,pedido,UM,proxy) |

UMn_novo_pedido(EBn_novo_pedido,pedido,UM,proxy)

end

Ver itens 25, 26 do diagrama do RDP sem handoff.

do ns.register("UM",UM)

;

loc Proxyn

with Proxyn_atualiza(mens_update,pRef_EB,UM,hand) =

Atualiza_LocCorx("Proxyn",pRef_EB);

if hand = VERDADEIRO

then \{ Reenvia_pedidos("Proxyn",UM); reply\}

else $\{$ reply\}

Ver itens 12, 13, 14 do diagrama do RDP sem handoff.

and Proxyn_ackp(ackp) $=$

Apaga_pedido_proxy(ackp,"Proxyn");

reply

Ver itens 33, 34 do diagrama do RDP sem handoff.

and Proxyn_res_pedido(EB_res_pedido_proxy,pedido,qtde $)=$

if qtde = ULTIMO

then $\{$ EB_res_pedido_proxy(EBn_res_pedido,pedido,UM_aux,EB_aux,

reply\}

"Proxyn",VERDADEIRO);

else $\{\mathrm{EB}$ _res_pedido_proxy(EBn_res_pedido,pedido,UM_aux,EB aux,

reply\}

"Proxyn",FALSO);

Ver itens 16, 17, 18 do diagrama do RDP sem handoff.

and Proxyn_novo_pedido(pedido $)=$

Inclui_pedido_proxy(pedido);

Envia_pedido_servidor(pedido);

reply

Ver itens J, K, L do diagrama do RDP sem handoff. 
end

do ns.register("Proxyn",Proxyn)

;

loc EBn

with $\mathrm{EBn}$ _antiga(EB_nova_retorno,mens_dereg,UM) =

Verifica_pRef(UM,pRef);

EB_nova_retorno(EBn_atualiza,deregAck,UM,pRef);

Apaga_LocalUM(UM,"EBn");

reply

Mesmo que do handoff.

and EBn_nova_inicial(EB_antiga,mens_greet,UM,oldEB) = EB_antiga(EBn_nova_retorno,dereg, $\bar{U} M)$;

reply

Mesmo que do handoff.

and $\mathrm{EBn}$ _nova_retorno(EB_atualiza,mens_deregAck,UM,pRef) = Inclui_LocalUM(UM,"EBn");

EB_atualiza(Proxyn_atualiza,update,"EBn",UM,VERDADEIRO);

reply

Mesmo que do handoff

and EBn_atualiza(Proxy_atualiza,mens_update,pRef,UM,hand) = Proxy_atualiza(mens_update,pRef,UM,hand);

reply

Mesmo que do handoff.

and EBn_novo_pedido(EB_atualiza,EB_novo_pedido_proxy,pedido,UM,

if proxy_existe $=$ NULL proxy,proxy_existe) $=$

then \{Cria_novo_proxy("EBn",UM);

Proxy_atualiza(update,"EBn",UM);

Atualiza_LocCorr(proxy,"EBn");

Proxy_novo_pedido(pedido);

reply\}

else \{ EB_novo_pedido_proxy(Proxyn_novo_pedido,pedido,proxy); 
reply\}

Ver itens B, C, D, E, F, G do diagrama do RDP sem handoff.

and EBn_novo_pedido_proxy(Proxy_novo_pedido,pedido,proxy) = Proxy_novo_pedido(pedido);

reply

Ver itens $\mathrm{H}$, I da funcionalidade do RDP.

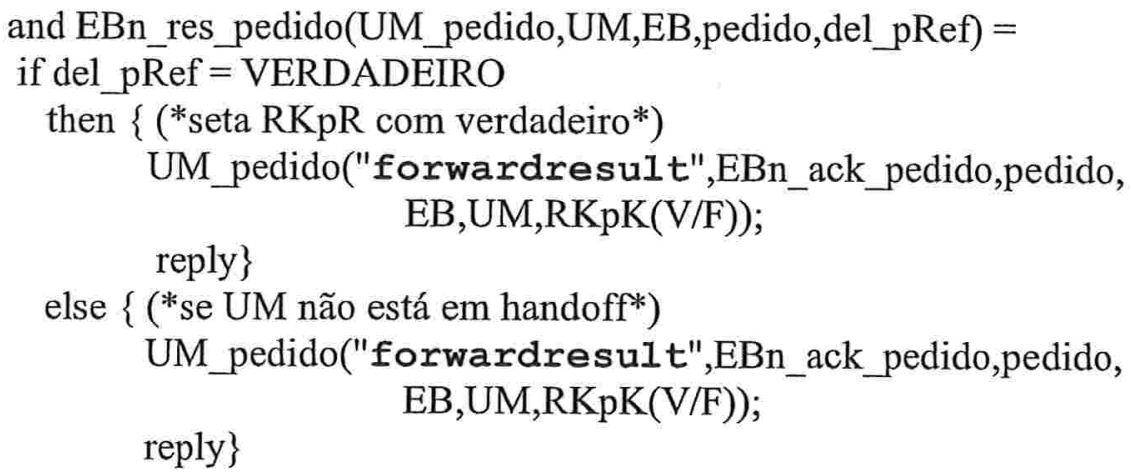

Ver itens 21, 22, 24 do diagrama do RDP sem handoff.

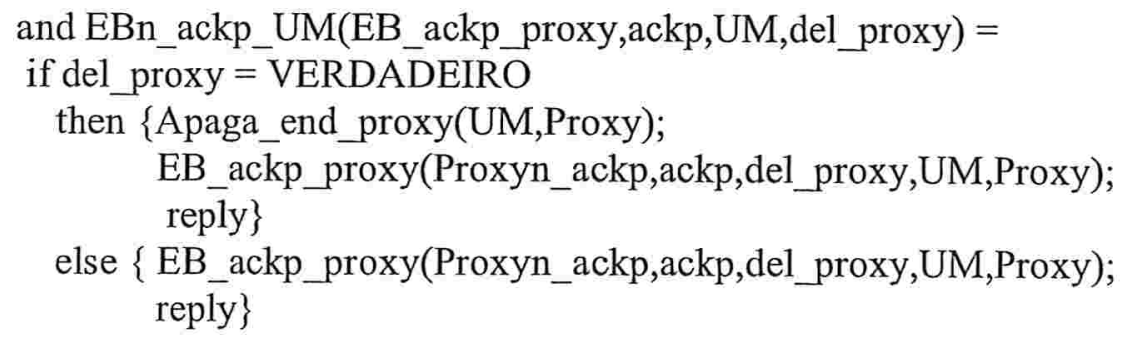

Ver itens 27, 28, 29 do diagrama do RDP sem handoff.

and $\mathrm{EBn}$ _res_pedido_proxy(EB_res_pedido,pedido,UM,EB,Proxy,del_pRef $)=$ EB_res_pedido(UMn_pedido,UM,EB,pedido,del_pRef);

reply

Ver itens 19, 20 do diagrama do RDP sem handoff.

and EBn_ackp_proxy(Proxy_ackp,ackp,del_Proxy,UM,Proxy) = if del_Proxy $=$ VERDADEIRO

then $\{$ Deleta_proxy(Proxy,UM);

reply\} 
else \{ Proxy_ackp(ackp);

reply\}

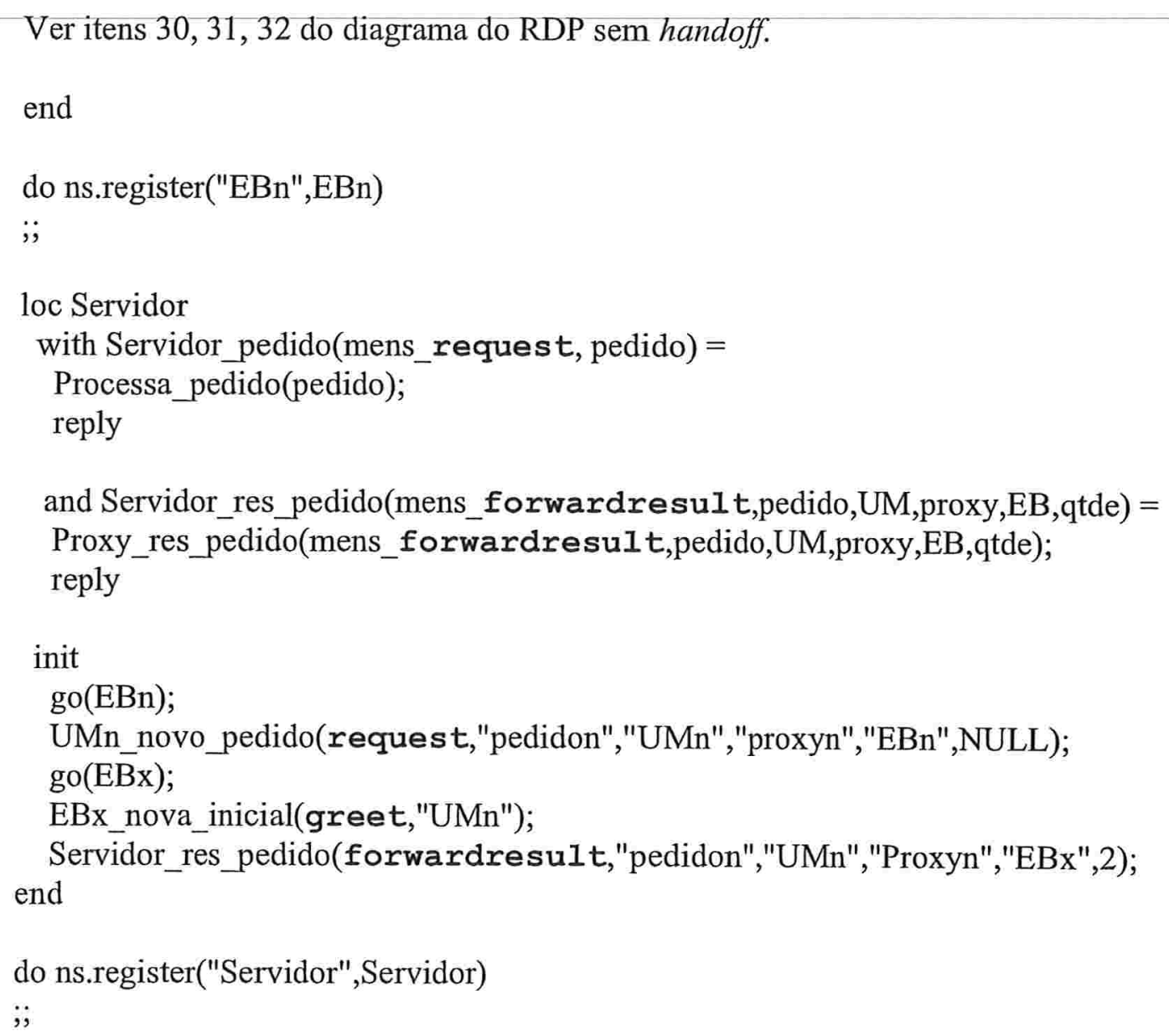

\subsection{Análise do uso da linguagem distributed join-calculus para agentes móveis}

Os critérios de avaliação utilizados se baseiam em propriedades tidas como essenciais quando uma linguagem de programação que dá suporte à mobilidade é considerada [GP00]. Assim, o estabelecimento desses critérios tem como objetivo prover um meio de avaliar a linguagem do distributed join-calculus, verificar se as exigências básicas de uma linguagem para dar suporte à mobilidade são atendidas e como tais requisitos são supridos do ponto de vista do programador pela linguagem do distributed join-calculus.

Os critérios a serem usados na avaliação da linguagem do distributed join-calculus são: 
- Identificação: existe uma forma de identificar um componente, permitindo uma forma de referência unívoca a ele no ambiente distribuído;

- Componente Móvel: existe uma entidade que apresente ou possa apresentar as características de um componente móvel, de acordo com o distributed join-calculus;

- Heterogeneidade: uma construção dos componentes deve levar em consideração a possibilidade de realização de computações em locais com arquiteturas heterogêneas, para que componentes móveis possam atingir toda a sua utilidade e capacidade;

- Transparência de localização: existe uma transparência ao usuário se uma aplicação está executando local ou remotamente;

- Abstração de dados: existe algum tipo de construção que permita a criação de tipos abstratos de dados;

\subsubsection{Identificação}

A identificação de um componente em um ambiente distribuído é uma questão importante pois diversas aplicações contendo componentes com o mesmo nome e que executam paralelamente podem existir. Neste caso, deve haver a possibilidade de se referenciar um componente sem correr o risco de estar-se referenciando a um outro componente de mesmo nome. Se essa questão é importante para sistemas distribuídos, o é também para aplicações com código móvel.

A linguagem do distributed join-calculus fornece mecanismos para identificar unicamente um componente utilizando um servidor de nomes centralizado que é o responsável por identificar cada componente. Este servidor de nomes permite que duas funções sejam registradas com o mesmo nome, mas mantém apenas o último registro feito para aquela função, ou seja, se duas funções forem registradas com o mesmo nome, o registro existente será sobreposto pelo último e será o único registro válido.

\subsubsection{Componente Móvel}

A questão do componente móvel está ligada ao distributed join-calculus pois é ela quem define como um componente móvel é representado. Na linguagem do distributed joincalculus, as funções definidas como localidades móveis são os componentes móveis que se movimentam entre localidades estáticas.

A facilidade ou dificuldade que o programador pode ter utilizando a linguagem do distributed join-calculus está relacionada ao costume que este possui de programar utilizando a linguagem e principalmente na adaptação a métodos formais e agentes móveis. 


\subsubsection{Heterogeneidade}

A heterogeneidade supõe a capacidade de componentes se movimentarem entre locais com arquiteturas e/ou plataformas diferentes. O distributed join-calculus determina como um componente é estruturado e como os componentes se comunicam e sua linguagem determina como o componente é executado em cada local e se ele pode ser criado em um local e ser executado em outro que possui características diferentes.

A capacidade de executar em ambientes heterogêneos se faz importante na mobilidade de código quando existe a idéia da criação de um componente móvel e sua execução em diversos locais na rede, não importando como eles sejam constituídos. Nestas considerações, a linguagem do distributed join-calculus não possui capacidade de prover componentes independentes de arquitetura e não utiliza qualquer mecanismo para obter esta característica. Componentes da linguagem do distributed join-calculus só executam em ambiente Unix e, recentemente, foi anunciada uma versão que deverá executar sobre ambiente Windows NT.

\subsubsection{Transparência de Localização}

A transparência de localização assume que a linguagem trata questões da comunicação ser local ou remota e onde um componente está executando fisicamente, de forma que o programador não precise se preocupar com esses aspectos. Ou seja, ele não precisa saber onde o componente está fisicamente mas apenas uma forma de referenciá-lo.

A linguagem do distributed join-calculus possui essa característica. Apesar do distributed join-calculus não apresentar o conceito de localização, tal conceito foi adicionado pelas linguagens. Para tanto, elas fornecem um servidor de nomes central que permite a identificação dos componentes e oferece a transparência de localização desejada. Isto porque o local físico em que um componente está executando é uma informação controlada apenas pelo servidor e é obtida quando o componente se registra. Assim, quando um componente se comunica com outro componente ou se move para o local onde outro componente está executando ele apenas utiliza uma referência ao componente

\subsubsection{Abstração de Dados}

A possibilidade de criar tipos abstratos de dados é um recurso útil e, muitas vezes, necessário. Os tipos abstratos de dados oferecem a possibilidade de utilização de vetores, estruturas, listas e outras formas de expandir os tipos básicos da linguagem e facilita o armazenamento de grande quantidade de informações e de dados de diferentes tipos, além de agrupar informações que individualmente podem não conter significado útil. 
O distributed join-calculus não prevê a utilização de tipos abstratos de dados pois possui apenas processos e canais. Os processos trocam dados através dos canais, que suportam apenas tipos básicos, como inteiros, caracteres e cadeia de caracteres. A idéia de um tipo abstrato de dados, no entanto, pode ser simulada pela utilização de n-uplas, onde cada nupla representa uma estrutura que pode conter valores de múltiplos tipos. Um conjunto de n-uplas de mesmo formato, contendo um valor que seria usado tal como um índice, poderia ser visto como um vetor ou uma lista.

A linguagem do distributed join-calculus possui a idéia de uma n-upla ser retornada por uma função, mas os valores deixam de ser trabalhados como um conjunto de valores logo após o retorno da função, sendo tratados como valores independentes a partir de então. Com isso, a linguagem do distributed join-calculus não proporciona qualquer forma de criação de tipos abstratos de dados.

\subsection{Análise da tradução da especificação do distributed join- calculus para a linguagem do distributed join-calculus}

Para a tradução da especificação no distributed join-calculus para a linguagem do distributed join-calculus, tentamos realizar uma tradução direta da sintaxe da especificação para a sintaxe da implementação. A sintaxe da especificação do distributed join-calculus é a apresentada na Figura 8 do Apêndice A e a sintaxe da implementação é a apresentada na Figura 11 do Apêndice B.

Inicialmente, incluímos na implementação, as variáveis necessárias e que na especificação não se faz uso. Além disso, as definições que estão na solução do sistema e que não fazem parte da especificação foram inicialmente implementadas.

As localidades foram especificadas como conjunções de definições. Em algumas destas definições, uma composição de padrões é quem ativa um processo. Essas composições de padrões foram assim especificadas para distinguir um fator verdadeiro ou falso como, por exemplo, se uma unidade móvel está ou não no período de handoff.

Na implementação, cada dupla de composição de padrões, que especifica uma condição verdadeira ou falsa foi substituída por uma única definição. Nesta nova definição, o uso da construção condicional if-then-else da linguagem do distributed join-calculus foi utilizada para determinar qual processo seria ativado: o especificado com o fator verdadeiro ou o especificado com o fator falso.

As demais definições especificadas com um padrão simples engatilhando um processo, foram implementadas da mesma forma, ou seja, com o mesmo padrão simples engatilhando o mesmo processo, mas utilizando a notação da implementação. 
$\mathrm{Na}$ especificação, os processos em execução são bem determinados, ou seja, quando uma localidade está sendo especificada com suas definições, seus processos em execução também são especificados, além dos processos do sistema que esta localidade engatilha, mas separados dos processos desta localidade.

$\mathrm{Na}$ implementação, os processos em execução, tanto da localidade quanto do sistema, são engatilhados no mesmo lugar. Para sabermos se um processo disparado é da localidade, precisamos verificar se ele aparece nas definições desta localidade.

Como a sintaxe da especificação e da implementação são bastante parecidas, a partir da especificação, não fica difícil escrever a implementação e verificar que a implementação corresponde à especificação. Contudo, vários elementos precisam ser adicionados para acompanharmos as simulações como, por exemplo, a impressão de mensagens na tela.

Com as simulações conseguimos acompanhar o comportamento dos protocolos handoff $\mathrm{e}$ RDP. Algumas dúvidas foram resolvidas durante essas simulações e outras partes incompletas da especificação dos protocolos no distributed join-calculus foram detectadas como, por exemplo, a necessidade de uma localidade chamada servidor para receber os pedidos das unidades móveis e encaminhar o resultado desses pedidos.

\subsection{Conclusão}

Neste capítulo sobre a implementação do RDP, uma implementação particular do protocolo handoff foi apresentada para um melhor entendimento do funcionamento da linguagem do distributed join-calculus. Posteriormente, a implementação completa do protocolo bem como do protocolo RDP seguindo a especificação de cada um no distributed join-calculus, vista no Capítulo 3, foi apresentada.

Analisando o uso da linguagem do distributed join-calculus para agentes móveis e considerando alguns critérios de avaliação que se baseiam em propriedades tidas como essenciais quando uma linguagem de programação que dá suporte à mobilidade é considerada, concluímos que a linguagem do distributed join-calculus satisfaz os critérios de identificação, componente móvel e transparência de localização.

Analisando a tradução da especificação do distributed join-calculus para a sua linguagem, concluimos que não é difícil escrever a implementação a partir de sua especificação no distributed join-calculus, uma vez que, as sintaxes da implementação e da especificação são bastante parecidas. 


\section{Capítulo 6 - Conclusão e Trabalhos Futuros}

Como proposta deste trabalho, utilizamos o formalismo do distributed join-calculus para especificar o modelo do protocolo Result Delivery Protocol, especialmente para a parte em que ele trata a mobilidade, que é no tratamento do protocolo handoff.

Para uma melhor compreensão de como representar o protocolo no distributed joincalculus, especificamos um modelo simplificado para o protocolo handoff. Depois especificamos e implementamos o protocolo handoff e partes necessárias do protocolo RDP e verificamos algumas propriedades esperadas pelo protocolo, usando lógica temporal e a especificação no cálculo.

Com o desenvolvimento deste trabalho, obtemos respostas quanto à adequação do uso do distributed join-calculus para a especificação de problemas como o proposto, às dificuldades de se especificar um protocolo com mobilidade, ao atendimento das propriedades esperadas pelo protocolo RDP, à análise do protocolo especificado, ao uso do distributed join-calculus para a prova das propriedades e à tradução da especificação do distributed join-calculus para a sua linguagem.

O protocolo result delivery protocol e o protocolo handoff são protocolos simples, mas seu entendimento foi complicado porque o artigo original, que explica sua especificação, não está detalhado o suficiente para uma implementação direta do mesmo. Durante a especificação do protocolo handoff e a especificação de partes necessárias do protocolo RDP no distributed join-calculus, observamos vários detalhes que seriam importantes estarem descritas na especificação do protocolo como, por exemplo, quando ocorre exatamente o término do protocolo handoff, principalmente se a unidade móvel não tem um proxy. Com a análise sobre a avaliação do distributed join-calculus em relação ao seu uso para agentes móveis, concluímos que este cálculo é adequado, em termos gerais, para a especificação de protocolos como o RDP.

Com as hipóteses, propriedades e as provas das propriedades dos protocolos RDP e handoff apresentadas, pudemos verificar que as propriedades inerentes aos protocolos são atendidas. Além disso, com a análise do uso da especificação do protocolo no distributed join-calculus para a prova das propriedades, sentimos grande necessidade de uma ferramenta para verificação das propriedades, pois tivemos que elaborar uma tabela da especificação em lógica temporal para nos auxiliar.

Além das propriedades provadas neste trabalho, há outras propriedades interessantes que também podem ser verificadas posteriormente como, por exemplo, quando o protocolo handoff efetivamente é concluído, considerando a existência ou não de um proxy; se há a possibilidade de formação de ciclo com as mensagens; se um pedido feito pela unidade móvel sempre chega ao seu proxy e posteriormente ao servidor; entre outras. 
Além disso, uma especificação completa do protocolo RDP pode ser feita, ou seja, considerando que a unidade móvel pode ficar inativa quando desligada e não considerar somente que uma unidade móvel não se desliga e só fica inativa quando está no período do protocolo handoff; considerando quando uma unidade móvel efetivamente entra no sistema e no domínio de uma estação base; entre outras. E todas as propriedades provadas neste trabalho e outras inerentes ao protocolo também podem ser verificadas na especificação completa do protocolo.

Assim que uma ferramenta de verificação para o distributed join-calculus estiver concluída, podemos utilizá-la para verificar as propriedades provadas neste trabalho, bem como outras propriedades inerentes ao protocolo. E verificar também outras propriedades inerentes ao protocolo se uma especificação completa deste protocolo for realizada.

Sentimos alguma dificuldade durante a implementação completa do protocolo handoff e a implementação de partes relevantes do protocolo RDP, na linguagem do distributed joincalculus, de acordo com suas especificações, pois o manual que explica o funcionamento da linguagem não é muito esclarecedora, apresentando apenas exemplos isolados durante a explicação. Examinamos outros exemplos mais completos implementados na linguagem, no entanto, não havia explicação dos mesmos e muitas funções pré-definidas e utilizadas não possuem comentários no manual. Com a análise sobre a avaliação da linguagem do distributed join-calculus, concluímos que esta linguagem é adequada, em termos gerais, para a especificação de protocolos como o RDP. Além disso, a tradução da especificação para a linguagem do distributed join-calculus não é complicada e pôde ser utilizada para simular o comportamento do protocolo.

Apesar de a tradução da especificação para a implementação não ser complicada, não podemos dizer, com certeza, que a implementação corresponde integralmente à especificação. Isso porque não existe nenhuma regra ou metodologia que defina a forma de se traduzir uma especificação do distributed join-calculus para a sua linguagem. Não conhecendo integralmente tudo sobre o que a linguagem oferece, fica difícil estabelecer uma regra definitiva para a tradução. No entanto, para a tradução de especificações como apresentadas neste trabalho, podemos estabelecer regras de tradução da especificação para a linguagem de forma a facilitar que outros protocolos de comunicação possam ser especificados e implementados da mesma forma.

Na sistema do join-calculus é possível executar partes do programa como servidor e outras como cliente, dependendo da forma como é feita a sua compilação. De fato, é possível desenvolver um sistema para o protocolo RDP que não simule somente o comportamento do protocolo, mas também com servidores e clientes em execução paralela. Assim, tanto o protocolo RDP como qualquer outro protocolo de comunicação pode ser especificado no distributed join-calculus e implementado em sua linguagem para ser simulado em execução paralela. 
Uma implementação completa do RDP pode ser feita, considerando todas as características do protocolo e simulando seu comportamento com servidores e clientes em execução paralela.

Com este trabalho, compreendemos o formalismo do distributed join-calculus, como especificar e implementar um protocolo de comunicação como o RDP. Com base nisso, podemos usar o distributed join-calculus para especificar, implementar e verificar algumas propriedades inerentes a outros protocolos de comunicação como, por exemplo, o Wireless Application Protocol - WAP que é um protocolo de comunicação mais completo e de uso comercial.

O WAP é um protocolo de comunicação comercial que visa permitir que usuários de dispositivos móveis sem fio acessem informações e serviços de forma instantânea. E, com isso, um grande número de computadores ligados à Internet vai exigir um suporte eficiente à mobilidade, o que será fundamental no desempenho de toda a rede. Como o WAP vem sendo utilizado em larga escala pela indústria como, por exemplo, nos telefones celulares, pagers e PDAs (Personal Digital Assistants), há uma grande exigência quanto à confiabilidade desses serviços para evitar perda e lentidão nas conexões, para que as mensagens sejam recebidas e enviadas corretamente, para garantir que os dados corretos sejam enviados para o destino correto, entre outros. Essa confiabilidade pode ser garantida com a especificação deste protocolo no distributed join-calculus, com essas propriedades verificadas e com uma implementação para analisar seu comportamento. 


\section{Referências Bibliográficas}

[Agh86] G. A. Agha. Actors: a model of conCorrent computation in distributed Systems. In RR 2913, INRIA, Junho de 1996.

[AMST93] G. Agha, I. Mason, S. Smith e C. Talcott. A foundation for actor computation. Technical report, UIUC. 1993.

[AP94] R. Amadio e S. Prasad. Localities and failures. In $14^{\text {th }}$ Foundations of Software Technology and Theoretical Computer Science Conference. Springer - Verlag, LNCS 880. 1994.

[AP98] R. M. amadio e S. Prasad. Modelling IP mobility. In IFCPAR 1502-1. CONCUR 98. Junho de 1998.

[BA90] G. Bruns e S. Anderson. The formalization and analysis of a comunications protocol. Technical report, University of Edinburgh. 1990.

[Ba190] J. C. M. Baeten, editors. Aplication of process algebra. Cambridge University Press. 1990.

[BB92] G. Berry e G. Boudol. The chemical abstract machine. Theoretical Computer Science, 96:217-248. 1992.

[BB94] C. E. Perkins e P. Bhagwat. A mobile networking system base on internet protocol. In IEEE Personal Communication 1:32-41. 1994.

[BBIM93] B. R. Badrinath, A. Bakre, T. Imielinski e R. Marantz. Handling mobile clients: a case for indirect interaction. In Proc. $4^{\text {th }}$ Workstation Operating Systems. Outubro 1993.

[BBP87] J. P. Banâtre, M. Banâtre e F. Ployette. Distributed system structuring using multi-functions. In Rapport de Recherche 694, INRIA Rennes. Junho de 1987.

[Ben93] M. Ben-Ari. Mathematical logic for computer science. Technion-Israel Institute of Technology. Prentice Hall. 1993.

[Bou92] G. Boudol. Asynchrony and the pi-calculus (note). In Rapport de Recherche 1702, INRIA Sophia-Antipolis. 1992. 
[Bou94] G. Boudol. Some chemical abstract machines. In j. W. De Bakker, W.-P. De Roever, e Grzegorz Rozenberg, editors, A Decade of conCorrency: reflections and perspectives: REX school/symposium, Noordwijkerhout, the Netherlands, Jiga 1-4, 1993: proceedins, volume 803 da Lecture Notes in Computer Science, 92-123. Springer-Verlag. 1994.

[Car95] L. Cardelli. A language with distributed scope. Computing Systems, 8(1):27 - 59. Janeiro de 1995,

[CF99] S. Conchon e F. L. Fessant. Jocaml: mobile agents for objective caml. In INRIA Rocquencourt. Maio de 1999.

[DMRR00] D. Déharbe, A. M. Moreira, L. Ribeiro e V. M. Rodrigues. Introdução à métodos formais: especificação, semântica e verificação de sistemas concorrentes. Revista de Informática Teórica e Aplicada, número 1, ano 2000. Universidade Federal do Rio Grande do Sul.

[EFJ91] P. Ernberg, L. Fredlund e B. Jonsson. Specifications and validation of simple overtaking protocol in lotos. In Proc. $4^{\text {th }}$ International Conference on Formal Description Techniques. 1991.

[ESO98] M. Endler, D. M. Silva e K. Okuda. A reliable connectionless protocol for mobile clients. Instituto de Matemática e Estatística - Universidade de São Paulo. 1998.

[ESO98] M. Endler, D. M. Silva e K. Okuda. RDP - A result delivery protocol for mobile computing. Instituto de Matemática e Estatística - Universidade de São Paulo. 1998.

[FG96] C. Fournet e G. Gonthier. The reflexive chemical abstract machine and the join-calculus. In $23^{\text {nd }} A C M$ Symposium on Principles of Programming Languages. Janeiro de 1996.

[FGLMR96] C. Fournet, G. Gonthier, J.-J. Lévy, L. Maranget e D. Rémy. A calculus of mobile agents. In $7^{\text {th }}$ International Conference on ConCorrency Theory, CONCUR'96, LNCS 1119. 1996.

[FL99] C. Fournet e C. Laneve. Bisimulations in the Join-Calculus. ESPDRIT CONFER-2. Junho de 1999.

[FM99] C. Fournet e L. Maranget. The Join-Calculus language release $1.04-$ Documentation and user's manual. INRIA, Janeiro de 1999. 
[FPV98] A. Fuggetta, G. P. Picco e G. Vigna. Understanding code mobility. IEEE Transactions on Software Engineering. vol. 24. 1998.

[GP00] D. Gilbert e C. Palamidessi. Concurrent constraint programming with process mobility. Technical report. City University e Penn State University. In Proceedings CL'2000. 2000.

[HB93] A. Harter e F. Bennett. Low bandwidth infra-red networks and protocols for mobile communications devices. In Technical report, Olivetti Research Ltd. 1993.

[Hua01] F. Huang. Mobile Agents. Technical report. Columbia University. Lecture Note in Computer Science. vol. 2164, Springer-Verlag. 2001.

[Ioa93] J. Ioannidis. Protocols for mobile internetworking. Technical report. Columbia University. 1993.

[LJ98] R. Lai e A. Jirachiefpattana. Communication protocol specification and verification. Kluwer Academic Publishers. 1998.

[Mar] A. L. Martinez. An investigation of mobile code languages. CD 63101 Course project of Kent State University.

[Mi189] R. Milner. Communication and Concurrency. In Prentice Hall, New York. 1989.

[Mil90] R. Milner. Functions as processes. In Automata, Languages and Programming $17^{\text {th }}$ Int. Coll. LNCS 332: 167-180. Springer Verlag. Julho de 1990.

[ML98] G. R. Mateus e A. A. F. Loureiro. Introdução à computação móvel. In $11^{\mathrm{a}}$ Escola de Computação, DCC UFRJ. Rio de Janeiro. Julho de 1998.

[MP91] Z. Manna e A. Pnueli. The temporal logic of reactive and concurent systems. Springer-Verlag. 1991.

[MP95] Z. Manna e A. Pnueli. Temporal verification of reactive systems - safety. Springer-Verlag. 1995.

[MPW92] R. Milner, J. Parrow e D. Walker. A calculus of mobile processes, parts I and II. Information and Computation, 1-40 e 41-77. Setembro de 1992.

[MR97] P. McCann e G.-C. Roman. Mobile UNITY coordination constructs applied to packet entregaring. In Proc. Coordination 97. LNCS 1292. 1997. 
[MW93] J. P. Mello e P. Waligar. Wireless mobile communication. In Byte. 147-153. 1993.

[Nic96] A. Nicolaou. A survey of distributed languages. 1996.

[Nis99] N. Nissanke. Formal specification: techniques and applications. SpringerVerlag. 1999.

[OP96] F. Orava e J. Parrow. An algebraic verification of a mobile network. In Formal Aspects of Computing 3:1-000. 1996.

[PRT93] B. C. Pierce, D. Rémy e D. N. Turner. A typed higher-order programming language based on the pi-calculus. In Workshop on Type Theory and its Application to Computer Science, Kyoto University. Julho de 1993.

[PRM97] G.-P. Picco, G. Roman e P. McCann. Expressing code mobility in mobile UNITY. In Proc. $6^{\text {th }}$ European Software Engineering Conference and $5^{\text {th }}$ ACM SIGSOFT Symposium on Foundations of Software Engineering. 1997.

[PS98] E. Pitoura e G. Samaras. Data management for mobile computing. Kluster Academic Publishers. 1998.

[PT195] B. C. Pierce e D. N. Turner. Pict: A programming language based on the picalculus. Technical report. 1995.

[PT295] B. C. Pierce e D. N. Turner. Concurrent objects in a process calculus. In T. Ito e A.Yonezawa, editores, Theory and Practice of Parallel Programming, Sendai, Japão, número 907 no Lecture Notes in Computer Science 187-215. Abril de 1995.

[RMP97] G. Roman, P. McCann e J. Plun. Mobile UNITY: reasoning and specification in mobile computing. ACM Transactions and Software Engineering and Methodology, 6(3): 250-283. Julho 1997.

[SIDAM] Projeto temático FAPESP.

[Smo94] G. Smolka. A foundation for higher-order conCorrent constraints programming. In J. P. Jouannaud, editors, $1^{\text {st }}$ International Conference on Constraints in Computational Logics. LNCS 845: 50-72, Müchen, Germany, 7-9. Springer - Verlag. Setembro de 1994.

[Wa195] D. Walker. Objects in the pi-calculus. In Information and Computation. 116(2): 253-271. 1995. 


\section{Apêndices}

\section{Apêndice A - Sintaxe, Escopo e Semântica Operacional do Distributed Join-Calculus}

\section{$\underline{\text { Sintaxe }}$}

$$
\begin{aligned}
& P \quad::= \\
& \text { processos } \\
& x<v_{1}, \ldots, v_{n}> \\
& \text { def } D \text { in } P \\
& P \mid P^{\prime} \\
& 0 \\
& g o<a, k> \\
& \text { mensagem } \\
& \text { definição local } \\
& \text { composição paralela } \\
& \text { processo nulo } \\
& \text { migração } \\
& \text { D ::= } \\
& J \triangleright P \\
& \mid D^{\wedge} D^{\prime} \\
& \text { T } \\
& \text { | } a[D: P] \\
& J \quad::= \\
& x<y_{1}, \ldots, y_{n}> \\
& J \mid J
\end{aligned}
$$

Figura 8 - Sintaxe do distributed join-calculus

\section{$\underline{\text { Escopo }}$}

Processos

$$
\begin{array}{rcl}
\mathrm{vl}\left[x<v_{1}, \ldots, v_{n}>\right] & \stackrel{\text { def }}{=} & \left\{x, v_{1}, \ldots, v_{n}\right\} \\
\mathrm{vl}[\operatorname{def} D \text { in } P] & \stackrel{\text { def }}{=} & (\mathrm{vl}[P] \cup \mathrm{vl}[D]) \backslash \mathrm{vd}[D] \\
\mathrm{vl}[P \mid P] & \stackrel{\text { def }}{=} & \mathrm{vl}[P] \cup \mathrm{vl}\left[P^{\prime}\right] \\
\mathrm{vl}[0] & \stackrel{\text { def }}{=} & \varnothing \\
\mathrm{vl}[g o<a, k>] & \stackrel{\text { def }}{=} & \{a, k\}
\end{array}
$$


Definições

\begin{tabular}{|c|c|c|}
\hline $\mathbf{v l}[J \triangleright P]$ & $\stackrel{\text { def }}{=}$ & $\mathbf{v d}[J] \cup(\operatorname{vl}[P] \backslash \operatorname{vr}[J])$ \\
\hline $\operatorname{vl}\left[D^{\wedge} D^{\prime}\right]$ & $\stackrel{\text { def }}{=}$ & $\operatorname{vl}[D] \cup \operatorname{vl}\left[D^{\prime}\right]$ \\
\hline $\mathrm{vl}[T]$ & $\stackrel{\text { def }}{=}$ & $\varnothing$ \\
\hline $\operatorname{vl}[a[D: P]]$ & $\stackrel{\text { def }}{=}$ & $\{a\} \cup \operatorname{vl}[\mathrm{D}] \cup \operatorname{vl}[\mathrm{P}]$ \\
\hline $\mathbf{v r}[J \triangleright P]$ & $\stackrel{\text { def }}{=}$ & $\mathrm{vd}[J$ \\
\hline $\operatorname{vr}\left[D^{\wedge} D^{\prime}\right]$ & $\stackrel{\text { def }}{=}$ & $\mathbf{v d}[D] \cup \mathbf{v d}\left[D^{\prime}\right]$ \\
\hline $\operatorname{vr}[T]$ & $\stackrel{\text { def }}{=}$ & $\varnothing$ \\
\hline $\operatorname{vr}[a[D: P]]$ & $\stackrel{\text { def }}{=}$ & $\{a\} \uplus \operatorname{vr}[D]$ \\
\hline
\end{tabular}

Padrões de união

$$
\begin{array}{rll}
\mathbf{v d}\left[x<y_{1}, \ldots, y_{n}>\right] & \stackrel{\text { def }}{=} & \{x\} \\
\mathbf{v d}\left[J \mid J^{\prime}\right] & \stackrel{\text { def }}{=} & \mathbf{v d}\left[J \uplus \mathbf{v d}\left[J^{\prime}\right]\right. \\
\mathbf{v r}\left[x<y_{1}, \ldots, y_{n}>\right] & \stackrel{\text { def }}{=} & \left\{y_{1}, \ldots, y_{n}\right\} \\
\operatorname{vr}[J \mid J] & \stackrel{\text { def }}{=} & \operatorname{vr}[J] \uplus \operatorname{vr}\left[J^{\prime}\right]
\end{array}
$$

Figura 9 - Escopos do Distributed Join-Calculus

\section{Semântica}

STR-JOIN
STR-NULL
STR-AND
STR-NODEF
STR-DEF
STR-LOC
RED
COMM
MOVE

$$
\begin{aligned}
& \vdash P \mid P^{\prime} \quad \rightleftharpoons \quad P, P^{\prime} \\
& \begin{aligned}
\vdash 0 & \rightleftharpoons \\
D^{\wedge} D^{\prime} \vdash & \rightleftharpoons D, D^{\prime} \vdash
\end{aligned} \\
& \text { T } \rightleftharpoons \quad \vdash \\
& \vdash \operatorname{def} D \text { in } P \quad \rightleftharpoons \quad D \sigma_{\mathrm{vd}} \vdash P \sigma_{\mathrm{vd}} \\
& \varepsilon a[D: P] \vdash_{\varphi} \rightleftharpoons \vdash_{\varphi} \|\{D\} \vdash_{\varphi} \varepsilon_{a}\{P\} \\
& J \triangleright P \vdash J \sigma_{\mathrm{rv}} \quad \rightarrow \quad J \triangleright P \vdash P \sigma_{\mathrm{rv}} \\
& \vdash_{\varphi} x<v_{1}, \ldots, v_{n}>\left\|\quad \rightarrow \quad \vdash_{\varphi}\right\| J \triangleright P \vdash x<v_{1}, \ldots, v_{n}> \\
& a[D: P \mid g o<b, k>] \quad \rightarrow \quad \vdash_{\varphi} \| a[D: P \mid k<>] \vdash_{\psi \mathbf{b} \varepsilon} \\
& \vdash_{\varphi} \| \vdash_{\psi \mathbf{b} \varepsilon}
\end{aligned}
$$

Condições para as substituições:

STR-DEF $\sigma_{\mathrm{vd}}$ instancia a porta de variáveis $\mathrm{vd}[D]$ para distinto, nomes livres: $\operatorname{Dom}\left(\sigma_{\mathrm{vd}}\right) \cap \operatorname{vl}[D \vdash P]=\varnothing$ onde $D \vdash P$ é a solução inicial 
STR-LOC $\boldsymbol{a}$ está resfriado: o nome $\boldsymbol{a}$ não ocorre em $\psi$ de qualquer solução distribuída

RED $\sigma_{\mathrm{rv}}$ substitui os nomes transmitidos para variáveis recebidas distintas $\operatorname{vr}[J]$

COMM $x \in \mathbf{d v}[J]$

Figura 10 - A máquina química reflexiva e distribuída (DRCHAM) 


\section{Apêndice B - Sintaxe da linguagem do distributed join-calculus}

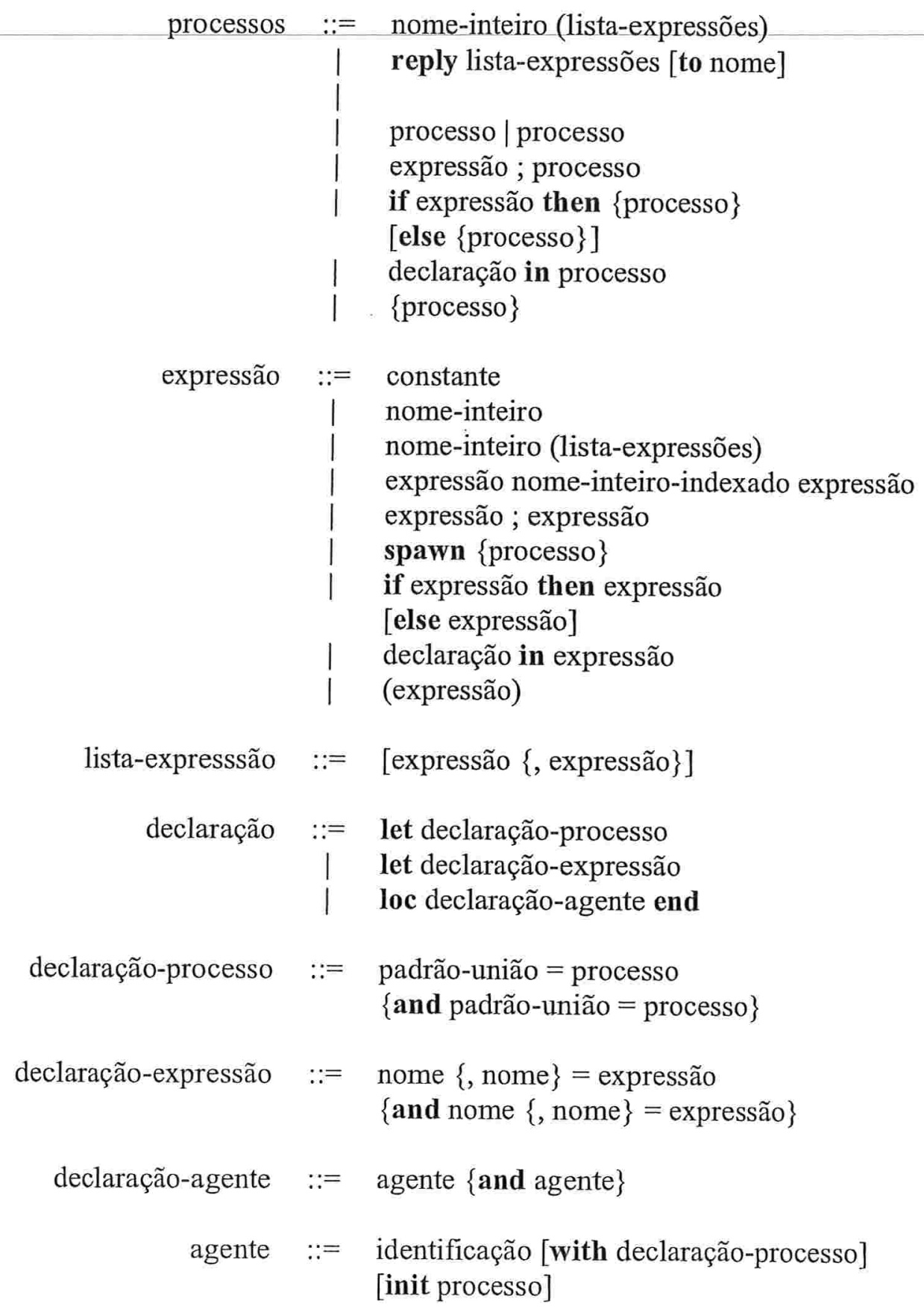

Figura 11 - Sintaxe da linguagem do distributed join-calculus 


\section{Apêndice C - Especificação do protocolo handoff versus lógica temporal}

\section{Funcões}

[001] Apaga_LocalUM(UM,EB)

[003] Inclui_LocalUM(UM,EB)

[005] Verifica_pRef(UM,pRef)

[007] Atualiza_LocCorr(Proxy,LocCorr)

[009] Reenvia_pedidos(Proxy,UM)

Proxy

\author{
apagar_UM(UM, EB) \\ incluir_UM(UM, $E B)$ \\ verificar_pRef(UM) \\ atualizar_proxy(Proxy, EB) \\ responder(Proxy, EB, $M$ )
}

para hand_verdadeiro 0, ou seja, quando ocorreu handoff

\begin{tabular}{|lll}
{$[011]$} & Proxy_atualiza(mens_update,pRef_EB,UM) & receber(Proxy, EB, update) \\
{$[012]$} & Atualiza_LocCorr("Proxy",pRef_EB) & atualizar_proxy(Proxy, EB) \\
{$[013]$} & Reenvia_pedidos("Proxy",UM) & responder(Proxy,EB, forwardresult)
\end{tabular}

para hand_falso(), ou seja, quando não ocorreu handoff

\begin{tabular}{|lll}
{$[014]$} & Proxy_atualiza(mens_update,pRef_EB,UM) & receber(Proxy, EB, update) \\
{$[015]$} & Atualiza_LocCorr("Proxy",pRef_EB) & atualizar_proxy(Proxy, EB)
\end{tabular}

EB

[018] EB_antiga(mens_dereg,UM)

[019] Verifica_pRef(UM,pRef)

[020] EB_nova_retorno(deregAck,UM,pRef)

[021] Apaga_LocalUM(UM,"EBn")

[022] EB_nova_inicial(mens_greet,UM,oldEB)

[023] EB_antiga(dereg,UM)

$\operatorname{receber}\left(E B_{a}, E B_{n}\right.$, dereg)

verificar_pRef(UM)

enviar $\left(E B_{a}, E B_{n}\right.$, deregAck)

apagar_UM(UM, EB)

receber $\left(E B_{n}, U M\right.$, greet $)$

[024] EB_nova_retorno(mens_deregAck,UM,pRef)

enviar $\left(E B_{n}, E B_{a}\right.$, dereg)

[025] Inclui_LocalUM(UM,"EBn")

[026] EB_atualiza(update,"EBn",UM)

[027] EB_atualiza(mens_update,pRef,UM)

[028] Proxy_atualiza(mens_update,pRef,UM)

UM

receber $\left(E B_{n}, E B_{a}\right.$, deregAck)

incluir_UM $U M, E B)$

enviar $\left(E B_{n}, E B_{p}\right.$, update)

receber $\left(E B_{p}, E B_{n}\right.$, update)

enviar(EB $B_{p}$ Proxy, update)

[035] EB_nova_inicial(greet,UM,"EB")

enviar(UM, $E B_{n}$, greet $)$ 


\title{
Apêndice D - Especificação de partes relevantes do protocolo RDP versus lógica temporal
}

\author{
Funcões \\ [001] Apaga_LocalUM(UM,EB) \\ [003] Inclui_LocalUM(UM,EB) \\ [005] Verifica_pRef(UM,pRef) \\ [007] Cria_novo_proxy(EB,UM) \\ [009] Inclui_pedido_proxy(pedido,proxy) \\ [011] Processa_pedido(pedido) \\ [013] Apaga_end_proxy(UM,proxy) \\ [015] Deleta_proxy(Proxy,UM) \\ [017] Apaga_pedido_proxy(pedido,Proxy) \\ [019] Atualiza_LocCorr(Proxy,LocCorr) \\ [021] Reenvia_pedidos(Proxy,UM) \\ $\underline{\mathrm{UM}}$ \\ apagar_UM(UM, $E B)$ \\ incluir_UM(UM,EB) \\ verificar_pRef(UM) \\ criar_proxy(Proxy, UM) \\ incluir_proxy(Proxy) \\ processar () \\ apagar_proxy $(U M)$ \\ destruir_proxy(Proxy) \\ apagar_proxy_pedido(Proxy) \\ atualizar_proxy(Proxy, EB) \\ responder(Proxy, EB, $M$ ) \\ para $R K p R \_$verdadeiro(), ou seja, se a estação base responsável confirmou a remoção de um proxy

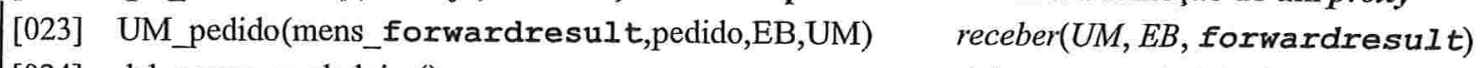 \\ [024] del_proxy_verdadeiro() \\ [025] EB_ackp_UM("forwresAck",ackp,UM,Proxy) \\ [026] RKpR_falso() \\ del_proxy_verdadeiro () \\ enviar (UM, $E B$, forwresAck) \\ $R K p R$ falso() \\ para $R K p R \_$falso 0, ou seja, se a estação base responsável não confirmou a remoção de um proxy \\ [027] UM_pedido(mens_forwardresult,pedido,EB,UM) receber(UM, $E B$, forwardresult) \\ [028] EB_ackp_UM("forwresAck",ackp,UM,Proxy) \\ enviar (UM, $E B$, forwresAck) \\ [029] UM_novo_pedido(pedido,UM,proxy) \\ receber (UM, $U M$, request $)$ \\ [030] EB_novo_pedido("request",pedido,UM,proxy) | \\ enviar (UM, $E B$, request) | \\ [031] UM_novo_pedido("pedido",UM,proxy) \\ enviar (UM, $U M$, request) \\ [034] EB_nova_inicial(greet,UM,EB) \\ [035] UM_novo_pedido("pedido",UM,proxy) \\ enviar $\left(U M, E B_{n}\right.$, greet $)$ \\ enviar (UM, $U M$, request) \\ Proxy \\ para hand_verdadeiro (, ou seja, quando ocorreu handoff \\ [036] Proxy_atualiza(mens_update,pRef_EB,UM) \\ [037] Atualiza_LocCorr("Proxy",pRef_EB) \\ [038] Reenvia_pedidos("Proxy",UM) \\ [039] hand_falso() \\ para hand falso(), ou seja, quando não ocorreu handoff \\ [040] Proxy_atualiza(mens_update,pRef_EB,UM) \\ [041] Atualiza_LocCorr("Proxy",pRef_EB) \\ [042] Proxy_ackp(mens_forwresAck,ackp) \\ [043] Apaga_pedido_proxy(ackp,"Proxyn")
receber(Proxy, EB, update)
atualizar_proxy(Proxy, $E B)$
responder(Proxy, $E B, M)$
$\neg$ handoff(UM)
receber(Proxy, $E B$, update)
atualizar_proxy(Proxy, EB)
receber(Proxy, $E B$, forwresAck) \\ apagar_pedido(Proxy) \\ para último_pedido0, ou seja, se o proxy está entregando o resultado do último pedido pendente da \\ unidade móvel \\ [044] Proxy_res_pedido(mens_forwardresult,pedido) receber(Proxy, Servidor, \\ forwardresult)
}


[045] del_pRef_verdadeiro()

[046] EB_res_pedido_proxy(mens_forwardresult,pedido, UM_aux,EB_aux,"Proxyn") del pRef verdadeiro()

enviar(Proxy, EB, forwardresult

para nao_último_pedido0, ou seja, se o proxy não está entregando o resultado do último pedido pendente da unidade móvel

[047] Proxy_res_pedido(mens_forwardresult,pedido)

[048] del_pRef_falso()

[049] EB_res_pedido_proxy(mens_forwardresult,pedido, receber(Proxy, servidor, forwardresult) del_pReffalso() UM_aux,EB_aux,"Proxyn") |

[050] ultimo_pedido()

[051] Proxy_novo_pedido(mens_request,pedido)

[052] Inclui_pedido_proxy(pedido)

[054] Servidor_pedido(mens_request,pedido)

enviar(Proxy, $E B$, forwardresult

\section{$\underline{\text { EB }}$}

[057] EB_antiga(mens_dereg,UM)

[058] Verifica_pRef(UM,pRef)

[059] EB_nova_retorno(deregAck,UM,pRef)

último_pedido()

receber(Proxy, EB, request)

incluir_pedido(Proxy)

enviar(Proxy, Servidor, request

[060] Apaga_LocalUM(UM,"EBn")

[061] EB_nova_inicial(mens_greet,UM,oldEB)

[062] EB_antiga(dereg,UM)

[063] EB_nova_retorno(mens_deregAck,UM,pRef)

[064] Inclui_LocalUM(UM,"EBn")

[065] hand_verdadeiro()

[066] EB_atualiza(update,"EBn",UM)

[067] EB_atualiza(mens_update,pRef,UM)

[068] Proxy_atualiza(mens_update,pRef,UM)

para nao_existe_proxy0, ou seja, se não existe proxy para a unidade móvel

[069] EB_novo_pedido(mens_request,pedido,UM,proxy)

[070] Cria_novo_proxy("EBn",UM)

[071] existe_proxy()

[072] Proxy_atualiza(update,pRef,UM)

receber $\left(E B_{a}, E B_{n}\right.$, dereg)

verificar_pRef(UM)

enviar $\left(E B_{a}, E B_{n}\right.$, deregAck)

apagar_UM(UM,EB)

receber $\left(E B_{n}, U M\right.$, greet $)$

enviar $\left(E B_{n}, E B_{a}\right.$, dereg)

receber $\left(E B_{n}, E B_{a}\right.$, deregAck)

incluir_UM $U M, E B)$

handoff(UM)

enviar $\left(E B_{n}, E B_{p}\right.$, update)

receber $\left(E B_{n}, E B_{p}\right.$, update)

enviar( $E B_{p}$, Proxy, update)

[073] Proxy_novo_pedido(mens_request,pedido)

receber ( $E B, U M$, request)

$\operatorname{criar}(\operatorname{Proxy}, E B)$

existe proxy ()

enviar(EB, Proxy, update)

enviar $(E B, \operatorname{Proxy}$, request)

para existe_proxy (), ou seja, se já existe proxy para a unidade móvel

[074] EB_novo_pedido(mens_request,pedido,UM,proxy) receber(EB, UM, request)

[075] EB_novo_pedido_proxy(mens_request,pedido,proxy)

[076] EB_novo_pedido_proxy(mens_request,pedido,proxy)

enviar $\left(E B, E B_{p}\right.$, request $)$

receber $\left(E B_{p}, E B\right.$, request $)$

[077] Proxy_novo pedido(mens_request,pedido)

enviar $\left(E B_{p}\right.$, Proxy, request)

para del_pRef_verdadeiro() e hand_falso 0, ou seja, se a referência de proxy pode ser apagado e se não ocorreu handoff

[078] EB_res_pedido(mens_forwardresult,UM,EB,pedido) receber(EB, EB $B_{p}$, forwardresult)

[080] RKpR_verdadeiro()

$R K p R$ verdadeiro()

[081] UM_pedido(mens_forwardresult,pedido,EB,UM)

enviar(EB, $U M$, forwardresult $)$ 
para del_pRef_falso 0 e hand_falso0, ou seja, se a referência de proxy não pode ser apagado e se não ocorreu handoff

[082] EB_res_pedido(mens_forwardresult, UM,EB,pedido) receber(EB, $E B_{p}$, forwardresult)

[084] UM_pedido(mens_forwardresult,pedido,EB,UM) enviar(EB, UM, forwardresult)

para del_proxy_verdadeiro 0, ou seja, se o proxy pode ser destruído

[085] EB_ackp_UM(mens_forwresAck,ackp,UM,Proxy) receber(EB, UM, forwresuAck)

[087] Apaga_end_proxy(UM,Proxy)

[088] EB_ackp_proxy(mens_forwresAck,ackp,UM,Proxy)

apagar_proxy $(U M)$

[089] del_proxy_falso()

enviar(EB, Proxy, forwardresult)

[090] del_pRef_falso()

$\neg$ del_proxy_verdadeiro()

para del_proxy_falso 0, ou seja, se o proxy pode ser destruído

[091] EB_ackp_UM(mens_forwresAck,ackp,UM,Proxy) receber(EB, UM, forwresuAck)

[092] EB_ackp_proxy(mens_forwresAck,ackp,UM,Proxy) enviar(EB, Proxy, forwardresult)

[093] EB_res_pedido_proxy(mens_forwardresult,pedido, $U$ $\mathrm{M}$,

receber $\left(E B_{p}\right.$,

Proxy,

EB,Proxy)

[094] EB_res_pedido(mens_forwardresult,UM,EB,pedido) enviar( $E B_{p}, E B$, forwardresult) para del_proxy_verdadeiro(, ou seja, se o proxy pode ser destruído

[095] EB_ackp_proxy(mens_forwresAck,ackp,UM,Proxy) $\operatorname{receber(} E B_{p}, E B$, forwresAck)

[097] Deleta_proxy(Proxy,UM) destruir_proxy(Proxy)

[098] nao_existe_proxy() ᄀexiste_proxy()

[099] del_proxy_falso()

$\neg$ del_proxy_verdadeiro()

para del_proxy_falso (0, ou seja, se o proxy não pode ser destruído

[100] EB_ackp_proxy(mens_forwresAck,ackp,UM,Proxy) $\operatorname{receber}\left(E B_{p}, E B\right.$, forwresAck)

[101] Proxy_ackp(mens_forwresAck,ackp)

enviar(EB , Proxy, forwresAck)

Servidor

[107] Servidor_pedido(mens_request,pedido)

[108] Processa_pedido(pedido)

[109] Servidor_res_pedido(mens_forwardresult,pedido)

receber(Servidor, Proxy, request)

processar()

receber(Servidor, Servidor,

forwardresult)

[110] Proxy_res_pedido(mens_forwardresult,"pedido", EB_res_pedido_proxy) |

enviar(Servidor, Proxy, forwrardresult)

[111] Servidor_res_pedido(mens_forwardresult,pedido)| enviar(Servidor, Servidor, forwardresult)|

[112] del_proxy_verdadeiro()।

del_proxy_verdadeiro() |

[113] ultimo_pedido()

[116] Servidor_res_pedido("forwardresult",pedido)

último_pedido()

enviar(Servidor, Servidor,

forwardresult) 


\section{Apêndice E - Simulação da implementação do Protocolo Handoff na linguagem do Distributed Join-Calculus}

Nova estacao base EB5 recebeu a mensagem greet da unidade movel UM1 que estava na estacao base antiga EB1

Nova estacao base EB5 enviando mensagem dereg para a estacao base antiga solicitando a pRef da unidade movel

Estacao base antiga EB1 recebeu a mensagem dereg

Verificando e retornando a pRef EB1 da unidade movel UM1

Estacao base antiga EB1 enviando mensagem deregAck para nova estacao base com a pRef da unidade movel

Apagando unidade movel UM1 da lista local da estacao base EB1

A nova Estacao Base EB5 recebeu a mensagem deregAck com a pRef EB1

Incluindo unidade movel UM1 na lista local estacao base EB5

A estacao base do proxy recebeu a mensagem update para enviar para o proxy

O Proxy1 recebeu a mensagem update

O proxy da estacao base sera atualizado com a pRef EB1 da Unidade Movel UM1

Atualizando o proxy Proxy1 com a atual localizacao EB1 da unidade movel

Se ocorreu handoff

Reenviando os resultados dos pedidos da unidade movel UM1 que estao no proxy Proxyl e que nao receberam confirmacao de recebimento do resultado pela unidade movel

Nova estacao base EB4 recebeu a mensagem greet da unidade movel UM2 que estava na estacao base antiga EB2

Nova estacao base EB4 enviando mensagem dereg para a estacao base antiga solicitando a pRef da unidade movel

Estacao base antiga EB2 recebeu a mensagem dereg

Nova estacao base EB1 recebeu a mensagem greet da unidade movel UM3 que estava na estacao base antiga EB3

Nova estacao base EB1 enviando mensagem dereg para a estacao base antiga solicitando a pRef da unidade movel

Estacao base antiga EB3 recebeu a mensagem dereg

Verificando e retornando a pRef EB3 da unidade movel UM3

Estacao base antiga EB3 enviando mensagem deregAck para nova estacao base com a pRef da unidade movel

Apagando unidade movel UM3 da lista local da estacao base EB3

A nova Estacao Base EB1 recebeu a mensagem deregAck com a pRef EB3

Incluindo unidade movel UM3 na lista local estacao base EB1

A estacao base do proxy recebeu a mensagem update para enviar para o proxy

O Proxy3 recebeu a mensagem update

O proxy da estacao base sera atualizado com a pRef EB3 da Unidade Movel UM3

Atualizando o proxy Proxy3 com a atual localizacao EB3 da unidade movel

Se ocorreu handoff

Reenviando os resultados dos pedidos da unidade movel UM3 que estao no proxy Proxy3 e que nao receberam confirmacao de recebimento do resultado pela unidade movel 
Nova estacao base EB3 recebeu a mensagem greet da unidade movel UM5 que estava na estacao base antiga EB5

Nova estacao base EB3 enviando mensagem dereg para a estacao base antiga solicitando a pRef da unidade movel

Estacao base antiga EB5 recebeu a mensagem dereg

Verificando e retornando a pRef EB5 da unidade movel UM5

Estacao base antiga EB5 enviando mensagem deregAck para nova estacao base com a pRef da unidade movel

Apagando unidade movel UM5 da lista local da estacao base EB5

A nova Estacao Base EB3 recebeu a mensagem deregAck com a pRef EB5

Incluindo unidade movel UM5 na lista local estacao base EB3

A estacao base do proxy recebeu a mensagem update para enviar para o proxy

O Proxy5 recebeu a mensagem update

O proxy da estacao base sera atualizado com a pRef EB5 da Unidade Movel UM5

Atualizando o proxy Proxy5 com a atual localizacao EB5 da unidade movel

Se ocorreu handoff

Reenviando os resultados dos pedidos da unidade movel UM5 que estao no proxy Proxy5 e que nao receberam confirmacao de recebimento do resultado pela unidade movel

Nova estacao base EB2 recebeu a mensagem greet da unidade movel UM4 que estava na estacao base antiga EB4

Nova estacao base EB2 enviando mensagem dereg para a estacao base antiga solicitando a pRef da unidade movel

Estacao base antiga EB4 recebeu a mensagem dereg

Verificando e retornando a pRef EB4 da unidade movel UM4

Estacao base antiga EB4 enviando mensagem deregAck para nova estacao base com a pRef da unidade movel

Apagando unidade movel UM4 da lista local da estacao base EB4

A nova Estacao Base EB2 recebeu a mensagem deregĀck com a pRef EB4

Incluindo unidade movel UM4 na lista local estacao base EB2

A estacao base do proxy recebeu a mensagem update para enviar para o proxy

O Proxy4 recebeu a mensagem update

O proxy da estacao base sera atualizado com a pRef EB4 da Unidade Movel UM4

Atualizando o proxy Proxy 4 com a atual localizacao EB4 da unidade movel

Se ocorreu handoff

Reenviando os resultados dos pedidos da unidade movel UM4 que estao no proxy Proxy4 e que nao receberam confirmacao de recebimento do resultado pela unidade movel

Verificando e retornando a pRef EB2 da unidade movel UM2

Estacao base antiga EB2 enviando mensagem deregAck para nova estacao base com a pRef da unidade movel

Apagando unidade movel UM2 da lista local da estacao base EB2

A nova Estacao Base EB4 recebeu a mensagem deregAck com a pRef EB2

Incluindo unidade movel UM2 na lista local estacao base EB4

A estacao base do proxy recebeu a mensagem update para enviar para o proxy

O Proxy2 recebeu a mensagem update 
O proxy da estacao base sera atualizado com a pRef EB2 da Unidade Movel UM2

Atualizando o proxy Proxy2 com a atual localizacao EB2 da unidade movel

Se ocorreu handoff

Reenviando os resultados dos pedidos da unidade movel UM2 que estao no proxy Proxy2 e que nao receberam confirmacao de recebimento do resultado pela unidade movel 


\section{Apêndice F - Simulação da implementação de partes relevantes do protocolo RDP na linguagem do Distributed Join-Calculus}

A unidade movel UM1 esta solicitando um novo pedido pedido1 para o proxy proxy1

Pedido sendo enviado para sua estacao base EB1

Estacao Base EB1 recebeu mensagem request com o novo pedido pedido1 da Unidade Movel UM1

Verificando existencia do proxy para a Unidade Movel UM1

Proxy nao existe

Criando novo proxy para a Unidade Movel UM1 na Estacao Base EB1

A estacao base EB1 enviando mensagem update para o proxy atualizar sua pRef

O proxy recebeu a mensagem update para atualizar a Estacao Base com a pRef EB1 da Unidade Movel UM1

A localidade atual EB1 do proxy Proxy1 atualizado

Verificando se ocorreu handoff

Nao ocorreu handoff, nao reenvia pedidos nao confirmados pela Unidade Movel UM1

A estacao base EB1 Enviando mensagem request com o pedido da unidade movel para o proxy proxy1

Proxyl recebeu a mensagem request com o pedido da unidade movel

Incluindo o pedido pedido1 no proxy Proxy1

Proxy1 enviando o pedido da unidade movel para o Servidor

O servidor recebeu a mensagem request com o pedido pedidol da unidade movel

Processando o pedido pedido 1

A unidade movel UM1 esta solicitando um novo pedido pedido2 para o proxy proxy1

Pedido sendo enviado para sua estacao base EB1

Estacao Base EB1 recebeu mensagem request com o novo pedido pedido2 da Unidade Movel UM1

Verificando existencia do proxy para a Unidade Movel UM1

Proxy existe

A estacao base EB1 enviando novo pedido pedido2 da unidade movel UM1 para a estacao base onde o proxy esta

Estacao base do proxy recebeu mensagem request com o pedido da unidade movel

Estacao base EB1 enviando mensagem request com o pedido da unidade movel para o proxy proxy1

Proxy1 recebeu a mensagem request com o pedido da unidade movel

Incluindo o pedido pedido2 no proxy Proxy1

Proxyl enviando o pedido da unidade movel para o Servidor

O servidor recebeu a mensagem request com o pedido pedido2 da unidade movel

Processando o pedido pedido2

A unidade movel UM2 esta solicitando um novo pedido pedido1 para o proxy proxy2

Pedido sendo enviado para sua estacao base EB2

Estacao Base EB2 recebeu mensagem request com o novo pedido pedido1 da Unidade Movel UM2

Verificando existencia do proxy para a Unidade Movel UM2

Proxy nao existe

Criando novo proxy para a Unidade Movel UM2 na Estacao Base EB2

A estacao base EB2 enviando mensagem update para o proxy atualizar sua pRef

O proxy recebeu a mensagem update para atualizar a Estacao Base com a pRef EB2 da Unidade Movel UM2 
A localidade atual EB2 do proxy Proxy2 atualizado

Verificando se ocorreu handoff

Nao ocorreu handoff, nao reenvia pedidos nao confirmados pela Unidade Movel UM2

A estacao base EB2 Enviando mensagem request com o pedido da unidade movel para o proxy proxy2

Proxy2 recebeu a mensagem request com o pedido da unidade movel

Incluindo o pedido pedidol no proxy Proxy2

Proxy2 enviando o pedido da unidade movel para o Servidor

O servidor recebeu a mensagem request com o pedido pedidol da unidade movel

Processando o pedido pedido1

A unidade movel UM2 esta solicitando um novo pedido pedido2 para o proxy proxy2

Pedido sendo enviado para sua estacao base EB2

Estacao Base EB2 recebeu mensagem request com o novo pedido pedido2 da Unidade Movel UM2

Verificando existencia do proxy para a Unidade Movel UM2

Proxy existe

A estacao base EB2 enviando novo pedido pedido2 da unidade movel UM2 para a estacao base onde o proxy esta

Estacao base do proxy recebeu mensagem request com o pedido da unidade movel

Estacao base EB2 enviando mensagem request com o pedido da unidade movel para o proxy proxy2

Proxy2 recebeu a mensagem request com o pedido da unidade movel

Incluindo o pedido pedido2 no proxy Proxy2

Proxy2 enviando o pedido da unidade movel para o Servidor

O servidor recebeu a mensagem request com o pedido pedido2 da unidade movel

Processando o pedido pedido2

A unidade movel UM3 esta solicitando um novo pedido pedidol para o proxy proxy3

Pedido sendo enviado para sua estacao base EB3

Estacao Base EB3 recebeu mensagem request com o novo pedido pedido1 da Unidade Movel UM3

Verificando existencia do proxy para a Unidade Movel UM3

Proxy nao existe

Criando novo proxy para a Unidade Movel UM3 na Estacao Base EB3

A estacao base EB3 enviando mensagem update para o proxy atualizar sua $p$ Ref

O proxy recebeu a mensagem update para atualizar a Estacao Base com a pRef EB3 da Unidade Movel UM3

A localidade atual EB3 do proxy Proxy3 atualizado

Verificando se ocorreu handoff

Nao ocorreu handoff, nao reenvia pedidos nao confirmados pela Unidade Movel UM3

A estacao base EB3 Enviando mensagem request com o pedido da unidade movel para o proxy proxy3

Proxy3 recebeu a mensagem request com o pedido da unidade movel

Incluindo o pedido pedidol no proxy Proxy3

Proxy3 enviando o pedido da unidade movel para o Servidor

O servidor recebeu a mensagem request com o pedido pedidol da unidade movel

Processando o pedido pedido 1

A unidade movel UM3 esta solicitando um novo pedido pedido2 para o proxy proxy3

Pedido sendo enviado para sua estacao base EB3

Estacao Base EB3 recebeu mensagem request com o novo pedido pedido2 da Unidade Movel UM3 
Verificando existencia do proxy para a Unidade Movel UM3

Proxy existe

A estacao base EB3 enviando novo pedido pedido2 da unidade movel UM3 para a estacao base onde o proxy esta

Estacao base do proxy recebeu mensagem request com o pedido da unidade movel

Estacao base EB3 enviando mensagem request com o pedido da unidade movel para o proxy proxy3

Proxy3 recebeu a mensagem request com o pedido da unidade movel

Incluindo o pedido pedido2 no proxy Proxy3

Proxy3 enviando o pedido da unidade movel para o Servidor

O servidor recebeu a mensagem request com o pedido pedido2 da unidade movel

Processando o pedido pedido2

A unidade movel UM4 esta solicitando um novo pedido pedido1 para o proxy proxy4

Pedido sendo enviado para sua estacao base EB4

Estacao Base EB4 recebeu mensagem request com o novo pedido pedido1 da Unidade Movel UM4

Verificando existencia do proxy para a Unidade Movel UM4

Proxy nao existe

Criando novo proxy para a Unidade Movel UM4 na Estacao Base EB4

A estacao base EB4 enviando mensagem update para o proxy atualizar sua pRef

O proxy recebeu a mensagem update para atualizar a Estacao Base com a pRef EB4 da Unidade Movel UM4

A localidade atual EB4 do proxy Proxy4 atualizado

Verificando se ocorreu handoff

Nao ocorreu handoff, nao reenvia pedidos nao confirmados pela Unidade Movel UM4

A estacao base EB4 Enviando mensagem request com o pedido da unidade movel para o proxy proxy 4

Proxy4 recebeu a mensagem request com o pedido da unidade movel

Incluindo o pedido pedido1 no proxy Proxy4

Proxy4 enviando o pedido da unidade movel para o Servidor

O servidor recebeu a mensagem request com o pedido pedidol da unidade movel

Processando o pedido pedido 1

A unidade movel UM4 esta solicitando um novo pedido pedido2 para o proxy proxy4

Pedido sendo enviado para sua estacao base EB4

Estacao Base EB4 recebeu mensagem request com o novo pedido pedido2 da Unidade Movel UM4

Verificando existencia do proxy para a Unidade Movel UM4

Proxy existe

A estacao base EB4 enviando novo pedido pedido2 da unidade movel UM4 para a estacao base onde o proxy esta

Estacao base do proxy recebeu mensagem request com o pedido da unidade movel

Estacao base EB4 enviando mensagem request com o pedido da unidade movel para o proxy proxy 4

Proxy4 recebeu a mensagem request com o pedido da unidade movel

Incluindo o pedido pedido2 no proxy Proxy4

Proxy4 enviando o pedido da unidade movel para o Servidor

O servidor recebeu a mensagem request com o pedido pedido2 da unidade movel

Processando o pedido pedido2

A unidade movel UM5 esta solicitando um novo pedido pedido 1 para o proxy proxy5 
Pedido sendo enviado para sua estacao base EB5

Estacao Base EB5 recebeu mensagem request com o novo pedido pedido1 da Unidade Movel UM5

Verificando existencia do proxy para a Unidade Movel UM5

Proxy nao existe

Criando novo proxy para a Unidade Movel UM5 na Estacao Base EB5

A estacao base EB5 enviando mensagem update para o proxy atualizar sua pRef

O proxy recebeu a mensagem update para atualizar a Estacao Base com a pRef EB5 da Unidade Movel UM5

A localidade atual EB5 do proxy Proxy5 atualizado

Verificando se ocorreu handoff

Nao ocorreu handoff, nao reenvia pedidos nao confirmados pela Unidade Movel UM5

A estacao base EB5 Enviando mensagem request com o pedido da unidade movel para o proxy proxy5

Proxy5 recebeu a mensagem request com o pedido da unidade movel

Incluindo o pedido pedido1 no proxy Proxy5

Proxy5 enviando o pedido da unidade movel para o Servidor

O servidor recebeu a mensagem request com o pedido pedidol da unidade movel

Processando o pedido pedido 1

A unidade movel UM5 esta solicitando um novo pedido pedido2 para o proxy proxy5

Pedido sendo enviado para sua estacao base EB5

Estacao Base EB5 recebeu mensagem request com o novo pedido pedido2 da Unidade Movel UM5

Verificando existencia do proxy para a Unidade Movel UM5

Proxy existe

A estacao base EB5 enviando novo pedido pedido2 da unidade movel UM5 para a estacao base onde o proxy esta

Estacao base do proxy recebeu mensagem request com o pedido da unidade movel

Estacao base EB5 enviando mensagem request com o pedido da unidade movel para o proxy proxy5

Proxy5 recebeu a mensagem request com o pedido da unidade movel

Incluindo o pedido pedido2 no proxy Proxy5

Proxy5 enviando o pedido da unidade movel para o Servidor

O servidor recebeu a mensagem request com o pedido pedido2 da unidade movel

Processando o pedido pedido2

Nova estacao base EB5 recebeu a mensagem greet da unidade movel UM1 que estava na estacao base antiga

Nova estacao base EB5 enviando mensagem dereg para a estacao base antiga solicitando a pRef da unidade movel

Estacao base antiga EB1 recebeu a mensagem dereg

Estacao base antiga EB1 enviando mensagem deregAck para nova estacao base com a pRef da unidade movel

Apagando a unidade movel UM1 da lista local da estacao base antiga EB1

A nova Estacao Base EB5 recebeu a mensagem deregAck com a pRef EB1

Incluindo a Unidade Movel UM1 na lista local da Estacao Base nova EB5

Enviando mensagem update para a estacao base onde o proxy esta

A estacao base do proxy recebeu a mensagem update para enviar para o proxy 
O proxy recebeu a mensagem update para atualizar a Estacao Base com a pRef EB1 da Unidade Movel UM1

A localidade atual EB1 do proxy Proxy1 atualizado

Verificando se ocorreu handoff

Ocorreu handoff

Reenviando os pedidos do Proxy Proxy1, que nao receberam confirmacao de recebimento da Unidade Movel UM1

A unidade movel UM1 esta solicitando um novo pedido pedido3 para o proxy proxy1

Pedido sendo enviado para sua estacao base EB5

Estacao Base EB5 recebeu mensagem request com o novo pedido pedido3 da Unidade Movel UM1

Verificando existencia do proxy para a Unidade Movel UM1

Proxy existe

A estacao base EB5 enviando novo pedido pedido3 da unidade movel UM1 para a estacao base onde o proxy esta

Estacao base do proxy recebeu mensagem request com o pedido da unidade movel

Estacao base EB1 enviando mensagem request com o pedido da unidade movel para o proxy proxy1

Proxyl recebeu a mensagem request com o pedido da unidade movel

Incluindo o pedido pedido3 no proxy Proxy1

Proxy1 enviando o pedido da unidade movel para o Servidor

O servidor recebeu a mensagem request com o pedido pedido 3 da unidade movel

Processando o pedido pedido 3

O servidor esta enviando o resultado do pedido pedido1 para o proxy Proxy1 enviar para sua unidade movel UM1

O proxy Proxyl recebeu a mensagem forwardresult do Servidor com o resultado do pedido pedido1 Verificando se eh ultimo pedido pendente do proxy Proxy1

Nao eh ultimo pedido pendente

Proxy1 enviando pedido para a sua EB

Estacao Base EB1 recebeu do proxy Proxyl a mensagem forwardresult com o resultado do pedido pedidol da Unidade Movel UM1

Estacao Base EB1 enviando pedido pedidol para a Estacao Base onde esta a Unidade Movel UM1

Estacao Base EB5 recebeu a mensagem forwardresult com o resultado do pedido pedido1 da Unidade Movel UM1

Verificando se eh o ultimo pedido pendente da Unidade Movel UM1

Nao eh o ultimo pedido pendente

A Estacao Base EB5 esta enviando resultado do pedido para a Unidade Movel UM1

A Unidade Movel UM1 recebeu a mensagem forwardresult com o resultado do pedido pedido1

A Unidade Movel UM1 enviando confirmacao do resultado do pedido com a mensagem forwresAck para a Estacao Base EB5

Estacao Base EB5 recebeu a mensagem forwresAck com confirmacao de recebimento do pedido pedidol pela Unidade Movel UM1

Verificando a possibilidade de apagar o endereco do proxy

Proxy nao vazio: nao eh possivel apaga-lo

Estacao Base EB5 enviando confirmacao de recebimento do pedido para a Estacao Base onde esta o proxy da Unidade Movel UM1 
Estacao Base EB1 recebeu a mensagem forwresAck de confirmacao de recebimento do pedido pedido1 pela Unidade Movel UM1

Verificando a possibilidade de destruir o proxy

Nao eh possivel destruir o proxy

Estacao Base EB1 enviando confirmacao de pedido pela Unidade Movel para o proxy Proxy1

O proxy Proxy1 recebeu a mensagem forwresAck de confirmacao de recebimento do pedido pedidol pela unidade movel UM1

Pedido pedidol removido da Lista de Pedidos do proxy Proxy1

O servidor esta enviando o resultado do pedido pedido2 para o proxy Proxy1 enviar para sua unidade movel UM1

O proxy Proxy1 recebeu a mensagem forwardresult do Servidor com o resultado do pedido pedido2

Verificando se eh ultimo pedido pendente do proxy Proxy1

Nao eh ultimo pedido pendente

Proxyl enviando pedido para a sua EB

Estacao Base EB1 recebeu do proxy Proxy1 a mensagem forwardresult com o resultado do pedido pedido2 da Unidade Movel UM1

Estacao Base EB1 enviando pedido pedido2 para a Estacao Base onde esta a Unidade Movel UM1

Estacao Base EB5 recebeu a mensagem forwardresult com o resultado do pedido pedido2 da Unidade Movel UM1

Verificando se eh o ultimo pedido pendente da Unidade Movel UM1

Nao eh o ultimo pedido pendente

A Estacao Base EB5 esta enviando resultado do pedido para a Unidade Movel UM1

A Unidade Movel UM1 recebeu a mensagem forwardresult com o resultado do pedido pedido2

A Unidade Movel UM1 enviando confirmacao do resultado do pedido com a mensagem forwresAck para a Estacao Base EB5

Estacao Base EB5 recebeu a mensagem forwresAck com confirmacao de recebimento do pedido pedido2 pela Unidade Movel UM1

Verificando a possibilidade de apagar o endereco do proxy

Proxy nao vazio: nao eh possivel apaga-lo

Estacao Base EB5 enviando confirmacao de recebimento do pedido para a Estacao Base onde esta o proxy da Unidade Movel UM1

Estacao Base EB1 recebeu a mensagem forwresAck de confirmacao de recebimento do pedido pedido2 pela Unidade Movel UM1

Verificando a possibilidade de destruir o proxy

Nao eh possivel destruir o proxy

Estacao Base EB1 enviando confirmacao de pedido pela Unidade Movel para o proxy Proxy1

O proxy Proxy1 recebeu a mensagem forwresAck de confirmacao de recebimento do pedido pedido2 pela unidade movel UM1

Pedido pedido2 removido da Lista de Pedidos do proxy Proxy1

Nova estacao base EB4 recebeu a mensagem greet da unidade movel UM2 que estava na estacao base antiga

Nova estacao base EB4 enviando mensagem dereg para a estacao base antiga solicitando a pRef da unidade movel

Estacao base antiga EB2 recebeu a mensagem dereg 
Estacao base antiga EB2 enviando mensagem deregAck para nova estacao base com a pRef da unidade movel

Apagando a unidade movel UM2 da lista local da estacao base antiga EB2

A nova Estacao Base EB4 recebeu a mensagem deregAck com a pRef EB2

Incluindo a Unidade Movel UM2 na lista local da Estacao Base nova EB4

Enviando mensagem update para a estacao base onde o proxy esta

A estacao base do proxy recebeu a mensagem update para enviar para o proxy

O proxy recebeu a mensagem update para atualizar a Estacao Base com a pRef EB2 da Unidade Movel UM2

A localidade atual EB2 do proxy Proxy2 atualizado

Verificando se ocorreu handoff

Ocorreu handoff

Reenviando os pedidos do Proxy Proxy2, que nao receberam confirmacao de recebimento da Unidade Movel UM2

A unidade movel UM2 esta solicitando um novo pedido pedido3 para o proxy proxy2

Pedido sendo enviado para sua estacao base EB4

Estacao Base EB4 recebeu mensagem request com o novo pedido pedido3 da Unidade Movel UM2

Verificando existencia do proxy para a Unidade Movel UM2

Proxy existe

A estacao base EB4 enviando novo pedido pedido3 da unidade movel UM2 para a estacao base onde o proxy esta

Estacao base do proxy recebeu mensagem request com o pedido da unidade movel

Estacao base EB2 enviando mensagem request com o pedido da unidade movel para o proxy proxy2

Proxy2 recebeu a mensagem request com o pedido da unidade movel

Incluindo o pedido pedido3 no proxy Proxy2

Proxy 2 enviando o pedido da unidade movel para o Servidor

O servidor recebeu a mensagem request com o pedido pedido3 da unidade movel

Processando o pedido pedido3

O servidor esta enviando o resultado do pedido pedido 1 para o proxy Proxy2 enviar para sua unidade movel UM2

O proxy Proxy 2 recebeu a mensagem forwardresult do Servidor com o resultado do pedido pedido1

Verificando se eh ultimo pedido pendente do proxy Proxy2

Nao eh ultimo pedido pendente

Proxy2 enviando pedido para a sua EB

Estacao Base EB2 recebeu do proxy Proxy2 a mensagem forwardresult com o resultado do pedido pedidol da Unidade Movel UM2

Estacao Base EB2 enviando pedido pedido1 para a Estacao Base onde esta a Unidade Movel UM2

Estacao Base EB4 recebeu a mensagem forwardresult com o resultado do pedido pedido1 da Unidade Movel UM2

Verificando se eh o ultimo pedido pendente da Unidade Movel UM2

Nao eh o ultimo pedido pendente

A Estacao Base EB4 esta enviando resultado do pedido para a Unidade Movel UM2

A Unidade Movel UM2 recebeu a mensagem forwardresult com o resultado do pedido pedido1 
A Unidade Movel UM2 enviando confirmacao do resultado do pedido com a mensagem forwresAck para a Estacao Base EB4

Estacao Base EB4 recebeu a mensagem forwresAck com confirmacao de recebimento do pedido pedido1 pela Unidade Movel UM2

Verificando a possibilidade de apagar o endereco do proxy

Proxy nao vazio: nao eh possivel apaga-lo

Estacao Base EB4 enviando confirmacao de recebimento do pedido para a Estacao Base onde esta o proxy da Unidade Movel UM2

Estacao Base EB2 recebeu a mensagem forwresAck de confirmacao de recebimento do pedido pedido1 pela Unidade Movel UM2

Verificando a possibilidade de destruir o proxy

Nao eh possivel destruir o proxy

Estacao Base EB2 enviando confirmacao de pedido pela Unidade Movel para o proxy Proxy2

O proxy Proxy2 recebeu a mensagem forwresAck de confirmacao de recebimento do pedido pedido1 pela unidade movel UM2

Pedido pedido1 removido da Lista de Pedidos do proxy Proxy2

O servidor esta enviando o resultado do pedido pedido2 para o proxy Proxy2 enviar para sua unidade movel UM2

O proxy Proxy2 recebeu a mensagem forwardresult do Servidor com o resultado do pedido pedido2

Verificando se eh ultimo pedido pendente do proxy Proxy2

Nao eh ultimo pedido pendente

Proxy2 enviando pedido para a sua EB

Estacao Base EB2 recebeu do proxy Proxy2 a mensagem forwardresult com o resultado do pedido pedido2 da Unidade Movel UM2

Estacao Base EB2 enviando pedido pedido2 para a Estacao Base onde esta a Unidade Movel UM2

Estacao Base EB4 recebeu a mensagem forwardresult com o resultado do pedido pedido2 da Unidade Movel UM2

Verificando se eh o ultimo pedido pendente da Unidade Movel UM2

Nao eh o ultimo pedido pendente

A Estacao Base EB4 esta enviando resultado do pedido para a Unidade Movel UM2

A Unidade Movel UM2 recebeu a mensagem forwardresult com o resultado do pedido pedido2

A Unidade Movel UM2 enviando confirmacao do resultado do pedido com a mensagem forwresAck para a Estacao Base EB4

Estacao Base EB4 recebeu a mensagem forwresAck com confirmacao de recebimento do pedido pedido2 pela Unidade Movel UM2

Verificando a possibilidade de apagar o endereco do proxy

Proxy nao vazio: nao eh possivel apaga-lo

Estacao Base EB4 enviando confirmacao de recebimento do pedido para a Estacao Base onde esta o proxy da Unidade Movel UM2

Estacao Base EB2 recebeu a mensagem forwresAck de confirmacao de recebimento do pedido pedido2 pela Unidade Movel UM2

Verificando a possibilidade de destruir o proxy

Nao eh possivel destruir o proxy

Estacao Base EB2 enviando confirmacao de pedido pela Unidade Movel para o proxy Proxy2 
O proxy Proxy2 recebeu a mensagem forwresAck de confirmacao de recebimento do pedido pedido2 pela unidade movel UM2

Pedido pedido2 removido da Lista de Pedidos do proxy Proxy2

Nova estacao base EB1 recebeu a mensagem greet da unidade movel UM3 que estava na estacao base antiga

Nova estacao base EB1 enviando mensagem dereg para a estacao base antiga solcitando a pRef da unidade movel

Estacao base antiga EB3 recebeu a mensagem dereg

Estacao base antiga EB3 enviando mensagem deregAck para nova estacao base com a pRef da unidade movel

Apagando a unidade movel UM3 da lista local da estacao base antiga EB3

A nova Estacao Base EB1 recebeu a mensagem deregAck com a pRef EB3

Incluindo a Unidade Movel UM3 na lista local da Estacao Base nova EB1

Enviando mensagem update para a estacao base onde o proxy esta

A estacao base do proxy recebeu a mensagem update para enviar para o proxy

O proxy recebeu a mensagem update para atualizar a Estacao Base com a pRef EB3 da Unidade Movel UM3

A localidade atual EB3 do proxy Proxy3 atualizado

Verificando se ocorreu handoff

Ocorreu handoff

Reenviando os pedidos do Proxy Proxy3, que nao receberam confirmacao de recebimento da Unidade Movel UM3

A unidade movel UM3 esta solicitando um novo pedido pedido3 para o proxy proxy3

Pedido sendo enviado para sua estacao base EB1

Estacao Base EB1 recebeu mensagem request com o novo pedido pedido3 da Unidade Movel UM3

Verificando existencia do proxy para a Unidade Movel UM3

Proxy existe

A estacao base EB1 enviando novo pedido pedido3 da unidade movel UM3 para a estacao base onde o proxy esta

Estacao base do proxy recebeu mensagem request com o pedido da unidade movel

Estacao base EB3 enviando mensagem request com o pedido da unidade movel para o proxy proxy3

Proxy3 recebeu a mensagem request com o pedido da unidade movel

Incluindo o pedido pedido3 no proxy Proxy3

Proxy3 enviando o pedido da unidade movel para o Servidor

O servidor recebeu a mensagem request com o pedido pedido3 da unidade movel

Processando o pedido pedido3

O servidor esta enviando o resultado do pedido pedido1 para o proxy Proxy3 enviar para sua unidade movel UM3

O proxy Proxy3 recebeu a mensagem forwardresult do Servidor com o resultado do pedido pedido 1

Verificando se eh ultimo pedido pendente do proxy Proxy3

Nao eh ultimo pedido pendente

Proxy3 enviando pedido para a sua EB

Estacao Base EB3 recebeu do proxy Proxy3 a mensagem forwardresult com o resultado do pedido pedido1 da Unidade Movel UM3 
Estacao Base EB3 enviando pedido pedido1 para a Estacao Base onde esta a Unidade Movel UM3

Estacao Base EB1 recebeu a mensagem forwardresult com o resultado do pedido pedido1 da Unidade Movel UM3

Verificando se eh o ultimo pedido pendente da Unidade Movel UM3

Nao eh o ultimo pedido pendente

A Estacao Base EB1 esta enviando resultado do pedido para a Unidade Movel UM3

A Unidade Movel UM3 recebeu a mensagem forwardresult com o resultado do pedido pedido1

A Unidade Movel UM3 enviando confirmacao do resultado do pedido com a mensagem forwresAck para a Estacao Base EB1

Estacao Base EB1 recebeu a mensagem forwresAck com confirmacao de recebimento do pedido pedido 1 pela Unidade Movel UM3

Verificando a possibilidade de apagar o endereco do proxy

Proxy nao vazio: nao eh possivel apaga-lo

Estacao Base EB1 enviando confirmacao de recebimento do pedido para a Estacao Base onde esta o proxy da Unidade Movel UM3

Estacao Base EB3 recebeu a mensagem forwresAck de confirmacao de recebimento do pedido pedido1 pela Unidade Movel UM3

Verificando a possibilidade de destruir o proxy

Nao eh possivel destruir o proxy

Estacao Base EB3 enviando confirmacao de pedido pela Unidade Movel para o proxy Proxy3

O proxy Proxy3 recebeu a mensagem forwresAck de confirmacao de recebimento do pedido pedido1 pela unidade movel UM3

Pedido pedido1 removido da Lista de Pedidos do proxy Proxy3

O servidor esta enviando o resultado do pedido pedido2 para o proxy Proxy3 enviar para sua unidade movel UM3

O proxy Proxy3 recebeu a mensagem forwardresult do Servidor com o resultado do pedido pedido2

Verificando se eh ultimo pedido pendente do proxy Proxy3

Nao eh ultimo pedido pendente

Proxy3 enviando pedido para a sua EB

Estacao Base EB3 recebeu do proxy Proxy3 a mensagem forwardresult com o resultado do pedido pedido2 da Unidade Movel UM3

Estacao Base EB3 enviando pedido pedido2 para a Estacao Base onde esta a Unidade Movel UM3

Estacao Base EB1 recebeu a mensagem forwardresult com o resultado do pedido pedido2 da Unidade Movel UM3

Verificando se eh o ultimo pedido pendente da Unidade Movel UM3

Nao eh o ultimo pedido pendente

A Estacao Base EB1 esta enviando resultado do pedido para a Unidade Movel UM3

A Unidade Movel UM3 recebeu a mensagem forwardresult com o resultado do pedido pedido2

A Unidade Movel UM3 enviando confirmacao do resultado do pedido com a mensagem forwresAck para a Estacao Base EB1

Estacao Base EB1 recebeu a mensagem forwresAck com confirmacao de recebimento do pedido pedido2 pela Unidade Movel UM3

Verificando a possibilidade de apagar o endereco do proxy

Proxy nao vazio: nao eh possivel apaga-lo 
Estacao Base EB1 enviando confirmacao de recebimento do pedido para a Estacao Base onde esta o proxy da Unidade Movel UM3

Estacao Base EB3 recebeu a mensagem forwresAck de confirmacao de recebimento do pedido pedido2 pela Unidade Movel UM3

Verificando a possibilidade de destruir o proxy

Nao eh possivel destruir o proxy

Estacao Base EB3 enviando confirmacao de pedido pela Unidade Movel para o proxy Proxy3

O proxy Proxy3 recebeu a mensagem forwresAck de confirmacao de recebimento do pedido pedido2 pela unidade movel UM3

Pedido pedido2 removido da Lista de Pedidos do proxy Proxy3

Nova estacao base EB3 recebeu a mensagem greet da unidade movel UM4 que estava na estacao base antiga

Nova estacao base EB3 enviando mensagem dereg para a estacao base antiga solicitando a pRef da unidade movel

Estacao base antiga EB4 recebeu a mensagem dereg

Estacao base antiga EB4 enviando mensagem deregAck para nova estacao base com a pRef da unidade movel

Apagando a unidade movel UM4 da lista local da estacao base antiga EB4

A nova Estacao Base EB3 recebeu a mensagem deregAck com a pRef EB4

Incluindo a Unidade Movel UM4 na lista local da Estacao Base nova EB3

Enviando mensagem update para a estacao base onde o proxy esta

A estacao base do proxy recebeu a mensagem update para enviar para o proxy

O proxy recebeu a mensagem update para atualizar a Estacao Base com a pRef EB4 da Unidade Movel UM4

A localidade atual EB4 do proxy Proxy4 atualizado

Verificando se ocorreu handoff

Ocorreu handoff

Reenviando os pedidos do Proxy Proxy4, que nao receberam confirmacao de recebimento da Unidade Movel UM4

A unidade movel UM4 esta solicitando um novo pedido pedido3 para o proxy proxy4

Pedido sendo enviado para sua estacao base EB3

Estacao Base EB3 recebeu mensagem request com o novo pedido pedido3 da Unidade Movel UM4

Verificando existencia do proxy para a Unidade Movel UM4

Proxy existe

A estacao base EB3 enviando novo pedido pedido3 da unidade movel UM4 para a estacao base onde o proxy esta

Estacao base do proxy recebeu mensagem request com o pedido da unidade movel

Estacao base EB4 enviando mensagem request com o pedido da unidade movel para o proxy proxy4

Proxy4 recebeu a mensagem request com o pedido da unidade movel

Incluindo o pedido pedido3 no proxy Proxy4

Proxy4 enviando o pedido da unidade movel para o Servidor

O servidor recebeu a mensagem request com o pedido pedido3 da unidade movel

Processando o pedido pedido3 
O servidor esta enviando o resultado do pedido pedido1 para o proxy Proxy4 enviar para sua unidade movel UM4

O proxy Proxy4 recebeu a mensagem forwardresult do Servidor com o resultado do pedido pedido1

Verificando se eh ultimo pedido pendente do proxy Proxy4

Nao eh ultimo pedido pendente

Proxy4 enviando pedido para a sua EB

Estacao Base EB4 recebeu do proxy Proxy4 a mensagem forwardresult com o resultado do pedido pedido1 da Unidade Movel UM4

Estacao Base EB4 enviando pedido pedido1 para a Estacao Base onde esta a Unidade Movel UM4

Estacao Base EB3 recebeu a mensagem forwardresult com o resultado do pedido pedido1 da Unidade Movel UM4

Verificando se eh o ultimo pedido pendente da Unidade Movel UM4

Nao eh o ultimo pedido pendente

A Estacao Base EB3 esta enviando resultado do pedido para a Unidade Movel UM4

A Unidade Movel UM4 recebeu a mensagem forwardresult com o resultado do pedido pedido1

A Unidade Movel UM4 enviando confirmacao do resultado do pedido com a mensagem forwresAck para a Estacao Base EB3

Estacao Base EB3 recebeu a mensagem forwresAck com confirmacao de recebimento do pedido pedido1 pela Unidade Movel UM4

Verificando a possibilidade de apagar o endereco do proxy

Proxy nao vazio: nao eh possivel apaga-lo

Estacao Base EB3 enviando confirmacao de recebimento do pedido para a Estacao Base onde esta o proxy da Unidade Movel UM4

Estacao Base EB4 recebeu a mensagem forwresAck de confirmacao de recebimento do pedido pedido1 pela Unidade Movel UM4

Verificando a possibilidade de destruir o proxy

Nao eh possivel destruir o proxy

Estacao Base EB4 enviando confirmacao de pedido pela Unidade Movel para o proxy Proxy4

O proxy Proxy4 recebeu a mensagem forwresAck de confirmacao de recebimento do pedido pedido 1 pela unidade movel UM4

Pedido pedido1 removido da Lista de Pedidos do proxy Proxy4

O servidor esta enviando o resultado do pedido pedido2 para o proxy Proxy4 enviar para sua unidade movel UM4

O proxy Proxy 4 recebeu a mensagem forwardresult do Servidor com o resultado do pedido pedido2

Verificando se eh ultimo pedido pendente do proxy Proxy 4

Nao eh ultimo pedido pendente

Proxy4 enviando pedido para a sua EB

Estacao Base EB4 recebeu do proxy Proxy4 a mensagem forwardresult com o resultado do pedido pedido2 da Unidade Movel UM4

Estacao Base EB4 enviando pedido pedido2 para a Estacao Base onde esta a Unidade Movel UM4

Estacao Base EB3 recebeu a mensagem forwardresult com o resultado do pedido pedido2 da Unidade Movel UM4

Verificando se eh o ultimo pedido pendente da Unidade Movel UM4

Nao eh o ultimo pedido pendente 
A Estacao Base EB3 esta enviando resultado do pedido para a Unidade Movel UM4

A Unidade Movel UM4 recebeu a mensagem forwardresult com o resultado do pedido pedido2

A Unidade Movel UM4 enviando confirmacao do resultado do pedido com a mensagem forwresAck para a Estacao Base EB3

Estacao Base EB3 recebeu a mensagem forwresAck com confirmacao de recebimento do pedido pedido2 pela Unidade Movel UM4

Verificando a possibilidade de apagar o endereco do proxy

Proxy nao vazio: nao eh possivel apaga-lo

Estacao Base EB3 enviando confirmacao de recebimento do pedido para a Estacao Base onde esta o proxy da Unidade Movel UM4

Estacao Base EB4 recebeu a mensagem forwresAck de confirmacao de recebimento do pedido pedido2 pela Unidade Movel UM4

Verificando a possibilidade de destruir o proxy

Nao eh possivel destruir o proxy

Estacao Base EB4 enviando confirmacao de pedido pela Unidade Movel para o proxy Proxy4

O proxy Proxy4 recebeu a mensagem forwresAck de confirmacao de recebimento do pedido pedido2 pela unidade movel UM4

Pedido pedido2 removido da Lista de Pedidos do proxy Proxy4

Nova estacao base EB2 recebeu a mensagem greet da unidade movel UM5 que estava na estacao base antiga

Nova estacao base EB2 enviando mensagem dereg para a estacao base antiga solicitando a pRef da unidade movel

Estacao base antiga EB5 recebeu a mensagem dereg

Estacao base antiga EB5 enviando mensagem deregAck para nova estacao base com a pRef da unidade movel

Apagando a unidade movel UM5 da lista local da estacao base antiga EB5

A nova Estacao Base EB2 recebeu a mensagem deregAck com a pRef EB5

Incluindo a Unidade Movel UM5 na lista local da Estacao Base nova EB2

Enviando mensagem update para a estacao base onde o proxy esta

A estacao base do proxy recebeu a mensagem update para enviar para o proxy

O proxy recebeu a mensagem update para atualizar a Estacao Base com a pRef EB5 da Unidade Movel UM5

A localidade atual EB5 do proxy Proxy5 atualizado

Verificando se ocorreu handoff

Ocorreu handoff

Reenviando os pedidos do Proxy Proxy5, que nao receberam confirmacao de recebimento da Unidade Movel UM5

A unidade movel UM5 esta solicitando um novo pedido pedido3 para o proxy proxy5

Pedido sendo enviado para sua estacao base EB2

Estacao Base EB2 recebeu mensagem request com o novo pedido pedido3 da Unidade Movel UM5

Verificando existencia do proxy para a Unidade Movel UM5

Proxy existe

A estacao base EB2 enviando novo pedido pedido3 da unidade movel UM5 para a estacao base onde o proxy esta 
Estacao base do proxy recebeu mensagem request com o pedido da unidade movel

Estacao base EB5 enviando mensagem request com o pedido da unidade movel para o proxy proxy5

Proxy5 recebeu a mensagem request com o pedido da unidade movel

Incluindo o pedido pedido3 no proxy Proxy5

Proxy5 enviando o pedido da unidade movel para o Servidor

O servidor recebeu a mensagem request com o pedido pedido 3 da unidade movel

Processando o pedido pedido3

O servidor esta enviando o resultado do pedido pedido1 para o proxy Proxy5 enviar para sua unidade movel UM5

O proxy Proxy5 recebeu a mensagem forwardresult do Servidor com o resultado do pedido pedido1

Verificando se eh ultimo pedido pendente do proxy Proxy5

Nao eh ultimo pedido pendente

Proxy5 enviando pedido para a sua EB

Estacao Base EB5 recebeu do proxy Proxy5 a mensagem forwardresult com o resultado do pedido pedidol da Unidade Movel UM5

Estacao Base EB5 enviando pedido pedidol para a Estacao Base onde esta a Unidade Movel UM5

Estacao Base EB2 recebeu a mensagem forwardresult com o resultado do pedido pedido1 da Unidade Movel UM5

Verificando se eh o ultimo pedido pendente da Unidade Movel UM5

Nao eh o ultimo pedido pendente

A Estacao Base EB2 esta enviando resultado do pedido para a Unidade Movel UM5

A Unidade Movel UM5 recebeu a mensagem forwardresult com o resultado do pedido pedido1

A Unidade Movel UM5 enviando confirmacao do resultado do pedido com a mensagem forwresAck para a Estacao Base EB2

Estacao Base EB2 recebeu a mensagem forwresAck com confirmacao de recebimento do pedido pedido1 pela Unidade Movel UM5

Verificando a possibilidade de apagar o endereco do proxy

Proxy nao vazio: nao eh possivel apaga-lo

Estacao Base EB2 enviando confirmacao de recebimento do pedido para a Estacao Base onde esta o proxy da Unidade Movel UM5

Estacao Base EB5 recebeu a mensagem forwresAck de confirmacao de recebimento do pedido pedidol pela Unidade Movel UM5

Verificando a possibilidade de destruir o proxy

Nao eh possivel destruir o proxy

Estacao Base EB5 enviando confirmacao de pedido pela Unidade Movel para o proxy Proxy5

O proxy Proxy5 recebeu a mensagem forwresAck de confirmacao de recebimento do pedido pedido1 pela unidade movel UM5

Pedido pedido 1 removido da Lista de Pedidos do proxy Proxy5

O servidor esta enviando o resultado do pedido pedido2 para o proxy Proxy5 enviar para sua unidade movel UM5

O proxy Proxy5 recebeu a mensagem forwardresult do Servidor com o resultado do pedido pedido2 Verificando se eh ultimo pedido pendente do proxy Proxy5

Nao eh ultimo pedido pendente

Proxy5 enviando pedido para a sua EB 
Estacao Base EB5 recebeu do proxy Proxy5 a mensagem forwardresult com o resultado do pedido pedido2 da Unidade Movel UM5

Estacao Base EB5 enviando pedido pedido2 para a Estacao Base onde esta a Unidade Movel UM5

Estacao Base EB2 recebeu a mensagem forwardresult com o resultado do pedido pedido2 da Unidade Movel UM5

Verificando se eh o ultimo pedido pendente da Unidade Movel UM5

Nao eh o ultimo pedido pendente

A Estacao Base EB2 esta enviando resultado do pedido para a Unidade Movel UM5

A Unidade Movel UM5 recebeu a mensagem forwardresult com o resultado do pedido pedido2

A Unidade Movel UM5 enviando confirmacao do resultado do pedido com a mensagem forwresAck para a Estacao Base EB2

Estacao Base EB2 recebeu a mensagem forwresAck com confirmacao de recebimento do pedido pedido2 pela Unidade Movel UM5

Verificando a possibilidade de apagar o endereco do proxy

Proxy nao vazio: nao eh possivel apaga-lo

Estacao Base EB2 enviando confirmacao de recebimento do pedido para a Estacao Base onde esta o proxy da Unidade Movel UM5

Estacao Base EB5 recebeu a mensagem forwresAck de confirmacao de recebimento do pedido pedido2 pela Unidade Movel UM5

Verificando a possibilidade de destruir o proxy

Nao eh possivel destruir o proxy

Estacao Base EB5 enviando confirmacao de pedido pela Unidade Movel para o proxy Proxy5

O proxy Proxy5 recebeu a mensagem forwresAck de confirmacao de recebimento do pedido pedido2 pela unidade movel UM5

Pedido pedido2 removido da Lista de Pedidos do proxy Proxy5

Nova estacao base EB4 recebeu a mensagem greet da unidade movel UM1 que estava na estacao base antiga

Nova estacao base EB4 enviando mensagem dereg para a estacao base antiga solicitando a pRef da unidade movel

Estacao base antiga EB5 recebeu a mensagem dereg

Estacao base antiga EB5 enviando mensagem deregAck para nova estacao base com a pRef da unidade movel

Apagando a unidade movel UM1 da lista local da estacao base antiga EB5

A nova Estacao Base EB4 recebeu a mensagem deregAck com a pRef EB5

Incluindo a Unidade Movel UM1 na lista local da Estacao Base nova EB4

Enviando mensagem update para a estacao base onde o proxy esta

A estacao base do proxy recebeu a mensagem update para enviar para o proxy

O proxy recebeu a mensagem update para atualizar a Estacao Base com a pRef EB5 da Unidade Movel UM1

A localidade atual EB5 do proxy Proxy1 atualizado

Verificando se ocorreu handoff

Ocorreu handoff

Reenviando os pedidos do Proxy Proxy1, que nao receberam confirmacao de recebimento da Unidade Movel UM1 
O servidor esta enviando o resultado do pedido pedido3 para o proxy Proxy1 enviar para sua unidade movel UM1

O proxy Proxyl recebeu a mensagem forwardresult do Servidor com o resultado do pedido pedido3

Verificando se eh ultimo pedido pendente do proxy Proxyl

Eh ultimo pedido pendente

Proxyl enviando pedido para a sua EB

Estacao Base EB1 recebeu do proxy Proxyl a mensagem forwardresult com o resultado do pedido pedido3 da Unidade Movel UM1

Estacao Base EB1 enviando pedido pedido3 para a Estacao Base onde esta a Unidade Movel UM1

Estacao Base EB4 recebeu a mensagem forwardresult com o resultado do pedido pedido3 da Unidade Movel UM1

Verificando se eh o ultimo pedido pendente da Unidade Movel UM1

Eh o ultimo pedido pendente

A Estacao Base EB4 esta enviando resultado do pedido para a Unidade Movel UM1

A Unidade Movel UM1 recebeu a mensagem forwardresult com o resultado do pedido pedido3

A Unidade Movel UM1 enviando confirmacao do resultado do pedido com a mensagem forwresAck para a Estacao Base EB4

Estacao Base EB4 recebeu a mensagem forwresAck com confirmacao de recebimento do pedido pedido3 pela Unidade Movel UM1

Verificando a possibilidade de apagar o endereco do proxy

Proxy vazio: eh possivel apaga-lo

Apagando o endereco do proxy Proxy1 da Unidade Movel UM1

Estacao Base EB4 enviando confirmacao de recebimento do pedido para a Estacao Base onde esta o proxy da Unidade Movel UM1

Estacao Base EB1 recebeu a mensagem forwresAck de confirmacao de recebimento do pedido pedido3 pela Unidade Movel UM1

Verificando a possibilidade de destruir o proxy

Eh possivel destruir o proxy

Destruindo o Proxy Proxy1 da Unidade Movel UM1

Nova estacao base EB1 recebeu a mensagem greet da unidade movel UM2 que estava na estacao base antiga

Nova estacao base EB1 enviando mensagem dereg para a estacao base antiga solcitando a pRef da unidade movel

Estacao base antiga EB4 recebeu a mensagem dereg

Estacao base antiga EB4 enviando mensagem deregAck para nova estacao base com a pRef da unidade movel

Apagando a unidade movel UM2 da lista local da estacao base antiga EB4

A nova Estacao Base EB1 recebeu a mensagem deregAck com a pRef EB4

Incluindo a Unidade Movel UM2 na lista local da Estacao Base nova EB1

Enviando mensagem update para a estacao base onde o proxy esta

A estacao base do proxy recebeu a mensagem update para enviar para o proxy

O proxy recebeu a mensagem update para atualizar a Estacao Base com a pRef EB4 da Unidade Movel UM2

A localidade atual EB4 do proxy Proxy2 atualizado 
Verificando se ocorreu handoff

Ocorreu handoff

Reenviando os pedidos do Proxy Proxy2, que nao receberam confirmacao de recebimento da Unidade Movel UM2

O servidor esta enviando o resultado do pedido pedido3 para o proxy Proxy2 enviar para sua unidade movel UM2

O proxy Proxy2 recebeu a mensagem forwardresult do Servidor com o resultado do pedido pedido3

Verificando se eh ultimo pedido pendente do proxy Proxy2

Eh ultimo pedido pendente

Proxy2 enviando pedido para a sua EB

Estacao Base EB2 recebeu do proxy Proxy2 a mensagem forwardresult com o resultado do pedido pedido3 da Unidade Movel UM2

Estacao Base EB2 enviando pedido pedido3 para a Estacao Base onde esta a Unidade Movel UM2

Estacao Base EB1 recebeu a mensagem forwardresult com o resultado do pedido pedido3 da Unidade Movel UM2

Verificando se eh o ultimo pedido pendente da Unidade Movel UM2

Eh o ultimo pedido pendente

A Estacao Base EB1 esta enviando resultado do pedido para a Unidade Movel UM2

A Unidade Movel UM2 recebeu a mensagem forwardresult com o resultado do pedido pedido3

A Unidade Movel UM2 enviando confirmacao do resultado do pedido com a mensagem forwresAck para a Estacao Base EB1

Estacao Base EB1 recebeu a mensagem forwresAck com confirmacao de recebimento do pedido pedido3 pela Unidade Movel UM2

Verificando a possibilidade de apagar o endereco do proxy

Proxy vazio: eh possivel apaga-lo

Apagando o endereco do proxy Proxy2 da Unidade Movel UM2

Estacao Base EB1 enviando confirmacao de recebimento do pedido para a Estacao Base onde esta o proxy da Unidade Movel UM2

Estacao Base EB2 recebeu a mensagem forwresAck de confirmacao de recebimento do pedido pedido3 pela Unidade Movel UM2

Verificando a possibilidade de destruir o proxy

Eh possivel destruir o proxy

Destruindo o Proxy Proxy2 da Unidade Movel UM2

Nova estacao base EB2 recebeu a mensagem greet da unidade movel UM3 que estava na estacao base antiga

Nova estacao base EB2 enviando mensagem dereg para a estacao base antiga solicitando a pRef da unidade movel

Estacao base antiga EB1 recebeu a mensagem dereg

Estacao base antiga EB1 enviando mensagem deregAck para nova estacao base com a pef da unidade movel

Apagando a unidade movel UM3 da lista local da estacao base antiga EB1

A nova Estacao Base EB2 recebeu a mensagem deregAck com a pRef EB1

Incluindo a Unidade Movel UM3 na lista local da Estacao Base nova EB2

Enviando mensagem upda te para a estacao base onde o proxy esta 
A estacao base do proxy recebeu a mensagem update para enviar para o proxy

O proxy recebeu a mensagem update para atualizar a Estacao Base com a pRef EB1 da Unidade Movel UM3

A localidade atual EB1 do proxy Proxy3 atualizado

Verificando se ocorreu handoff

Ocorreu handoff

Reenviando os pedidos do Proxy Proxy3, que nao receberam confirmacao de recebimento da Unidade Movel UM3

O servidor esta enviando o resultado do pedido pedido3 para o proxy Proxy3 enviar para sua unidade movel UM3

O proxy Proxy3 recebeu a mensagem forwardresult do Servidor com o resultado do pedido pedido3

Verificando se eh ultimo pedido pendente do proxy Proxy3

Eh ultimo pedido pendente

Proxy3 enviando pedido para a sua EB

Estacao Base EB3 recebeu do proxy Proxy3 a mensagem forwardresult com o resultado do pedido pedido3 da Unidade Movel UM3

Estacao Base EB3 enviando pedido pedido3 para a Estacao Base onde esta a Unidade Movel UM3

Estacao Base EB2 recebeu a mensagem forwardresult com o resultado do pedido pedido3 da Unidade Movel UM3

Verificando se eh o ultimo pedido pendente da Unidade Movel UM3

Eh o ultimo pedido pendente

A Estacao Base EB2 esta enviando resultado do pedido para a Unidade Movel UM3

A Unidade Movel UM3 recebeu a mensagem forwardresult com o resultado do pedido pedido3

A Unidade Movel UM3 enviando confirmacao do resultado do pedido com a mensagem forwresAck para a Estacao Base EB2

Estacao Base EB2 recebeu a mensagem forwresAck com confirmacao de recebimento do pedido pedido3 pela Unidade Movel UM3

Verificando a possibilidade de apagar o endereco do proxy

Proxy vazio: eh possivel apaga-lo

Apagando o endereco do proxy Proxy3 da Unidade Movel UM3

Estacao Base EB2 enviando confirmacao de recebimento do pedido para a Estacao Base onde esta o proxy da Unidade Movel UM3

Estacao Base EB3 recebeu a mensagem forwresAck de confirmacao de recebimento do pedido pedido3 pela Unidade Movel UM3

Verificando a possibilidade de destruir o proxy

Eh possivel destruir o proxy

Destruindo o Proxy Proxy3 da Unidade Movel UM3

Nova estacao base EB5 recebeu a mensagem greet da unidade movel UM4 que estava na estacao base antiga

Nova estacao base EB5 enviando mensagem dereg para a estacao base antiga solicitando a pRef da unidade movel

Estacao base antiga EB3 recebeu a mensagem dereg

Estacao base antiga EB3 enviando mensagem deregAck para nova estacao base com a pRef da unidade movel 
Apagando a unidade movel UM4 da lista local da estacao base antiga EB3

A nova Estacao Base EB5 recebeu a mensagem deregAck com a pRef EB3

Incluindo a Unidade Movel UM4 na lista local da Estacao Base nova EB5

Enviando mensagem update para a estacao base onde o proxy esta

A estacao base do proxy recebeu a mensagem update para enviar para o proxy

O proxy recebeu a mensagem update para atualizar a Estacao Base com a pRef EB3 da Unidade Movel UM4

A localidade atual EB3 do proxy Proxy4 atualizado

Verificando se ocorreu handoff

Ocorreu handoff

Reenviando os pedidos do Proxy Proxy4, que nao receberam confirmacao de recebimento da Unidade Movel UM4

O servidor esta enviando o resultado do pedido pedido3 para o proxy Proxy4 enviar para sua unidade movel UM4

O proxy Proxy4 recebeu a mensagem forwardresult do Servidor com o resultado do pedido pedido3

Verificando se eh ultimo pedido pendente do proxy Proxy 4

Eh ultimo pedido pendente

Proxy4 enviando pedido para a sua EB

Estacao Base EB4 recebeu do proxy Proxy4 a mensagem forwardresult com o resultado do pedido pedido3 da Unidade Movel UM4

Estacao Base EB4 enviando pedido pedido3 para a Estacao Base onde esta a Unidade Movel UM4

Estacao Base EB5 recebeu a mensagem forwardresult com o resultado do pedido pedido3 da Unidade Movel UM4

Verificando se eh o ultimo pedido pendente da Unidade Movel UM4

Eh o ultimo pedido pendente

A Estacao Base EB5 esta enviando resultado do pedido para a Unidade Movel UM4

A Unidade Movel UM4 recebeu a mensagem forwardresult com o resultado do pedido pedido3

A Unidade Movel UM4 enviando confirmacao do resultado do pedido com a mensagem forwresAck para a Estacao Base EB5

Estacao Base EB5 recebeu a mensagem forwresAck com confirmacao de recebimento do pedido pedido3 pela Unidade Movel UM4

Verificando a possibilidade de apagar o endereco do proxy

Proxy vazio: eh possivel apaga-lo

Apagando o endereco do proxy Proxy4 da Unidade Movel UM4

Estacao Base EB5 enviando confirmacao de recebimento do pedido para a Estacao Base onde esta o proxy da Unidade Movel UM4

Estacao Base EB4 recebeu a mensagem forwresAck de confirmacao de recebimento do pedido pedido3 pela Unidade Movel UM4

Verificando a possibilidade de destruir o proxy

Eh possivel destruir o proxy

Destruindo o Proxy Proxy4 da Unidade Movel UM4

Nova estacao base EB3 recebeu a mensagem greet da unidade movel UM5 que estava na estacao base antiga 
Nova estacao base EB3 enviando mensagem dereg para a estacao base antiga solicitando a pRef da unidade movel

Estacao base antiga EB2 recebeu a mensagem dereg

Estacao base antiga EB2 enviando mensagem deregAck para nova estacao base com a pRef da unidade movel

Apagando a unidade movel UM5 da lista local da estacao base antiga EB2

A nova Estacao Base EB3 recebeu a mensagem deregAck com a pRef EB2

Incluindo a Unidade Movel UM5 na lista local da Estacao Base nova EB3

Enviando mensagem update para a estacao base onde o proxy esta

A estacao base do proxy recebeu a mensagem update para enviar para o proxy

O proxy recebeu a mensagem update para atualizar a Estacao Base com a pRef EB2 da Unidade Movel UM5

A localidade atual EB2 do proxy Proxy5 atualizado

Verificando se ocorreu handoff

Ocorreu handoff

Reenviando os pedidos do Proxy Proxys, que nao receberam confirmacao de recebimento da Unidade Movel UM5

O servidor esta enviando o resultado do pedido pedido3 para o proxy Proxy5 enviar para sua unidade movel UM5

O proxy Proxy5 recebeu a mensagem forwardresult do Servidor com o resultado do pedido pedido3

Verificando se eh ultimo pedido pendente do proxy Proxy5

Eh ultimo pedido pendente

Proxy5 enviando pedido para a sua EB

Estacao Base EB5 recebeu do proxy Proxy5 a mensagem forwardresult com o resultado do pedido pedido3 da Unidade Movel UM5

Estacao Base EB5 enviando pedido pedido3 para a Estacao Base onde esta a Unidade Movel UM5

Estacao Base EB3 recebeu a mensagem forwardresult com o resultado do pedido pedido3 da Unidade Movel UM5

Verificando se eh o ultimo pedido pendente da Unidade Movel UM5

Eh o ultimo pedido pendente

A Estacao Base EB3 esta enviando resultado do pedido para a Unidade Movel UM5

A Unidade Movel UM5 recebeu a mensagem forwardresult com o resultado do pedido pedido3

A Unidade Movel UM5 enviando confirmacao do resultado do pedido com a mensagem forwresAck para a Estacao Base EB3

Estacao Base EB3 recebeu a mensagem forwresAck com confirmacao de recebimento do pedido pedido3 pela Unidade Movel UM5

Verificando a possibilidade de apagar o endereco do proxy

Proxy vazio: eh possivel apaga-lo

Apagando o endereco do proxy Proxy5 da Unidade Movel UM5

Estacao Base EB3 enviando confirmacao de recebimento do pedido para a Estacao Base onde esta o proxy da Unidade Movel UM5

Estacao Base EB5 recebeu a mensagem forwresAck de confirmacao de recebimento do pedido pedido3 pela Unidade Movel UM5

Verificando a possibilidade de destruir o proxy 
Eh possivel destruir o proxy

Destruindo o Proxy Proxy5 da Unidade Movel UM5 